\title{
Female genital mutilation/cutting in Kenya: Is change taking place? Descriptive statistics from four waves of Demographic and Health Surveys
}

Bettina Shell-Duncan

David Gathara

Zhuzhi Moore

Follow this and additional works at: https://knowledgecommons.popcouncil.org/departments_sbsr-rh

Part of the Demography, Population, and Ecology Commons, Family, Life Course, and Society Commons, International Public Health Commons, Maternal and Child Health Commons, and the Sociology of Culture Commons

How does access to this work benefit you? Let us know!

\section{Recommended Citation}

Shell-Duncan, Bettina, David Gathara, and Zhuzhi Moore. 2017. "Female genital mutilation/cutting in Kenya: Is change taking place? Descriptive statistics from four waves of Demographic and Health Surveys," Evidence to End FGM/C: Research to Help Women Thrive. New York: Population Council. 


\section{Evidence to End FGM/C}

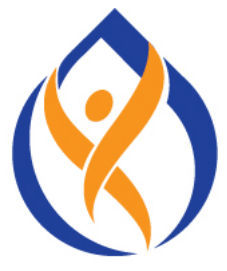

Research to Help Girls and Women Thrive

\section{FEMALE GENITAL \\ MUTILATION/CUTTING IN KENYA: IS CHANGE TAKING PLACE? \\ DESCRIPTIVE STATISTICS FROM FOUR WAVES OF DEMOGRAPHIC AND HEALTH SURVEYS}




\section{FEMALE GENITAL MUTILATION/ CUTTING IN KENYA: IS CHANGE TAKING PLACE? \\ Descriptive Statistics from Four Waves of Demographic and Health Surveys}

FEBRUARY 2017

BETTINA SHELL-DUNCAN University of Washington

DAVID GATHARA

Consultant, Population Council

ZHUZHI MOORE Consultant, Population Council 
Evidence to End FGM/C: Research to Help Girls and Women Thrive generates evidence to inform and influence investments, policies, and programs for ending female genital mutilation/cutting in different contexts. Evidence to End FGM/C is led by the Population Council, Nairobi in partnership with the Africa Coordinating Centre for the Abandonment of Female Genital Mutilation/Cutting (ACCAF), Kenya; Gender and Reproductive Health \& Rights Resource Center (GRACe), Sudan; Global Research and Advocacy Group (GRAG), Senegal; Population Council, Nigeria; Population Council, Egypt; Population Council, Ethiopia; MannionDaniels, Ltd. (MD); Population Reference Bureau (PRB); University of California, San Diego (Prof. Bettina Shell-Duncan); and University of Washington (Dr. Gerry Mackie).

\section{POPULATION} COUNCIL

Ideas. Evidence. Impact.

The Population Council confronts critical health and development issues, from stopping the spread of HIV to improving reproductive health and ensuring that young people lead full and productive lives. Through biomedical, social science, and public health research in 50 countries, we work with our partners to deliver solutions that lead to more effective policies, programs, and technologies that improve lives around the world. Established in 1952 and headquartered in New York, the Council is a nongovernmental, non-profit organization governed by an international board of trustees. popcouncil.org

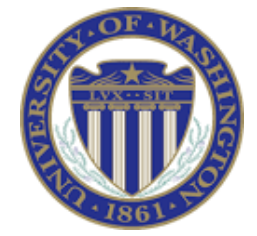

The University of Washington is one of the world's preeminent public universities. Our impact on individuals, our region, and the world is profound-whether we are launching young people into a boundless future or confronting the grand challenges of our time through undaunted research and scholarship. We turn ideas into impact and transform lives and our world. washington.edu

Shell-Duncan, B., Gathara, D. and Moore, Z. Female Genital Mutilation/Cutting in Kenya: Is Change Taking Place? Descriptive Statistics from Four Waves of Demographic and Health Surveys. February 2017, Evidence to End FGM/C: Research to Help Women Thrive. New York: Population Council.

More information about the Evidence to End FGM/C: Research to Help Women Thrive work is available on our website: http://www.popcouncil.org/EvidencetoEndFGM-C.

Dr. Jacinta Muteshi, Project Director, jmuteshi@popcouncil.org

(c) 2017 The Population Council, Inc.

Funded by:

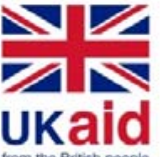

This document is an output from a project funded by UK aid by the UK Government for the benefit of developing countries. However, the views expressed and information contained in it are not necessarily those of, or endorsed by the UK Government, which can accept no responsibility for such views or information or for any reliance placed on them. 


\section{Contents}

I. Background on FGM/C

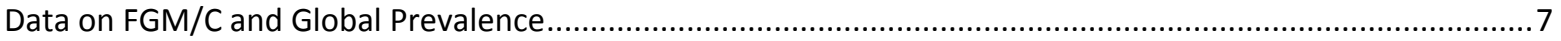

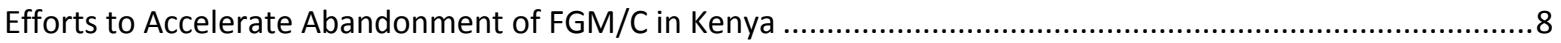

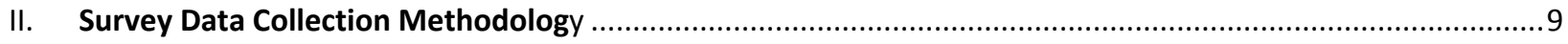

III. FGM/C Among Women: Prevalence, Support and Circumstances under which is Carried Out .....................13

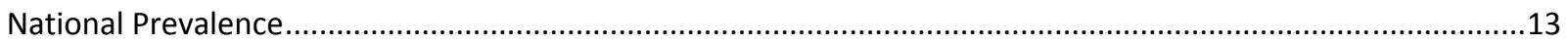

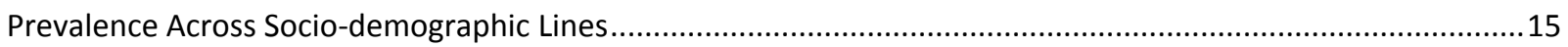

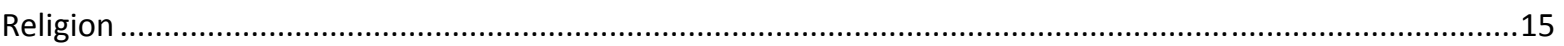

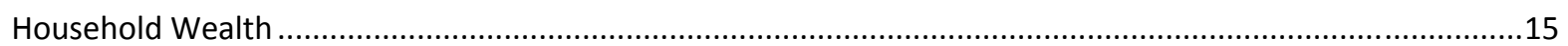

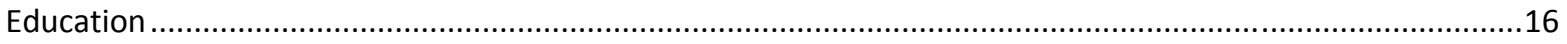

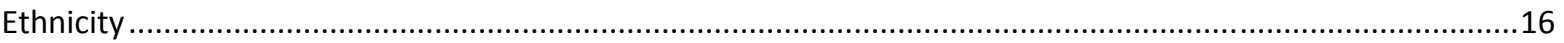

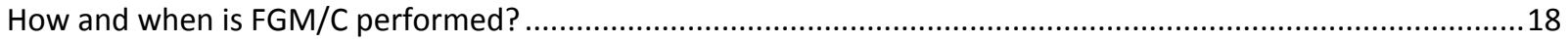

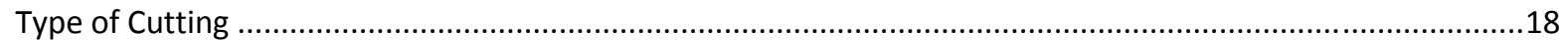

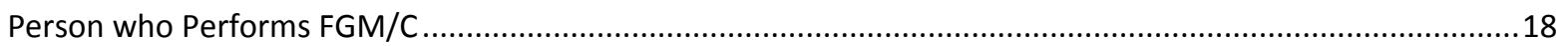

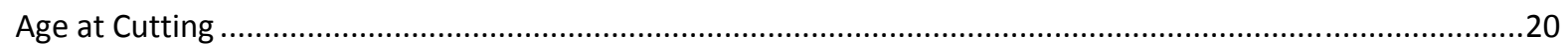

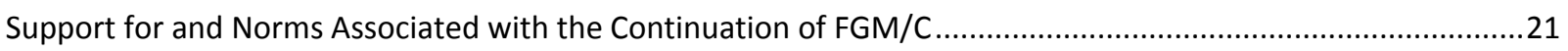

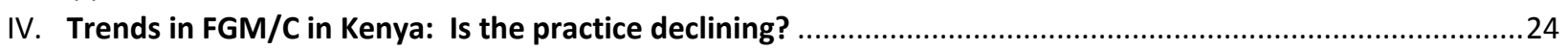

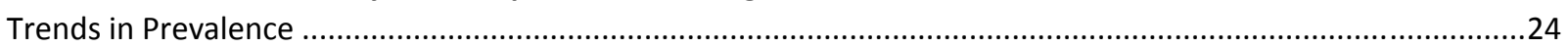

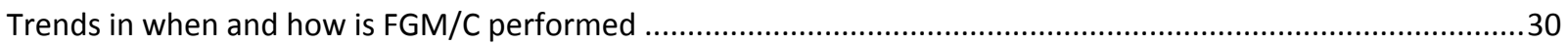

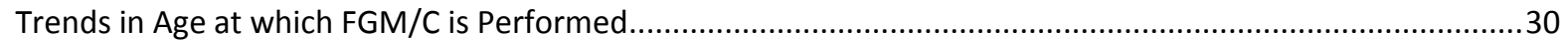

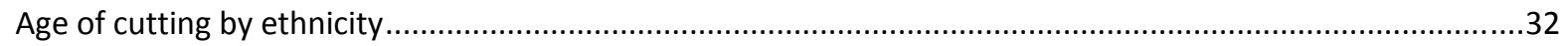

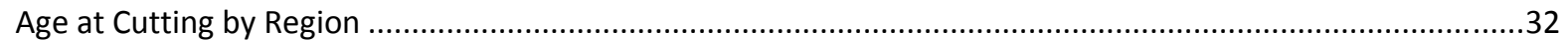

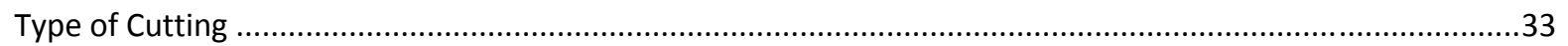

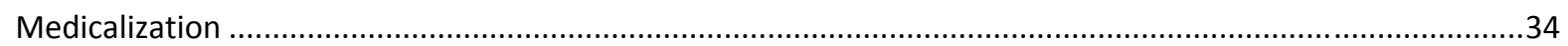

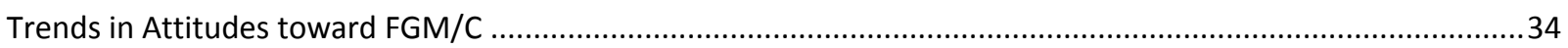

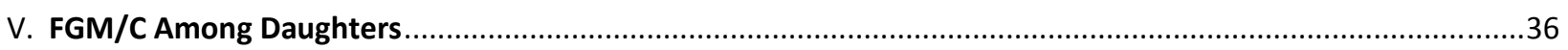

Different Ways that Data on Daughter's FGM/C has been Collected.................................................................36

Considerations for Analysis of Complete Daughter Data: Understanding the Difference between Current and

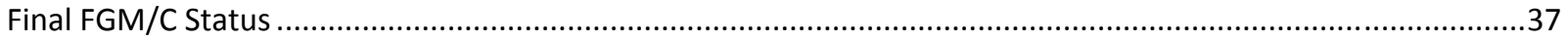

Prevalence of FGM/C Among Daughters 0-14 Along Sociodemographic Lines................................................40

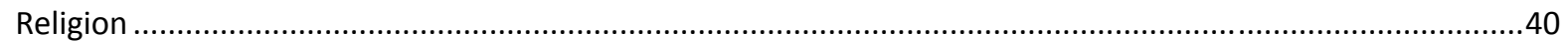

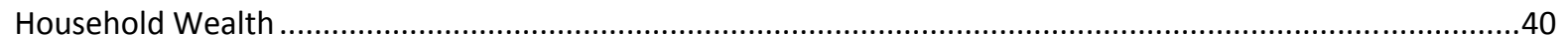

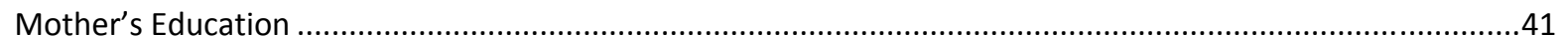

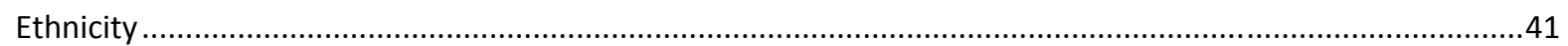

How and When is FGM/C Performed Among Girls Aged 0-14? ..................................................................42

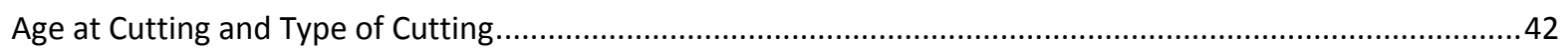

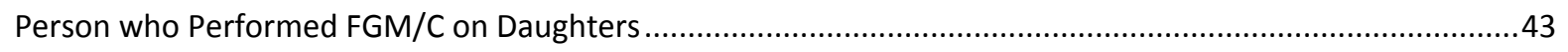

VI. Intergenerational Changes: Mother-Daughter Comparisons .....................................................................43

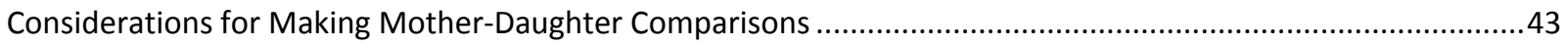

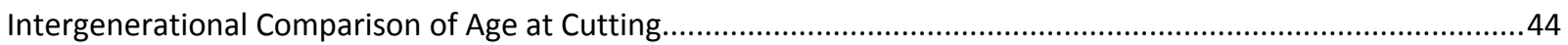

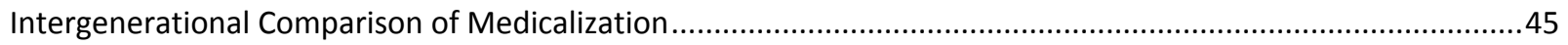

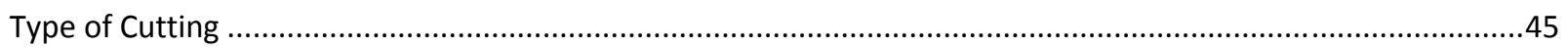

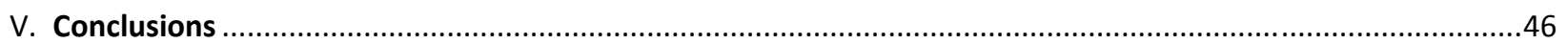

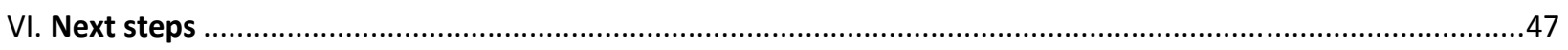

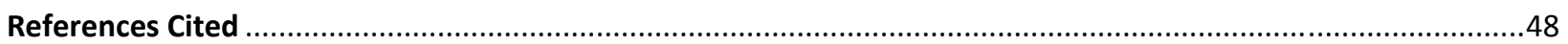




\section{Executive Summary}

Nationally representative survey data on FGM/C in Kenya are available from four waves of Demographic and Health Surveys, implemented in 1998, 2003, 2008-09, and 2014. These survey data provide a rich and detailed picture of when, where and how FGM/C has been carried out, and trends in changes in the practice.

Key findings from the 2014 survey include the following: The estimated prevalence of FGM/C among women aged $15-49$ is $21 \%$. The prevalence varies substantially by province, with the highest prevalence in Northeastern Province (98\%) and lowest prevalence in Western Province (1\%). As population densities vary in different regions of the country, it is also of interest to know where most women 15-49 years of age living with FGM/C reside. The data show that $72 \%$ of Kenyan women living with FGM/C reside in three provinces: Northeastern, Rift Valley and Nyanza. Prevalence of FGM/C also varies along sociodemographic lines, most strikingly in relation to ethnicity. Less than $1 \%$ of Luhya and Luo women report being cut, while $94 \%$ of ethnic Somali women report being cut. The circumstances surrounding FGM/C also vary. Nationwide, among all women who report having undergone $\mathrm{FGM} / \mathrm{C}$ report having had flesh removed, but not being sewn closed. About $9 \%$ of women report having been sewn closed. The vast majority of women report having been cut by a traditional practitioner (83\%), while $15 \%$ report that the person who performed their $\mathrm{FGM} / \mathrm{C}$ was a health care professional. Regarding age at cutting, $70 \%$ of women report having been cut between age 5 and 14 years. In most countries it is rare for women to undergo FGM/C after the age of 15. In this regard, Kenya is an exception; $27 \%$ of women report having been cut age 15 or older. Data from the 2014 KDHS show that the majority of both women (93\%) and men (89\%) are opposed to the continuation of FGM/C. Two questions in the 2014 survey are designed to measure social or religious norms. The data show that $5 \%$ of women and $6 \%$ of men report that they believe $\mathrm{FGM} / \mathrm{C}$ is required by religion. Additionally $8 \%$ of women and $11 \%$ of men report that they believe that $\mathrm{FGM} / \mathrm{C}$ is required by their community.

Examination of successive waves of survey data allow us to examine trends in FGM/C in Kenya, with the key question being: Is the practice of $\mathrm{FGM} / \mathrm{C}$ declining? National prevalence data from successive waves of surveys show a steady decrease in the prevalence of FGM/C among women aged 15-49, declining from $38 \%$ in 1998 to $21 \%$ in 2014 . By looking at the prevalence across 5 year age cohorts, we see that there has been a steady, long-term decline in rates of FGM/C that began in the early 1980's. The declines have not occurred evenly among women from all ethnic groups. Rates of FGM/C remain very high among ethnic Somali women. Rates of FGM/C are high in older cohorts of Maasai and Kisii women, but appear to be declining among younger cohorts of women. Other ethnic groups have had long-term steady declines in FGM/C. The prevalence of $\mathrm{FGM} / \mathrm{C}$ has dropped to $5 \%$ or lower in the youngest cohort of women (aged 15-19) in four ethnic groups: Kalenjin, Kamba, Kikuyu and Taita/Taveta. Other changes over time include a trend toward younger age at cutting, increased medicalization (cutting performed by a health care professional, as opposed to a traditional practitioner).

The most recent changes in $\mathrm{FGM} / \mathrm{C}$ are found by looking at data reported by mothers regarding their daughters. The 2014 KDHS survey provides information on the prevalence of FGM/C among girls aged $0-14$. Overall $2.8 \%$ of girls under age 15 have been cut. Interpretation of this number requires understanding that not all girls have reached their final cutting status; some girls who are not cut may still be cut in the future. Specialized statistical methods are, therefore, needed to conduct multivariate analyses on these data. Rates of cutting among girls 0-14 vary in several ways: rates of cutting are higher among girls from poor household, those whose mothers have no education, and those whose mothers are ethnic Somali or Kisii. Girls age 0-14 who have been cut live in either Northeastern Province (65\%) or Nyanza (20\%). In comparison to their mothers, girls with FGM/C are being cut at earlier ages, and are more likely to be cut by a medical practitioner than were their mothers. Medicalized cutting of girls is located exclusively in Nyana and Rift Valley Provinces. 


\section{Next steps}

While the data we report is descriptive, it provides useful insights on the progress of FGM/C abandonment at national and sub-national levels. The observed changes observed overtime provide an important opportunity for understanding how, where and in what sub-groups change is happening. These findings are useful for policy makers in steering discussions on policies, but also for guiding where to target interventions especially due to the large ethnic and religious diversity. It also highlights where there are large numbers of women living with FGM/C who may be in need of specialized health services.

However, to better understand trends overtime and the determinants of FGM/C we propose further multivariate analysis that take into account censoring but also time and space. For instance, the DHS surveys collect information on current FGM/C status of daughters, however, this is different from final FGM/C status: a girl who is not cut may still be cut in the future. This type of challenges could be addressed statistically, through censoring an approach we have attempted by using survival analysis methods but can be improved upon. Additionally, there is a proposition that FGM/C is a social norm, as such, communities that close to one another are likely to harbor similar practices compared to those further away. Because DHS data has coordinates of the clusters sampled during each survey, spatio-temporal models can be used to account for space and time and therefore provide more precise estimates adjusted for space, time and other determinants. These analyses are now ongoing and will compliment this report. 


\section{Background on FGM/C}

Female genital mutilation, also known as female genital cutting or female circumcision, refers to a set of practices involving the "partial or total removal of the external genitalia, or other injury to the female organs for non-medical reasons" (WHO, 2008:4). The choice of terminology conveys important connotations, and has therefore been the subject of ongoing debate. Many commentators initially used the term "female circumcision" as it reflects the fact that in some societies genital cutting is incorporated into both male and female initiation rites, and in some local African languages is described by the same term. Some activists against this practice objected to the use of this term on grounds including that it inappropriately suggests that female circumcision is physically analogous to male circumcision, whereas most forms are much more severe than removal of the male foreskin. To emphasize the more extensive physical damage and to create a linguistic distinction, activists have since the early 1970s forwarded the term female genital mutilation and its acronym FGM. This distinction may be of even greater importance now that male circumcision may be promoted as a means of reducing HIV transmission in the very same communities where there exist ongoing campaigns to end FGM. In the 1989 the term FGM was adopted by the Inter-African Committee on Traditional Practices Affecting the Health of Women and Children (IAC), and in 1991 WHO recommended that the United Nations adopt this term. Objections have been raised to the use of the word "mutilation" because it is judgmental and denotes condemnation (Eliah, 1996). In an effort to be more culturally sensitive the term female genital cutting, or FGC, has become widely used by researchers, as well as by the United States Agency for International Development (USAID). In 1999 "the UN Special Rapporteur on Traditional Practices called for tact and patience regarding this area and drew attention to the risk of 'demonizing' certain cultures, religions and communities" (Warzazi, 1998, cited in UNICEF, 2005a: 2). UNICEF and UNFPA currently favor a hybrid term, female genital mutilation/cutting or FGM/C, to capture the significance of the term 'mutilation' at the policy level and, at the same time, when working with practicing communities, recognizing the importance of employing nonjudgmental terminology to avoid alienation (UNICEF, 2005).

All of these terms are euphemisms for what in reality are a broad range of practices. More precise anatomical descriptions are provided by a typology developed by WHO in 1995, and updated in 2007 (WHO, 2008):

Type I: Partial or total removal of the clitoris and/or the prepuce;

Type II: Partial or total removal of the clitoris and labia minora, with or without excision of the labia majora

Type III: Narrowing of the vaginal orifice with creation of a covering seal by cutting and adhesion the labia minora and/or the labia majora, with or without excision of the clitoris. In most instances adhesion is completed by stitching together the cut edges of the labia, and is referred to as infibulation. The adhesion of the labia results in a near complete covering of the urethra and the vaginal orifice that must be opened for sexual intercourse and childbirth, a procedure known as defibulation. In some instances, this is followed by reinfibulation.

Type IV: All other harmful procedures to the female genitalia for non-medical purposes, for example: pricking, piercing, incising, scraping, and cauterization. Pricking or nicking involves cutting to draw blood, but no removal of tissue or and no permanent alteration of the external genitalia.

Although this typology offers a more precise anatomical description of varied practices, it may be more useful in clinical observations than in surveys that rely on self-reported FGM/C status. The categories in this typology may not clearly correspond with local terminology. Yoder and colleagues explain that "each society has its own language and ways of classifying types of cutting that are known to members, types of cutting that do not necessarily correspond to the WHO designations. Establishing equivalence between such locally defined types and those proposed as guidelines by the WHO is not a simple matter" (2004:19). 


\section{Data on FGM/C and Global Prevalence}

For many years there was insufficient data to track changes in the prevalence and distribution of FGM/C. Fran Hosken, in the 1979 and subsequent editions of The Hosken Report (most recently 1993), was a pioneer in generating estimates of the prevalence of FGM/C on a country by country basis. However, in the absence of large scale, nationally representative data, she was forced to rely on piecing together anecdotal accounts. Since that time, important sources of reliable data have been generated, providing more accurate estimates of the prevalence of FGM/C that can guide the strategic allocation of resources and planning of interventions. Macro International (now ICF Macro) first introduced a module on FGM/C in the population based Demographic and Health Survey (DHS) in 1989 in North Sudan, and subsequently varied forms of the FGM/C module have been implemented over time. UNICEF has also taken part in generating nationally representative data on FGM/C, implementing the Multiple Indicator Cluster Surveys (MICS). Since 2010 the FGM/C module has been standardized, providing comparative data across surveys. Together, these surveys have generated data from 29 countries in Africa and the Middle East, with repeat surveys, typically 5 years apart, in some countries. They include information on whether a woman has undergone $\mathrm{FGM} / \mathrm{C}$, and if so, her age at the time of the procedure and who performed it. Additional questions include a respondent's attitude toward the practice, and whether the respondent's daughter has undergone FGM/C.

The results of these surveys provide a comprehensive picture on the national prevalence of FGM/C, defined as the proportion of women aged 15-49 who report having undergone some form of genital cutting (Figure 1). A nationallyrepresentative survey has also been conducted in Indonesia, but it obtained data only for girls under age 12 , and is therefore not included in this map. The prevalence of FGM/C varies substantially across countries. The prevalence exceeds $90 \%$ in Somali and Djibouti, but is less than $10 \%$ in Benin, Cameroon, Niger, Togo, and Uganda. At $21 \%$, the prevalence in Kenya is moderately low.

Figure 1: Prevalence of FGM/C among girls and women aged 15-49, by country (Updated from Shell-Duncan et al 2016)

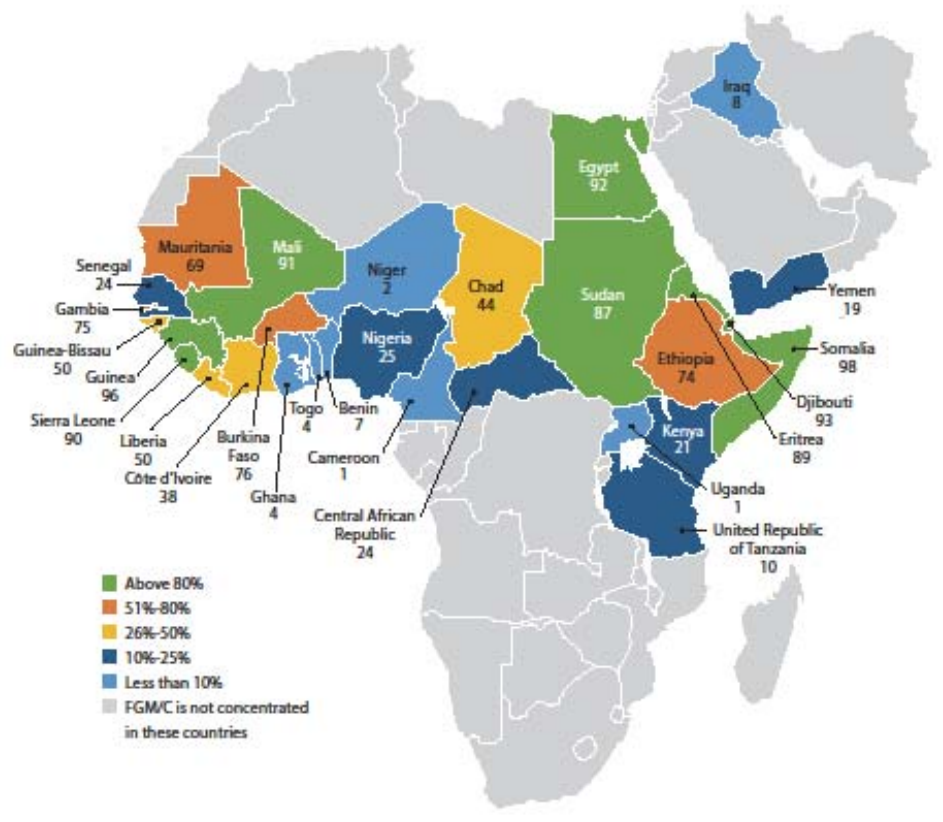


Since nationally representative data are not available for all countries, estimates of the global prevalence of FGM/C are not precise. Until recently estimates of the number of gills and women who have undergone $\mathrm{FGM} / \mathrm{C}$ worldwide typically ranged from about 100 to 140 million (WHO, 2015). In light of survey findings on rates of FGM/C among girls under the age of 12 in Indonesia, indirect estimation methods have revised the global estimated prevalence of FGM/C to be near 200 million (UNICEF, 2016).

\section{Efforts to Accelerate Abandonment of FGM/C in Kenya}

Kenya has experienced a long history of activism aimed at encouraging abandonment of FGM/C. Beginning as early as 1906 a number of Protestant missions, led by the Church of Scotland mission, denounced female genital cutting (FGC) on moral grounds, describing the practice as "barbaric" (Thomas 2000: 132). In the 1920's, as their medical work expanded, these missionaries began to ground opposition based on health concerns, a stance that gained influence in colonial circles. Subsequent efforts of colonial administrators initially involved restricting the severity of the cutting and mandating medicalization. The situation escalated in 1929 when a number of missions called for abandonment of $\mathrm{FGM} / \mathrm{C}$ by its members, and punished those who failed to comply by denying religious participation or enrollment of children in mission run schools (Murray 1976; Pedersen, 1991). This led to a significant backlash, particularly among the Kikuyu. The Kikuyu Central Association, a nascent nationalist organization, vehement defended the practice of FGM/C. Opposition to FGC in Kenya thus became equated with colonial oppression and took on important meaning in the nationalist struggle for independence from British rule. Jomo Kenyatta, the general secretary of the KCA and future president of Kenya, sharply criticized the interference of missionaries and Europeans as an "attack on this country's old customs to disintegrate their social order and thereby hasten their Europeanization" (Kenyatta 1978 [1938]; 133). For Kenyatta, circumcision became a powerful symbol of African "tradition," and he described it as "the very essence of an institution which has enormous educational, social, moral, and religious implications" (Kenyatta 1978 [1938]: 133). Later efforts to curb the practice expanded to enacting legal measures. For instance, in 1956 the Njuri Ncheke Council of Meru passed a ban on female circumcision. This ban, like legal bans enacted under colonial rule elsewhere in Africa, resulted in large-scale resistance. Historian Lynn Thomas (2000) recounts events in Meru Kenya where, following the 1956 ban on excision, young girls defied the ban by electing to circumcise themselves. In response to local opposition, the colonial government rescinded all resolutions governing female circumcision in 1958 (Chege et al., 2001).

Although FGC had been viewed as a symbol of cultural loyalty and defiance against European colonialism, it no longer had the same significance once Kenyan independence was gained in 1963. Christian church-led efforts discourage the practice of FGM/C were revived in the 1970's (UNICEF, 2013), and were joined by activist and government reform efforts as Kenya became an actor in an international community that embraced a renewed global campaign to eliminate FGM/C. Sparked by a series of conferences in the 1970's and 1980's during the UN Decade for Women, the global campaign to eliminate $\mathrm{FGM} / \mathrm{C}$ recast the issue in discourses on women's health and empowerment and placed great pressure on ruling elites and lawmakers in African nations to enact bans or formal legislation prohibiting the practice. Elected government officials were placed in a tenuous position and forced to tread a fine line, weighing on one hand demands of local activists and the international community who exerted pressure to conform to international norms, in some instances by conditioning aid, while at the same time balancing the concerns of their local constituencies who included strong supporters of the practice (Obiora 1997; Boyle and Preves 2000). In 1982 President Moi offered a compromise solution by issuing a statement calling for an end to FGM/C, labeling it "useless" and advocating for prosecution of persons who perform the practice. This ban, however, carried no legal weight, and was interpreted by some to be a measure to appease Western sensitivities. 
Subsequent presidential decrees were issued in 1989, 1998 and 2001, along with a series of policy directives from the Director of Medical Services to stop medical professionals FGM/C. Several attempts to pass formal legislation incited acrimonious debate centering on the conceptualization of $\mathrm{FGM} / \mathrm{C}$ as crime or culture, and were defeated in the Kenyan Parliament, most recently in 1999 (Thomas, 2003). Thus, many observers believed that Kenya would be one of the last nations in Africa, if ever, to pass legislation criminalizing FGM/C. Then, to the astonishment of many, in 2001 the Kenyan Parliament voted to pass the Children's Act, which bolsters state authority to protect children from numerous violations such as sexual exploitation, but also specifically bans early marriage and FGM/C in girls under the age of 18. Any person found circumcising a girl under the age of 18 can be charged and imprisoned for one year or fined KSh 50,0000 (\$700) or both (IRIN News, July 10, 2006; Children's Act, 2001 No. 8, Section 20). According to Thomas (2003), the Children's Act aimed to bring Kenyan law in accordance with the 1989 United Nations Convention on Rights of the Child prior to President Moi's attendance at a U.N. Session on Children, held in September 2001. Thomas (2003) suggests that the Kenyan government, like those of other African countries, responded to the mounting pressure in the 1990's from international funders, as well as local constituencies, by outlawing the practice. While this is indeed plausible, it is important to note that an expanded notion of children's rights emerged in Kenya prior to passage of the Children's Act, including injunctions filed in civil court preventing parents from having daughters undergo forced early marriage and FGM/C.

Shell-Duncan and Olungah (2009) argue that this expanded notion of children's rights created a climate allowing this law to be passed. For some, the passage of the law was considered to be an assault on culture. One media report, for instance, declared the passage of the law to be "A case study in modern legislation against cultural identity" (IRIN News July 10, 2006). Such commentators contribute to a larger debate that emerged in the 1990's that weighed human rights against a right to culture (see Hernlund and Shell-Duncan, 2007). The passage of the law in Kenya did not, however, draw the sort of mass outcries and public protests witnessed during colonial rule because it has been preceded by a fundamental shift in the perceived boundaries of parental and extended family rights toward children in relation to those of the government and church institutions (Shell-Duncan and Olungah, 200). Influenced by a human rights movement focused on children's rights, a growing consensus centered on the fact that there are fundamental expectations of entitlements by girls that include the right to not be forced to marry early and against their will and not be forced to undergo female genital cutting as a prerequisite to marriage. Furthermore, these entitlements were not seen as relegated solely to the private domestic sphere, but deemed concerns of the broader community, including the religious community and the state. This shift in family and community rights resulted in interventions to act in what is perceived to be the best interest of the girl, creating novel ways of navigation tensions regarding the distinction between "crime," "faith," and "culture" (Shell-Duncan and Olungah, 2009).

The legal restriction against FGM/C was expanded in 2011 with adoption of the Prohibition of Female Genital Mutilation Act. This law prohibits FGM/C to be performed on women of any age. It also criminalizes aiding, abetting or counseling a person who performs FGM, procuring a person to perform FGM, allowing the use of one's premises for performing FGM, failing to report cases of FGM, and the use of abusive or derogatory language against someone who has not undergone FGM. It also contains and extraterritoriality clause, banning any resident or citizen of Kenya from performing FGM outside of the country. Violation of the law carries a penalty of imprisonment for up to seven years or a fine of KSh 500,000.

\section{Survey Data Collection Methodology}

Data used in this study are from the most recent four waves of Kenya DHS spanning 1998 to 2014. The DHS is a wellestablished source of reliable population-level data with a substantial focus on health. The Kenya DHS surveys are conducted by the National Council of for Population and Development in collaboration with Central Bureau of Statistics and Macro International (now ICF Macro). The surveys are national in scope and employ a cross-sectional 
design with a two-stage stratified random sampling design. The design of each survey, organization, sample size and sampling design, questionnaires used and implementation are described in detail in the DHS Final Country Reports for each of the four surveys (www.dhsprogram.com). The questions of interest for this analysis were those on sociodemographic factors (age of the woman, ethnicity, woman's highest level of education, region of residence, residence type -urban/rural, religion and wealth index as measure of the socio-economic status) and questions in the FGM/C module. The FGM/C module has been improved over time and there are variations across the surveys in the questions asked and how questions were asked. The questions in the FGM/C module and the variations overtime are outlined in Table 1.

Table 1: Questions Administered in the Survey for Women (Ages 15-49)

\begin{tabular}{|c|c|c|c|c|}
\hline & KDHS 1998 & KDHS 2003 & KDHS 2008-09 & KDHS 2014* \\
\hline $\begin{array}{l}\text { Have any of your daughters been circumcised (2008-09)? } \\
\text { Is (NAME OF EACH DAUGHTER 0-14) circumcised? }\end{array}$ & & & $\mathrm{v}$ & $\sqrt{ }$ \\
\hline $\begin{array}{l}\text { In many communities, girls are introduced to womanhood by } \\
\text { participating in some ceremonies and undergoing specific } \\
\text { procedures. I want to discuss with you the circumcision of } \\
\text { girls. In this community, is female circumcision practiced? }\end{array}$ & $\mathrm{V}$ & $\sqrt{ }$ & & \\
\hline $\begin{array}{l}\text { Are you circumcised }(1998,2003) ? \\
\text { Have you yourself ever been circumcised }(2008-09 ; 2014) ?\end{array}$ & $\mathrm{~V}$ & $\sqrt{ }$ & $\sqrt{ }$ & $\sqrt{ }$ \\
\hline How old were you when you were circumcised? & $\mathrm{V}$ & & $\mathrm{V}$ & $\mathrm{V}$ \\
\hline Was any flesh removed from the genital area? & & & $\mathrm{V}$ & $\mathrm{V}$ \\
\hline Was the genital area just nicked without removing any flesh? & & & $\sqrt{ }$ & $\mathrm{V}$ \\
\hline Was your vaginal area sewn closed? & & & $\mathrm{V}$ & $\mathrm{V}$ \\
\hline Who performed the circumcision? & & & $\sqrt{ }$ & $\mathrm{V}$ \\
\hline $\begin{array}{l}\text { Do you think circumcision should be continued, or should it } \\
\text { be discontinued (stopped)? }\end{array}$ & $\sqrt{ }$ & & $\sqrt{ }$ & $\sqrt{ }$ \\
\hline Why do you think circumcision should be continued? & $\mathrm{V}$ & & & \\
\hline Why do you think circumcision should be discontinued? & $\mathrm{V}$ & & & \\
\hline $\begin{array}{l}\text { In the last } 12 \text { months, have you discussed the practice of } \\
\text { female circumcision with anyone? } \\
\text { IF YES: With whom? }\end{array}$ & $\mathrm{V}$ & & & \\
\hline $\begin{array}{l}\text { Is this practice expected/required by the religion }(2008-09) \text { ? } \\
\text { Do you believe that this practice is required by your religion } \\
\text { (2014)? }\end{array}$ & & & $\mathrm{V}$ & $\sqrt{ }$ \\
\hline $\begin{array}{l}\text { Do you believe that this practice is required by your } \\
\text { community? }\end{array}$ & & & & $\sqrt{ }$ \\
\hline \multicolumn{5}{|c|}{ Questions Administered About Daughters** } \\
\hline $\begin{array}{l}\text { Have any of your daughters been circumcised (2008-09)? } \\
\text { Is (NAME OF EACH DAUGHTER 0-14) circumcised? }\end{array}$ & & & $\sqrt{ }$ & $\sqrt{ }$ \\
\hline $\begin{array}{l}\text { Is (NAME OF ELDEST DAUGHTER) circumcised (1998)? } \\
\text { Has your eldest daughter been circumcised (2003)? }\end{array}$ & $\sqrt{ }$ & $\sqrt{ }$ & & \\
\hline How many were circumcised? & & & $\sqrt{ }$ & \\
\hline To which of your daughters did this happen to most recently? & & & $\sqrt{ }$ & \\
\hline Was any flesh removed from the genital area? & & & $\sqrt{ }$ & \\
\hline Was her genital area just nicked without removing any flesh? & & & $\sqrt{ }$ & \\
\hline Was her genital area sewn closed? & & & $\sqrt{ }$ & $\mathrm{V}$ \\
\hline $\begin{array}{l}\text { During the circumcision of (NAME OF ELDEST DAUGHTER) } \\
\text { which parts of the body were removed? }\end{array}$ & $\mathrm{V}$ & & & \\
\hline $\begin{array}{l}\text { How old was (NAME OF DAUGHTER) when she was } \\
\text { circumcised? }\end{array}$ & $\mathrm{V}$ & & $\mathrm{V}$ & $\mathrm{v}$ \\
\hline Who performed the circumcision? & $\mathrm{V}$ & & $\mathrm{V}$ & $\sqrt{ }$ \\
\hline $\begin{array}{l}\text { Do you plan to have (NAME OF ELDEST DAUGHTER) } \\
\text { circumcised (1998, 2003)? } \\
\text { Do you intend to have [you (other) daughter/any of your } \\
\text { (other) daughters] circumcised (2008-09)? }\end{array}$ & $\mathrm{V}$ & $\mathrm{V}$ & $\mathrm{V}$ & \\
\hline
\end{tabular}




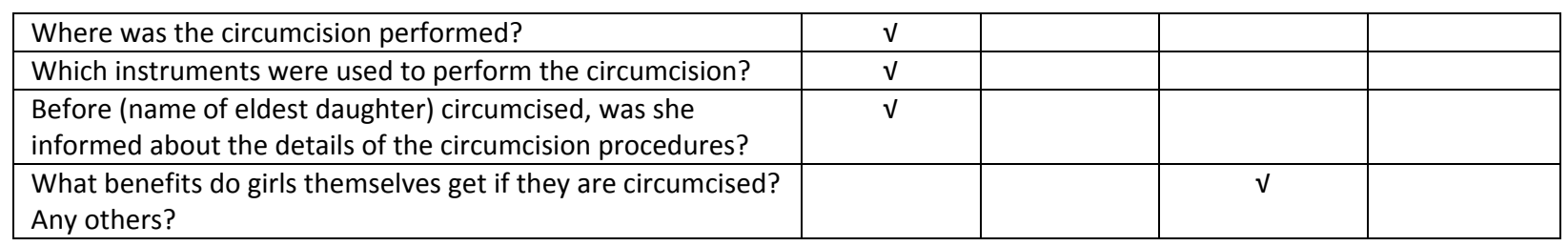

* FGC Module was included only in the long version of 2014 KDHS Woman's Questionnaire (not included in the short version aimed at collecting and reporting data at the county-level)

** In the 2014 KDHS, FGC questions were asked for all daughters aged 0-14 years.

The sampling frame for the 1998 survey did not include Northeastern (where many ethnic Somalis live and who almost universally practice FGM/C) but Northeastern is represented in the 2003, 2008-09 and 2014 DHS surveys. In 2014 the sampling frame was revised and the sample size increased to allow reporting estimates for a sub-set of DHS indicators, however the FGM/C module was not included in this list and therefore estimates can only be reported at regional (provincial) level. Additionally, from 2010, the DHS and MICS FGM/C modules were revised to collect data on all girls within the household. We have also explored FGM/C indicators for men in the 2014 dataset (Table 2).

Table 2: Questions Administered in the Survey for Men (Ages 15-54/59)

\begin{tabular}{|c|c|c|c|c|}
\hline & KDHS 1998 & KDHS 2003 & KDHS 2008-09 & KDHS 2014 \\
\hline Have you heard about circumcision? & & & & $\mathrm{V}$ \\
\hline $\begin{array}{l}\text { In some countries, there is a practice in which a girl may have } \\
\text { part of her genitals cut. Have you ever heard about this } \\
\text { practice? }\end{array}$ & & & & $\mathrm{V}$ \\
\hline $\begin{array}{l}\text { In many communities, girls are (also) circumcised. In this } \\
\text { community, is female circumcision practiced? }\end{array}$ & & $\sqrt{ }$ & & \\
\hline Has your eldest daughter been circumcised? & & $\sqrt{ }$ & & \\
\hline Do you plan to have your eldest daughter circumcised? & & $\mathrm{V}$ & & \\
\hline $\begin{array}{l}\text { Do you believe that female circumcision is required by your } \\
\text { community? }\end{array}$ & & & & $\mathrm{V}$ \\
\hline $\begin{array}{l}\text { Do you believe that female circumcision is required by your } \\
\text { religion? }\end{array}$ & & & & $\sqrt{ }$ \\
\hline $\begin{array}{l}\text { Do you think that female circumcision should be continued, or } \\
\text { should it be stopped? }\end{array}$ & & & & $\sqrt{ }$ \\
\hline
\end{tabular}




\section{Text Box 1: Validity of Self-Reported Data on FGM/C}

A number of studies have attempted to determine the reliability of self-reports of FGC status by verifying them through clinical examinations. This body of research has assessed two aspects of self-reported data: 1) the reliability of women's self-reports about having been cut or not, and 2) the reliability of self-reports of the type of FGM/C performed. Studies that have compared women's self-report of being cut or not to clinically observed signs of $F G M / C$ have reported variable rates of concordance. While one study in Sudan reported complete agreement between clinical examination and women's reports of having undergone some form of FGM/C or not (Elmusharaf et al., 2006), others report variable degrees of discrepancy. Morison and colleagues found 3\% disagreement in The Gambia, whereas studies in Tanzania and Nigeria reported disagreements in more than 20\% of women (Adinma, 1997; Msuya et al., 2002; Klouman et al., 2005; Snow et al., 2002). Nicking would not be expected to produce any clinically observable alteration of the external genitalia, and may account for some degree is difference between self-reports and clinical observations. However, inaccuracies of self-reported data on FGM/C must be considered. A longitudinal study in Ghana afforded a unique opportunity to assess the consistency of women's self-reports of FGM/C status over repeat surveys (Jackson et al., 2003). The data showed that a substantial number of adolescent girls who initially reported having undergone FGM/C later denied being cut. The authors concluded that denials of having undergone FGM/C were influenced by exposure to anti-FGM/C interventions, and by passage of a law banning $\mathrm{FGM} / \mathrm{C}$. In a detailed overview of methodological considerations for measuring change in FGM/C, Askew (2005: 472-73) emphasizes the need to consider the context in which questions of FGM/C status are being asked: "If FGC is widespread, socially acceptable and there is no wellpublicized interventions causing people to question its acceptability and legality..., then self-reporting is likely to be valid. If there are reasons why it would not be attractive for respondents to declare that they are cut..., then self-reported measures should be questioned and ways sought to validate the results." With this warning in mind, we concur with Yoder and colleagues (2004: 10), who conclude that "there is sufficiently strong confirmation of FGC status from women's reports to warrant the use of survey data to calculate the prevalence of FGC" (Yoder et al., 2004: 10). 


\section{FGM/C Among Women: Prevalence, Support and Circumstances under which is Carried Out}

\section{National Prevalence}

The national prevalence of FGM/C is calculated based on self-reported cutting status of female respondents aged 15-49 years (worded as, "Are you circumcised?" in the 1998 and 2003 surveys, and as "Have you yourself ever been circumcised?" in the 2008-09 and 2014 surveys). Self-reported data on FGM/C needs to be treated with caution as inaccuracies may arise for a number of reasons. Because of the sensitivity of the topic or illegal status, women may be unwilling to disclose having undergone FGM/C (Askew, 2005). Additionally, particularly when FGM/C is performed at an early age, women may be unaware of whether they have been cut or the extent of the cutting.

The 2014 KDHS estimates the prevalence of FGM/C among women ages 15-49 to be $21.0 \%$. Using data from the U.S Census International Data Base, we estimate that 2.75 million Kenyan girls and women ages 15 and over live with FGM/C. The prevalence, however, varies substantially across regions. In Northeastern Province $98 \%$ of women have been circumcised, whereas the prevalence is only $1 \%$ in Western Province (Figure 2).

Figure 2. Prevalence of FGM/C across Kenya's Provinces (KDHS 2014)

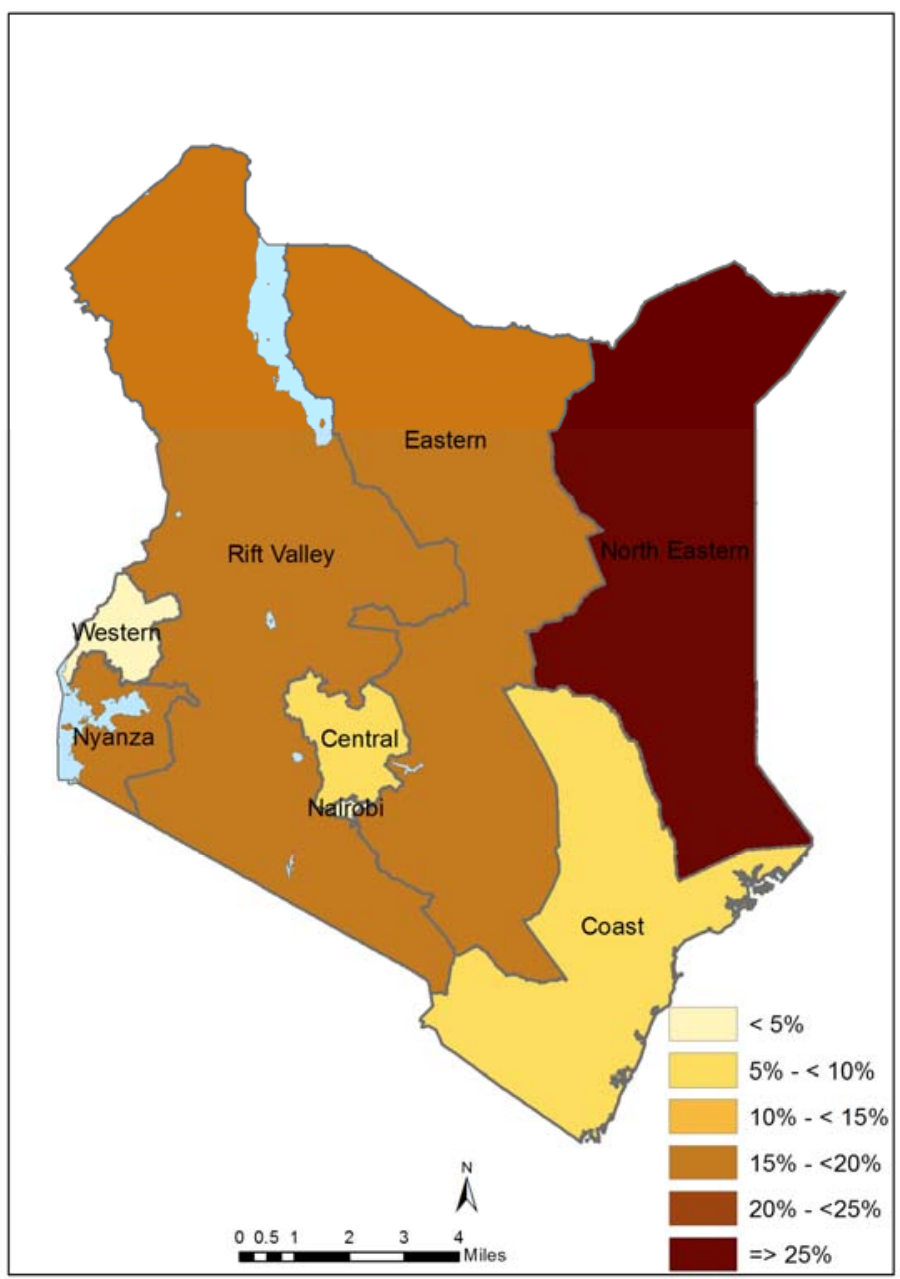


The population densities also vary substantially between Provinces. We use the prevalence estimates of FGM/C at the Province level along with population numbers for women age 15 and over to examine the distribution of girls and women age 15 and over living with FGM/C. Figure 3 demonstrates that $72 \%$ of all women age 15 and over living with FGM/C are found in three Provinces: Northeastern (27.5\%), Rift Valley (25.9\%) and Nyanza (18.4\%).

Figure 3. Distribution of Kenyan Women Age 15 and Over Living with FGM/C

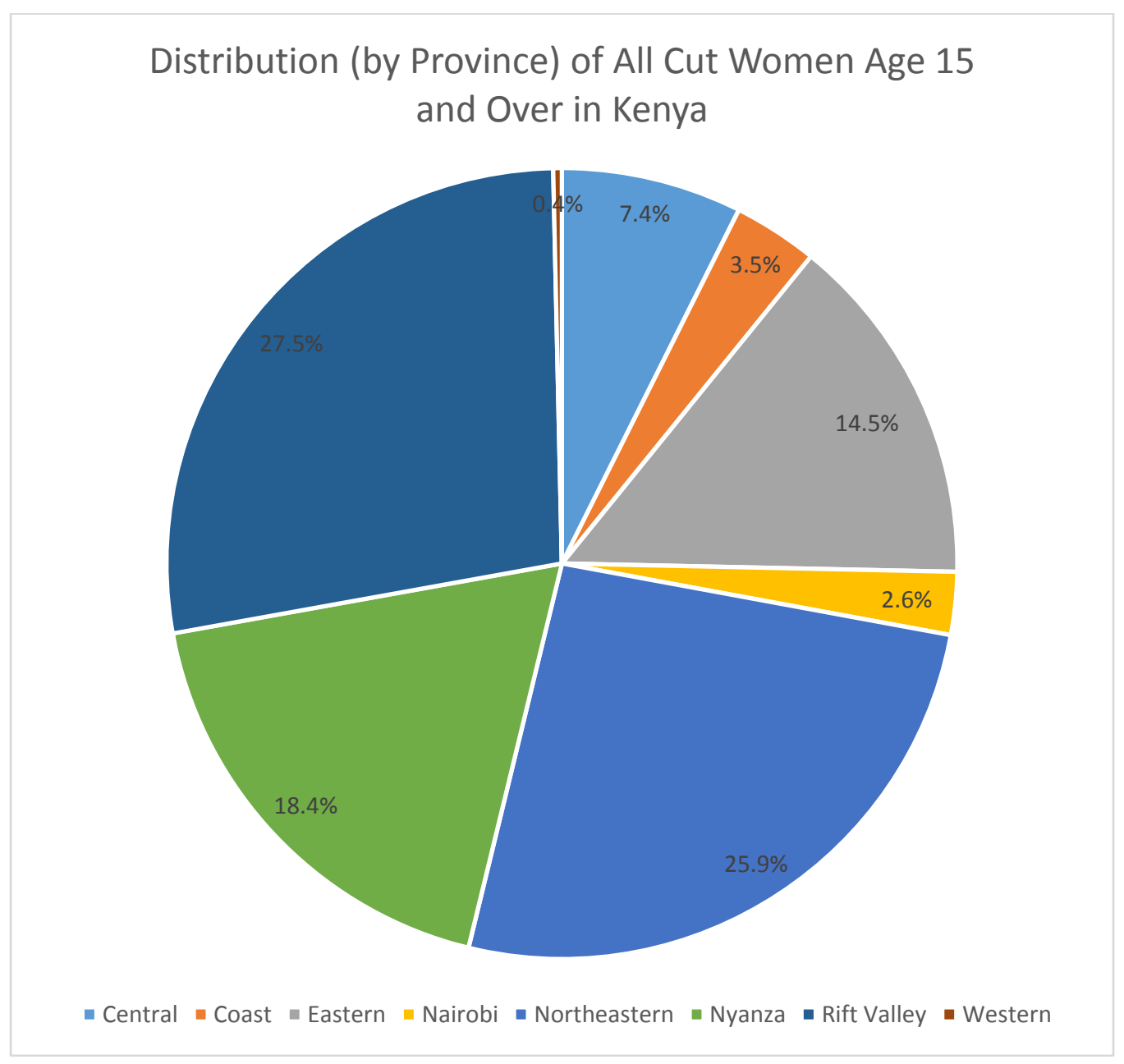

It is often assumed that FGM/C is less likely to be carried out in urban than rural settings. Rural settings may be more likely to have kin-based communities with limited cultural diversity. In communities where nearly all members favor the continuation of FGM/C, it may be difficult to escape the sanctions of norms and conventions that hold the practice in place. Urban settings, by contrast, may be more culturally diverse, and people may be more likely to associate with multiple reference groups across settings such as work, school, church, home, or others. Particularly where this results in a mixture of practicing and non-practicing groups, people may have a greater opportunity to see that women who are not cut do not experience negative sanctions such as ostracization. Additionally, membership in multiple social networks may lessen the importance of the lineage social network, whose members share normative expectations for continuing the practice of $F G M / C$. Ongoing interactions with members of other social networks who do not share such expectations may contribute to shifting opinions regarding FGM/C. The data from the $2014 \mathrm{KDHS}$ do, indeed, demonstrate that the prevalence of $\mathrm{FGM} / \mathrm{C}$ is substantially higher in rural residence locations, compared to urban setting (Figure 4). 
Figure 4: Prevalence of FGM/C among women aged 15-49 years in urban and rural locations

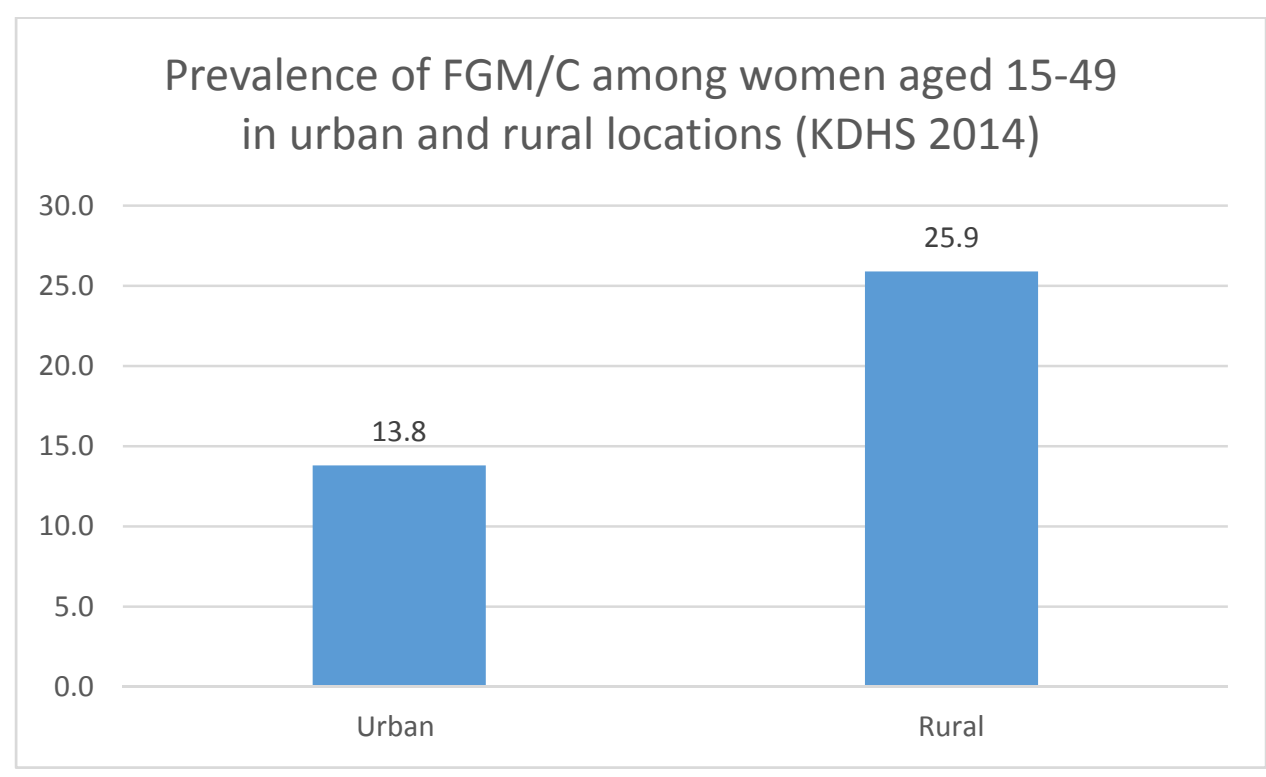

\section{Prevalence Across Socio-demographic Lines}

\section{Religion}

$\mathrm{FGM} / \mathrm{C}$ is often seen to be somehow connected to Islam, a view that is perhaps unsurprising given the frequency with which it is practiced in many Muslim African groups. However, not all Islamic groups practice FGM/C, and many non-Islamic ones do. Gruenbaum has emphasized that followers of all three monotheistic religions, Christianity, Judaism and Islam, "have at times practiced female circumcision and consider their practices sanctioned, or at least not prohibited, by God" (2001:60). On the other hand, religious leaders have at various times and places actively campaigned against the practice. Unsurprisingly, the association between religion and FGM/C prevalence varies widely across countries. Table 3 presents data on the prevalence of FGM/C among Kenyan women aged 15-49 according to religion. For the purpose of this analysis, comparisons are made across three groups: 1) Muslim, 2) Roman Catholic, 3) Protestant, Orthodox/Other Christian, and 4) no religion. As is true many countries where FGM/C is found, the prevalence of FGM/C is highest in Kenya amongst Muslim women (51\%). The practice, however, is also found among Catholic and Protestant women, and women in other/non-religious communities. Clearly, the variation in prevalence among the different religious groups demonstrates that $\mathrm{FGM} / \mathrm{C}$ is a challenge for all religious groups of the affected countries, and religious leadership may have to be engaged in further work to understand the prevalence of $\mathrm{FGM} / \mathrm{C}$ in their religious communities.

\section{Household Wealth}

Modernization theory posits that improvements in economic status, particularly for women, will have broad social effects, including a decline in the support for FGM/C. Economic development may be accompanied by increased commerce and migration; it is also posited that it may weaken traditional family structures and draw women into the labor market, changing their economic and social roles, as well as their dependence on FGM/C as a means to assure a secure future via marriage (Kennedy, 1970; Hayes, 1975; van der Kwaak, 1992; Yount, 2002; Hayford, 2005). Gruenbaum notes, however, that economic development projects can have contradictory impacts on FGM/C, particularly if they do little to enhance women's autonomy and instead reinforce patriarchal relations and women's 
economic dependency (Gruenbaum 2001: 270). If economic development serves to reduce the demand for FGM/C, we expect to see lower support for continuation of $\mathrm{FGM} / \mathrm{C}$ among women from wealthier households. Furthermore, if it also enhances women's decision-making authority, we would expect to see a decline in FGM/C amongst daughters of women from wealthier households. Mackie (2000) points to a potential fallacy in this line of reasoning. It presumes that women are willing and individually able to abandon FGM/C. If, however, the practice of FGM/C is held in place by reciprocal expectations, even wealthier women will not be able to individually opt out of performing FGM/C on their daughter without suffering negative sanctions. Where change in normative expectations has not been communicated and abandonment coordinated, there may be discrepancies between preference and behavior. We therefore begin our analysis by asking: Is there an association between wealth and prevalence of FGM/C? We examine this using a wealth index constructed using items on household assets, such as ownership of televisions and cars, as well as material living conditions, such as sanitation facilities, access to safe drinking water, and dwelling characteristics (Rutstein et al., 2000; Rutstein, 1999). Each item is assigned a weight, and individuals are ranked according to the total score of the household in which they reside. The household wealth index separates the population into quintiles ranging from one (lowest) to five (richest). This measure is used to determine whether there are differentials pertaining to FGM/C among the wealthiest and poorest sectors of society. The 2014 KDHS show that the prevalence of FGM/C progressively increases as women's household wealth decreases. This, however, does not indicate a causal influence of household wealth, since cutting occurs at young ages when women live in their natal homes rather than in the marital home for which wealth is most commonly reported.

\section{Education}

Women's education may also have a spurious correlation with women's FGM/C rates, particularly in areas where cutting occurs at early ages before a girl has completed her education. However, in a number of regions of Kenya girls are withdrawn from school and undergo FGM/C in preparation for marriage. A number of campaigns have therefore focused on these three issues in concert: ending early marriage, keeping girls in school and stopping FGM/C (Shell-Duncan and Olungah, 2009). Notably, it is women with no education at all who have the highest rates of $\mathrm{FGM} / \mathrm{C}(58 \%)$.

\section{Ethnicity}

FGM/C in many settings derives much of its meaning and tenacity from its intimate association with ethnic identity. The strong association between ethnicity and $\mathrm{FGM} / \mathrm{C}$ raises a key question: What role does ethnicity play in the perpetuation of $\mathrm{FGM} / \mathrm{C}$ ? Clearly in many instances $\mathrm{FGM} / \mathrm{C}$ is a powerful marker of ethnic identity that can generate deep resistance to change efforts. Gruenbaum (2001: 131) emphasizes that "for most people ethnic identity is carefully guarded and markers of it are changed only when there are persuasive incentives." Where there exists a strong link between FGM/C and ethnicity, it may be the case that ethnicity signals reciprocal expectations that hold the practice in place; ethnicity may be a proxy for shared norms concerning marriageability, sexual restraint, personhood, or other shared values. In some societies FGM/C plays an integral role in defining personhood by having become incorporated into coming of age rituals that confer the status of adulthood. At the same time, however, it is becoming increasingly common for $\mathrm{FGM} / \mathrm{C}$ to become dissociated from initiation rituals, although the practice may continue to be an important physical marker of insider/outsider status, and intertwined with shared values. Intervention programs that involve alternative rituals introduce modification of current or past initiation ceremonies by emphasizing cultural meaning and training, but not cutting (Chege et al., 2001).

Ethnic classifications are, however, not static, and are often more complex than can be summarized with simple measures. Consequently, there are a number of challenges in tracing ethnicity from survey data. Ongoing processes of migration, mixing, and socioeconomic and political change can contribute to ethnic definitions that change over time, and may even contribute to the spread of FGM/C in certain situations. For instance, Ellen Gruenbaum (2001) 
describes how FGM/C can serve as an important marker of privileged ethnic group status, and has at times contributed to spread of the practice among lower status groups in an assimilative strategy. An additional challenge in examining ethnic identity is posed by the fact that ethnic groups may have subgroups that differ with respect to FGM/C practices. Some ethnic groups are subdivided into several lineages that vary in terms of whether they do or do not practice $\mathrm{FGM} / \mathrm{C}$, and the categorization of ethnic identity can be complicated by inter-ethnic marriage by contributing to fluidity in ethnic identification (Yoder et al., 2004; Shell-Duncan et al., 2011). Despite these challenges, measures of ethnicity explain more variation and change in $\mathrm{FGM} / \mathrm{C}$ prevalence rates than any other sociodemographic variable.

Table 3: Prevalence of FGM/C by Sociodemographic Background Characteristics (KDHS 2014)

\begin{tabular}{|l|r|r|}
\hline Background Characteristic & \% & n \\
\hline Religion & 21.5 & 2,920 \\
Roman Catholic & 17.9 & 10,497 \\
Protestant/other Christian & 51.1 & 916 \\
Muslim & 32.9 & 244 \\
No religion & 19.7 & 48 \\
Other & & \\
Ethnicity & 27.9 & 1,785 \\
Kalenjin & 10.7 & 1,649 \\
Kamba & 14.6 & 3,136 \\
Kikuyu & 84.4 & 863 \\
Kisii & 0.4 & 2,301 \\
Luhya & 0.2 & 1,560 \\
Luo & 77.9 & 280 \\
Maasai & 30.7 & 973 \\
Meru/Embu & 2.4 & 767 \\
Mijikenda/Swahili & 93.6 & 354 \\
Somali & 22.3 & 139 \\
Taita/Taveta & 35.9 & 815 \\
Other & & \\
Wealth Quintile & 39.8 & 2,236 \\
Lowest & 26.0 & 2,590 \\
Second & 17.8 & 2,859 \\
Middle & 17.2 & 3,114 \\
Higher & 12.0 & 3,827 \\
Highest & & \\
Education & 58.1 & 1,015 \\
No education & 23.3 & 7,336 \\
Primary & 13.4 & 4,696 \\
Secondary & $\mathbf{2 1 . 0}$ & 1,578 \\
Higher & & \\
Total & & \\
\hline & & \\
& & \\
\hline & & \\
\hline
\end{tabular}

In Kenya, the prevalence of FGM/C varies substantially along line of ethnicity. The prevalence ranges from being less than $1 \%$ among Luhya and Mijikenda/Swahili women to $94 \%$ among Somali women (Table 3). To understand the role that ethnicity plays in the perpetuation or abandonment of $\mathrm{FGM} / \mathrm{C}$ further multivariate analyses are required, along with exploration of ethnographic data. 


\section{How and when is FGM/C performed?}

\section{Type of Cutting}

The questions in the FGM module inquire about type of cutting using a series of question that describe the extent and nature of physical modification: "Was any flesh removed from the genital area?," and, "Was your vaginal area sewn closed?" "Flesh removed", but not "sewn closed" may describe Type I (clitoridectomy), or Type II (excision), while a positive response to the question about being "sewn closed" may correspond to Type III, infibulation. However, Gele and colleagues (2013: 7) report that one of the most common forms of "sunna circumcision" in Somalia is clitoridectomy followed by two stitches. Thus, survey responses of "sewn closed" may include this non-infibulating form of FGM/C. Studies of the correspondence between self-reported type of FGM/C and clinically observed type also report variable levels of disagreement, with more frequent under-reporting than over-reporting of the extent of cutting (Morison, et al., 2001; Elmusharaf et al., 2006). It may be difficult to make a clear correspondence between the local vernacular describing type and descriptions used in survey questions. Additionally, some women may be unaware of the details of their own genital modification. Information on the FGM/C status of daughters, the type, and the circumstances surrounding the practice is generally regarded as more reliable than women's self-reports since daughter's FGM/C occurred more recently, and mothers are assumed to have been involved in the event (Yoder et al., 2004).

The 2014 data reveal that among women who have experienced FGM/C, 89\% report having "flesh removed" but not "sewn closed," while $9 \%$ report having been sewn closed) (Figure 5).

Figure 2: Type of FGM/C among women aged 15-49 (KDHS 2014)

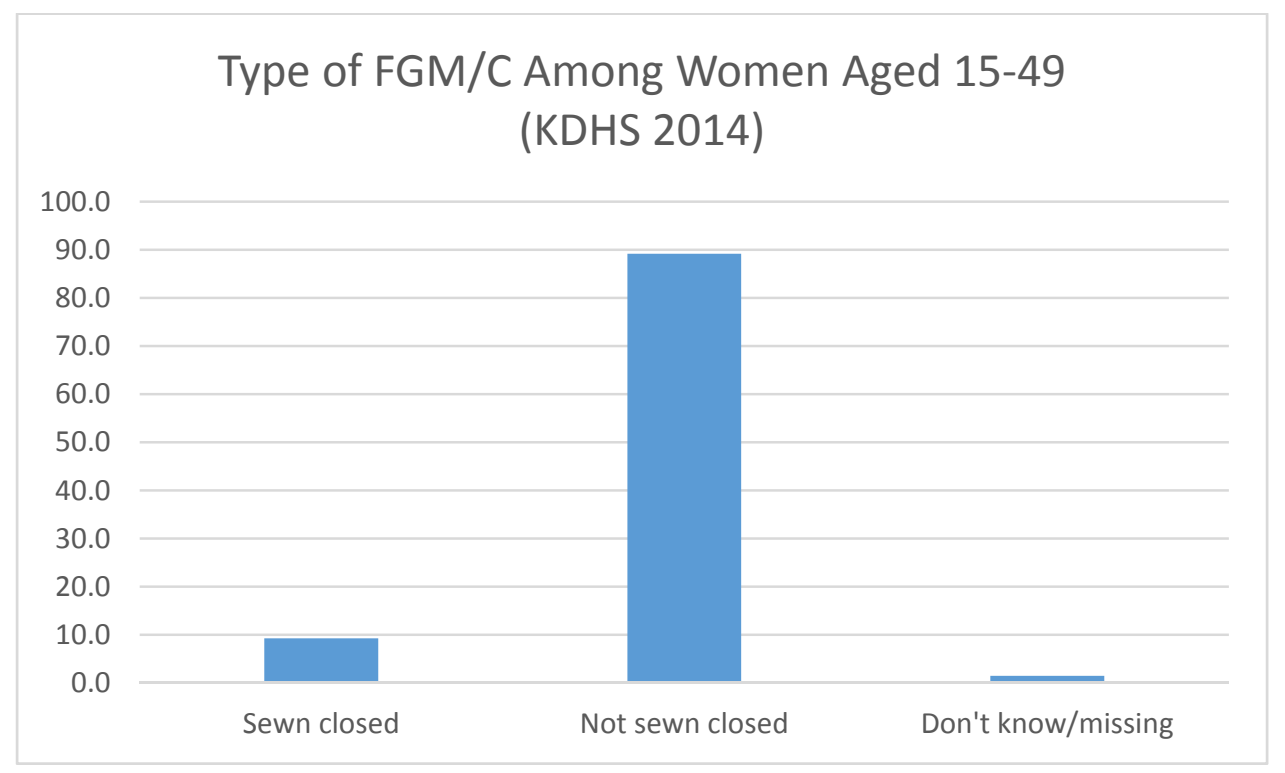

\section{Person who Performs FGM/C}

The term "medicalization" is defined by the World Health Organization as "situation in which FGM is practiced by any category of health-care provider, whether in a public or private clinic, at home, or elsewhere" (WHO 2010: 2). The current standardized DHS module on FGC collects information only on the type of practitioner who performed FGM/C, and these data are used to operationalize the WHO definition of medicalization. The trend toward increased medicalization of $\mathrm{FGM} / \mathrm{C}$ has been attributed to decades of advocacy that centered on delivering a message regarding the health risks of FGM/C (UNICEF, 2005). While these campaign messages are acknowledged to have 
succeeded in raising awareness of the medical risks, they may have also inadvertently promoted the conceptualization of FGM/C as an issue amenable to treatment through medical care (Shell-Duncan, 2001; Njue and Askew, 2004, Christoffersen-Deb, 2005; Shell-Duncan and Njue, 2017). Since the early 1990's efforts have been made to move beyond the narrow health focus, and contextualize FGM/C as a larger human rights violation (Boyle, 2002; UNICEF, 2005; Shell-Duncan, 2008). The United Nations agencies first condemned medicalization in 1979, and reiterated this position in two recent interagency statements: Eliminating female genital mutilation: An interagency statement (WHO, 2008), and Global strategy to stop health-care providers from performing female genital mutilation (WHO, 2010). The former statement specifies that any procedure conducted by a trained professional "is not necessarily less severe, or conditions sanitary". Furthermore, there is no evidence that medicalization reduces the documented obstetric or other long-term complications associated with female genital mutilation" (WHO, 2008: 12). Additionally, given that medical personnel often hold positions of authority and respect, medicalization may institutionalize the practice in the medical system and legitimize the practice as medically sanctioned. Numerous medical associations condemn medicalization, including the International Federation of Gynecology and Obstetrics (FIGO), which passed a resolution in 1994 at its General Assembly opposing the performance of FGM/C under any circumstances, in health establishments or by health professionals (Budiharsana, 2004, cited in WHO, 2008).

The 2014 data reveal that the majority of women ages 15-49 (83\%) were cut by traditional practitioners (traditional circumcisers or traditional birth attendants), while $15 \%$ were cut by health care professionals (a doctor, nurse or midwife) (Figure 6).

Figure 3: Person who performed FGM/C among women aged 15-49 years

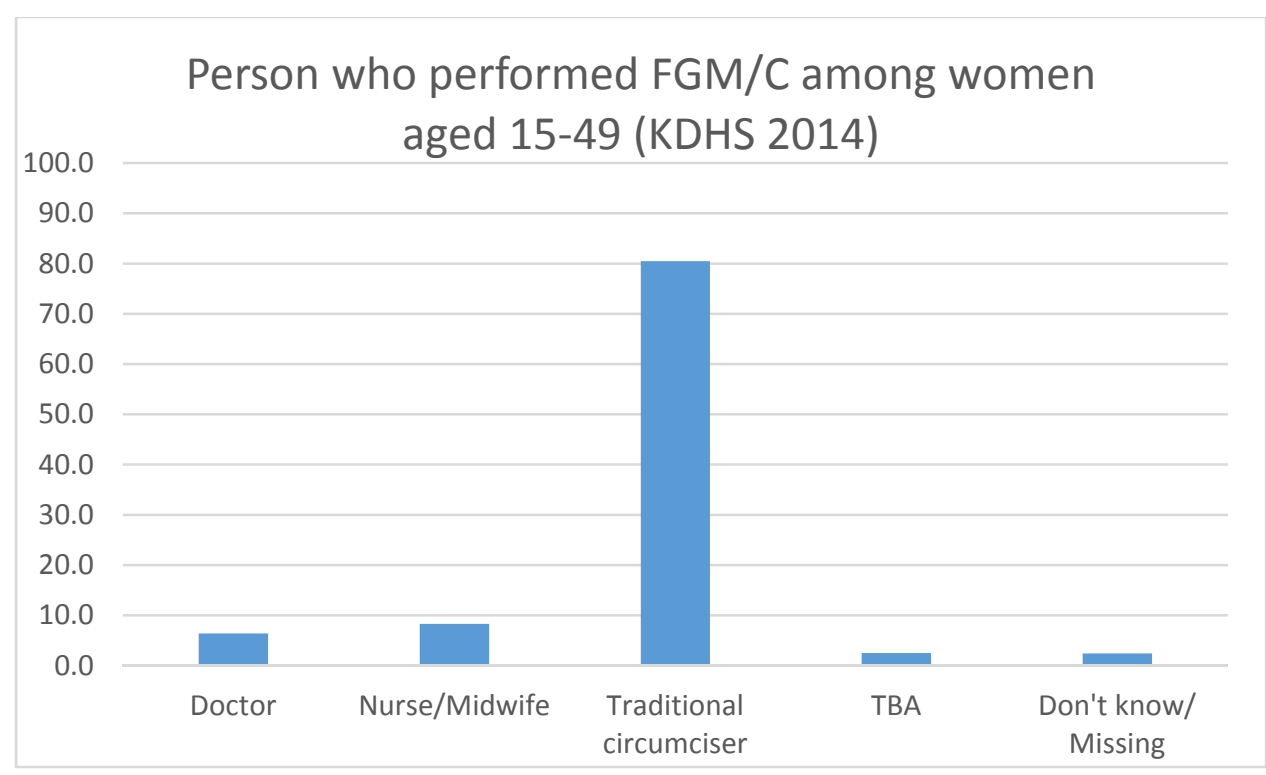

Shell-Duncan and Njue (2017) have completed a comparative overview of medicalization (cutting by a health professional) drawing on data from 25 countries with data on type of provider. They estimate that across these 25 countries, nearly 15 million women between ages 15-49 have undergone medicalized cutting; of these, 35,796 live in Kenya. This represents approximately $2 \%$ of all women aged $15-49$ who have undergone medicalized cutting (Figure 7). 
Figure 7. Geographic distribution of women who report having been cut by a medical professional (Source: Shell-Duncan and Njue, 2017)

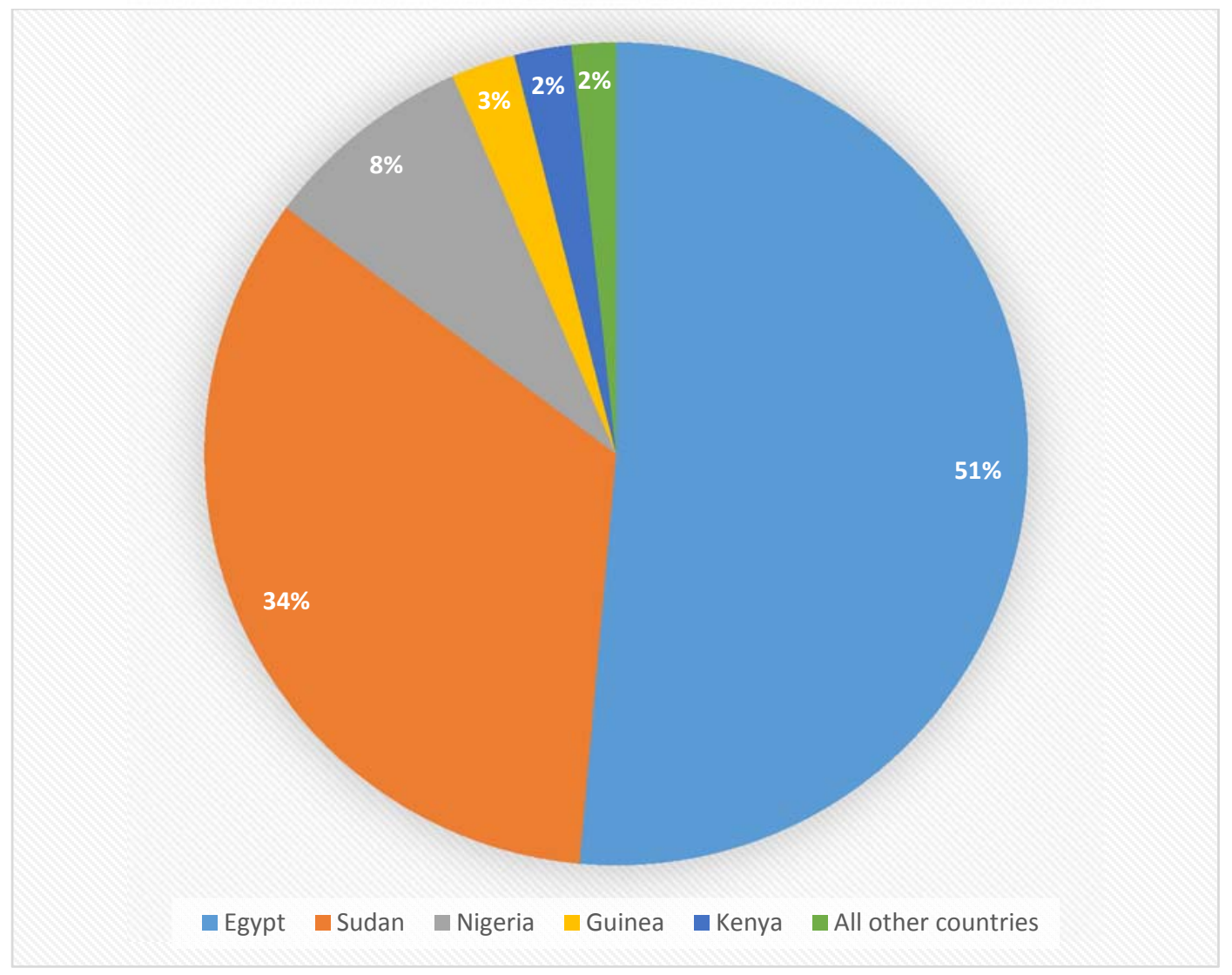

\section{Age at Cutting}

Data on age at which FGM/C was performed is of interest in order to understand when girls are most commonly at risk of being cut, and to monitor trends over time. Accounts from a number of settings describe that there is a trend for FGM/C to be performed at younger and younger ages. Occasionally, as the timing of FGM/C shifts from adolescence to younger ages, it is performed individually rather than in groups, and becomes uncoupled from training and celebration performed in the course of a coming-of-age rituals (e.g. Hernlund, 2000 on The Gambia; Njue and Askew, 2004 on Kenya; Yoder and Mahy, 2001 on Guinea). One commonly cited reason for performing FGM/C at earlier ages is being able to perform it more discretely, particularly when people are aware of campaigns aimed at ending their custom or where the practice has become criminalized (Hernlund, 2000; Shell-Duncan et al., 2010; Njue and Askew, 2004). It is also commonly reported that young girls heal more quickly than older girls or women, and put up less resistance (Shell-Duncan et al., 2010). It is understandable that parents and families may be resistant to stopping the practice of FGM/C if they have not been provided with the knowledge and means of opting out of the practice without suffering negative social sanctions. Yet in places where FGM/C has become a purely physical procedure performed at young ages, it is possible that for some, the practice loses its broader social meanings (e.g., Njue and Askew, 2004). This may result in the weakening of social norms that in the past held the practice in place, and present an opportunity for change. It should be noted, however, that there are a number of groups that have long performed FGM/C at very early ages and in the absence of training, and for many, the practice has been retained and continues to hold great cultural importance. 
The Kenya DHS surveys routinely collected information on the age at cutting for the woman being interviewed in three rounds: 1998, 2008-09 and 2014. The unadjusted 2014 data, shown in Figure 8, show that the vast majority of cutting takes place when girls are age 5 and over. This is in sharp contrast to many other countries, including Nigeria, Mali, Eritrea, Ghana, Mauritania, Senegal, Ethiopia, Niger and Burkina Faso, where most girls are cut in infancy or very early childhood (UNICEF, 2013). Additionally, in most countries it is rare for cutting to take place after the age of 15 . In this regard, the situation in Kenya is a unique exception; a substantial fraction of cutting (27\%) takes place at age 15 or over.

Figure 8. Age at which FGM/C was performed on women aged 15-49

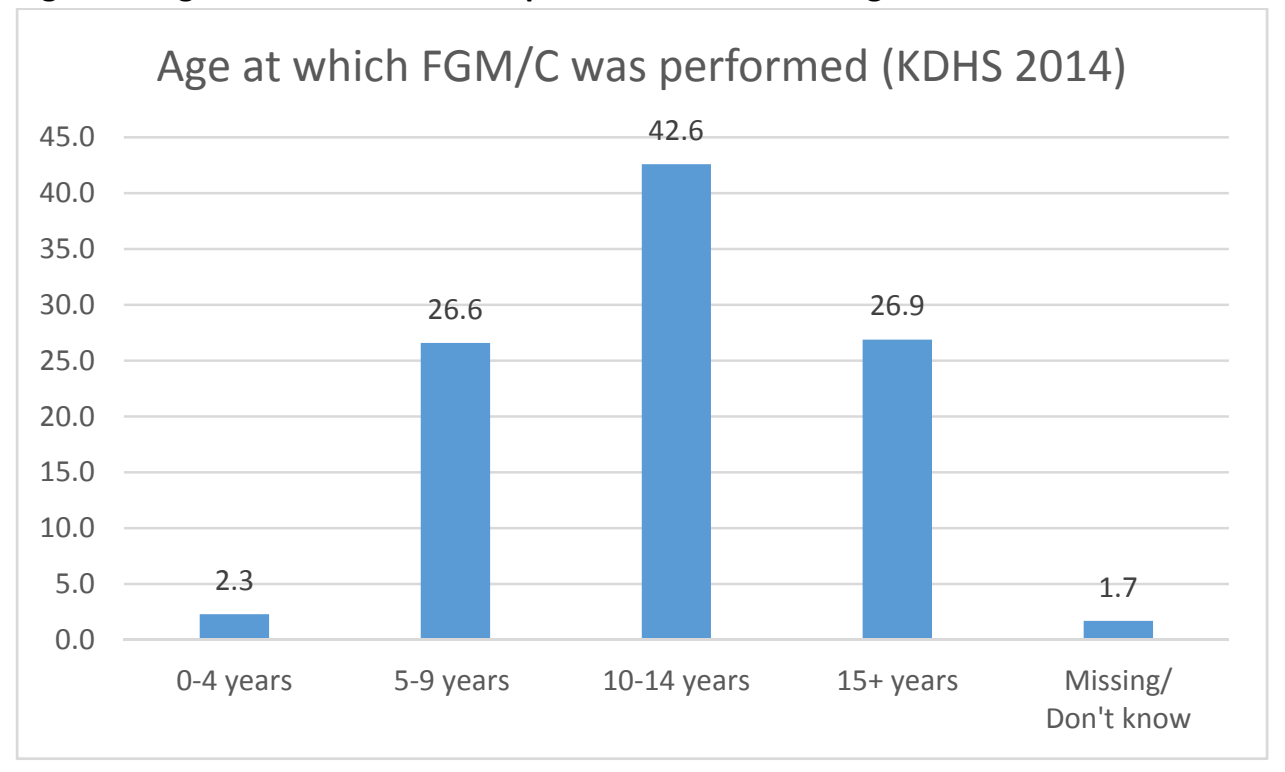

\section{Support for and Norms Associated with the Continuation of FGM/C}

The module on FGC included a question on the respondent's opinion on the continuation or discontinuation of FGM/C in 3 surveys: 1998, 2008-09, and 2014. The question is posed as, "Do you think this practice should continue, or should it be discontinued?", and is followed by pre-coded responses including "continued," "discontinued," as well as an ambivalent response, "it depends" or "not sure." It is important to note that this question captures a respondent's opinion at one point in time, and in the context of responding to a formal survey. Amongst those who report favoring the discontinuation of $F G M / C$, it is possible that, with intense exposure to campaign messages against FGM/C, there may be a courtesy bias in which the respondent reports what she perceives to be the "correct" answer rather than her true opinion. Additionally, even a truthful response at one point in time fails to take into account that a person's opinion may shift as they are exposed to new information about the practice, or about the opinions of others about the practice. For instance, writing on Senegal and The Gambia, Hernlund and Shell-Duncan (2007: 46) emphasize that "there is a broad range of realities inhabited by those who participate in FGC in this region - ranging from strong support to strong opposition, but with the potential movement over time by an individual or even community from one category to another, and potentially back again." They add that "the construction of a person's 'opinion' about the practice is more correctly an ongoing positioning in relation to fluctuating needs and realities, representing contingencies that affect decision making" (2007: 44).

Although responses to this simple survey question are plagued by ambiguity, they still provide useful insights. New information about the harms of the practice disseminated in culturally appropriate ways can stimulate a dialogue that allows FGM/C to be called into question as a social rule. Experience indicates that where this has been done 
effectively support for the continuation tends to erode. However, since FGM/C may be understood as a social norm, expectations about social rewards and sanctions may motivate continuation of FGM/C even among individuals who personally favor stopping the practice. Concerns over the social status of a girl and her family may continue to influence adherence to the community's social norms. Questions on a respondent's opinion on support for continuation of FGM/C do not capture information on normative expectations. Nonetheless, we can begin to understand the social dynamics of FGM/C by examining an individual's opinion on FGM/C alongside their actual or intended behavior. We describe this below using a concept known as readiness to change.

Given the social expectations to perform FGM/C, we anticipate that the strongest self-reported support for the continuation of $\mathrm{FGM} / \mathrm{C}$ to be among women who have been cut. However, after decades of campaigns aimed at ending FGM/C, as well as increased awareness of international norms opposing the practice, we may expect to see an increasing number of women - both those who have and have not undergone $\mathrm{FGM} / \mathrm{C}$ - who state that they favor stopping the practice. It is also predicted that if $\mathrm{FGM} / \mathrm{C}$ is linked to patriarchal control over women, men should be resistant to change, and stronger supporters of the practice than women.

The data from the 2014 KDHS survey reveal that the vast majority of women, cut and uncut alike, express a desire to have FGM/C stop. As predicted, support for continuation of FGM/C is higher among cut (23\%) than uncut (2\%) women. Comparing the responses of men to women (cut and uncut combined), both groups strongly prefer to see FGM/C stop, although responses are slightly lower among men (Figure 9).

Figure 9. Support for the Continuation of FGM/C by Kenyan Women and Men, 2014

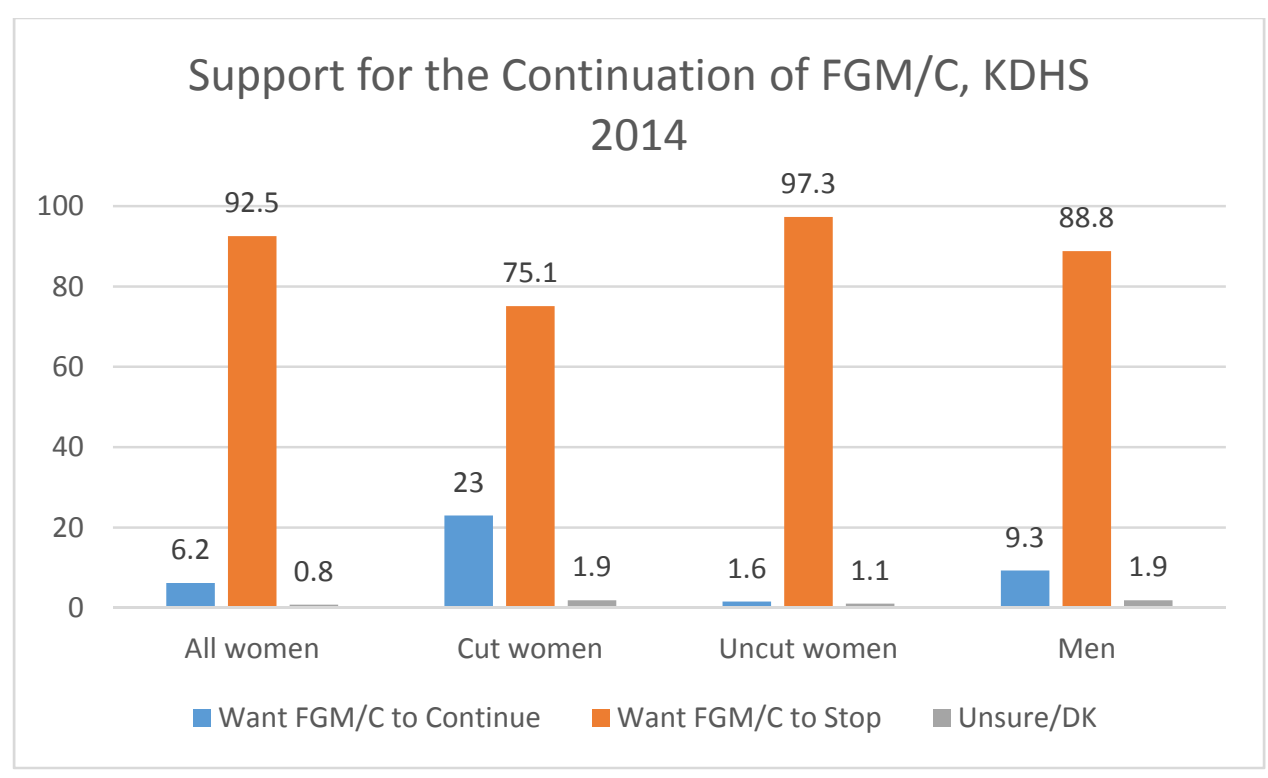

Data on support for continuation of FGM/C can be compared for men and women residing in the same household to assess the degree to which their opinions align or differ. Figure 10 shows that the majority of cohabiting men and women agree in wanting FGM/C to stop (82\%). Among $15 \%$ of couples surveyed, men and women disagree about the continuation of $\mathrm{FGM} / \mathrm{C}$. These represent households where prevention efforts are needed to support the stance of those who have come to oppose the practice of FGM/C. 
Figure 10. Concordance among cohabiting couples

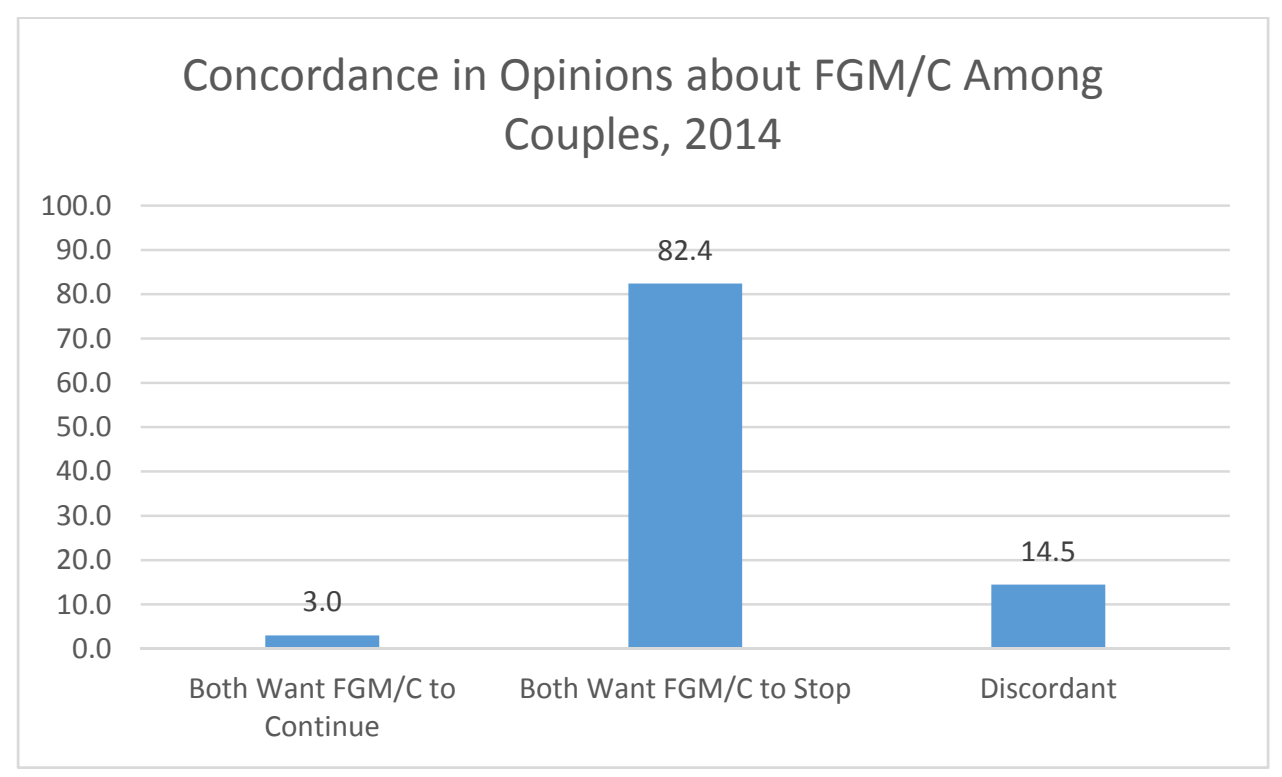

In 2014 two questions were added to the Kenya DHS FGC module aimed to capture social norms and religious norms. Both men and women were asked whether they believe that circumcision is required by religion. Overall, $4.5 \%$ of women and $5.5 \%$ of men believe this to be true. However, when women are divided into those who have been cut and those not cut, the data reveal that the belief that $\mathrm{FGM} / \mathrm{C}$ is required by religion is highest among women who have been cut (Figure 11). Similarly, the belief that FGM/C is required by the community is also substantially higher among cut women than uncut women or men (Figure 12).

Figure 11. Percent women and men who believe FGM/C is required by religion

\section{Percent of Women and Men Who Believe FGM/C is Required by Religion, KDHS 2014}

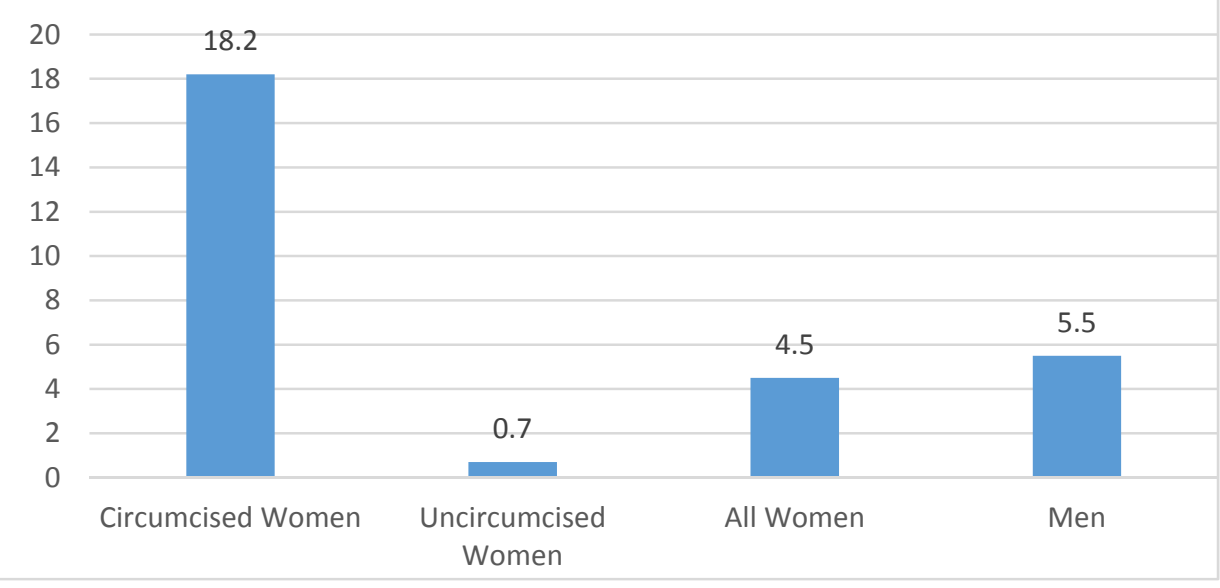


Figure12. Percent of women and men who believe FGM/C is required by their community

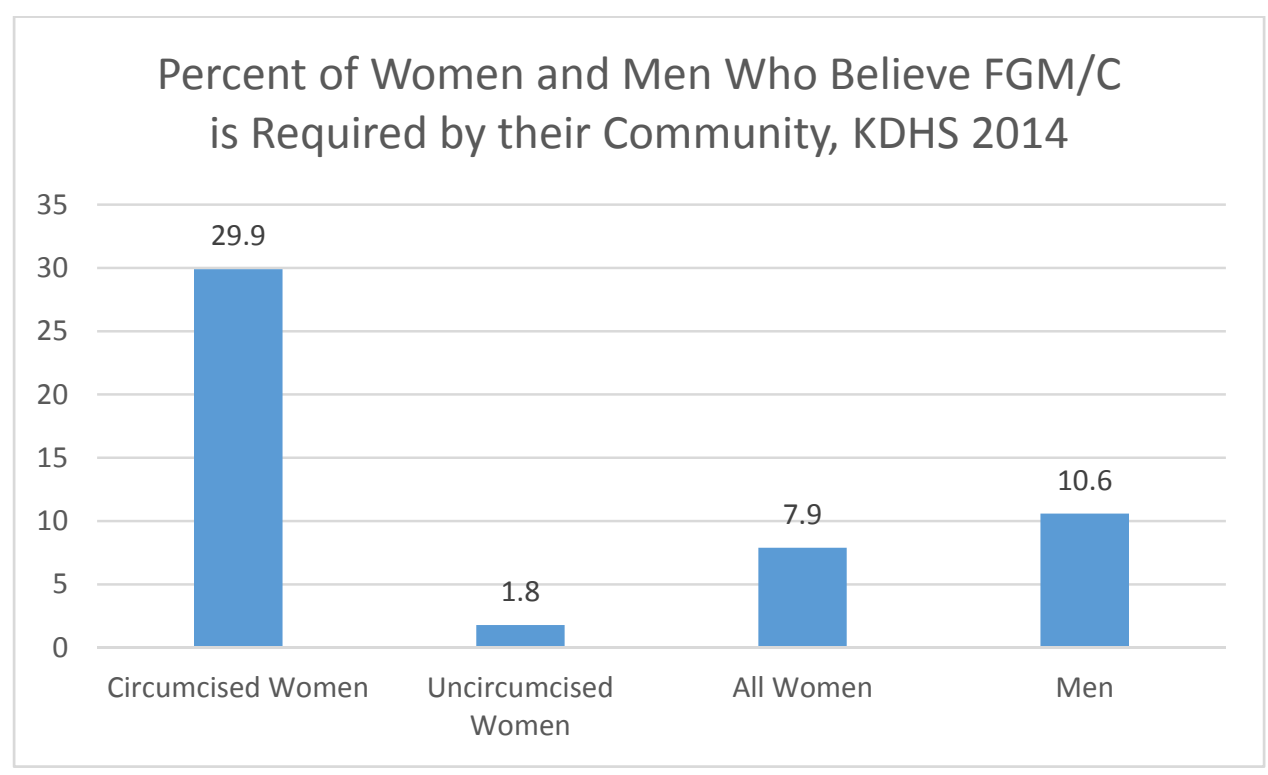

\section{Trends in FGM/C in Kenya: Is the practice declining?}

\section{Trends in Prevalence}

Trends in prevalence of FGM/C can be analyzed in a number of ways, each offering different insights regarding whether and when change has occurred. The clearest picture on change comes from using two methods in combinations: 1) comparing national prevalence across successive surveys, and 2) examining prevalence rates across among different age groups, known as the age-cohort approach. In the following chapter we further analyze intergenerational change by comparing data from mothers and daughters.

The first approach compares rates of FGM/C in women ages 15-49 across 4 successive surveys conducted at 5 year intervals, beginning in 1998. Direct comparison of national prevalence reveals a steady and dramatic decline in rates of FGM/C, dropping from 38\% in 1998 to $21 \%$ in 2014 (Figure 13). The actual decline in national prevalence across this interval is even larger than this direct comparison suggests, as the 1998 survey did not include women in Northeastern Kenya, the region with the highest prevalence of FGM/C. While this comparison is the simplest means of tracking change in FGM/C, national prevalence figures mask a great deal of variability along lines of age, region and sociodemographic characteristics. It is therefore useful to track changes, even in a descriptive fashion, in more refined ways. One particularly useful alternative that allows for a better understanding of the timing of change is the age-cohort method. 
Figure 13: Trends in national prevalence across successive surveys

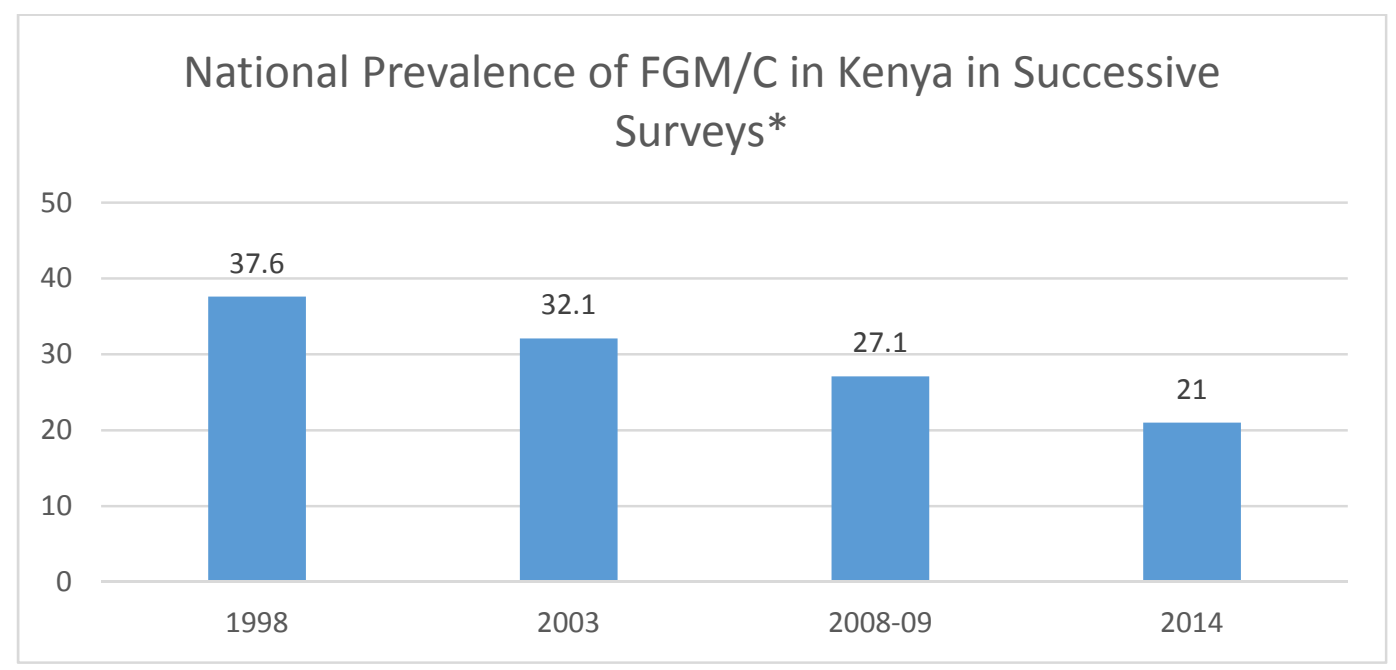

*The 1998 KDHS survey sample excluded the entire Northeastern Province and northern parts of Rift Valley and Eastern Provinces.

The age-cohort method involves subdividing surveyed women into 5-year age cohorts, and computing prevalence for each subgroup. This allows us to see where declines in the prevalence of FGM/C first began. In the 1998 and 2003 surveys, the prevalence of FGC appears steady in the eldest age cohorts only. In the 2008-09 and 2014 surveys, there is a steady decline in prevalence across all age cohorts. To understand the timing of cutting that these data reflect, is important to consider age at time of cutting (discussed in further detail below). For instance, if women were cut on average at age 15, the changes that first appeared in the 30-34 year old cohort in 1998 occurred some 15-20 years prior to the date the survey, corresponding to the late 1970's or early 1980's (Figure 14).

\section{Figure 14. Prevalence by Age Cohorts}

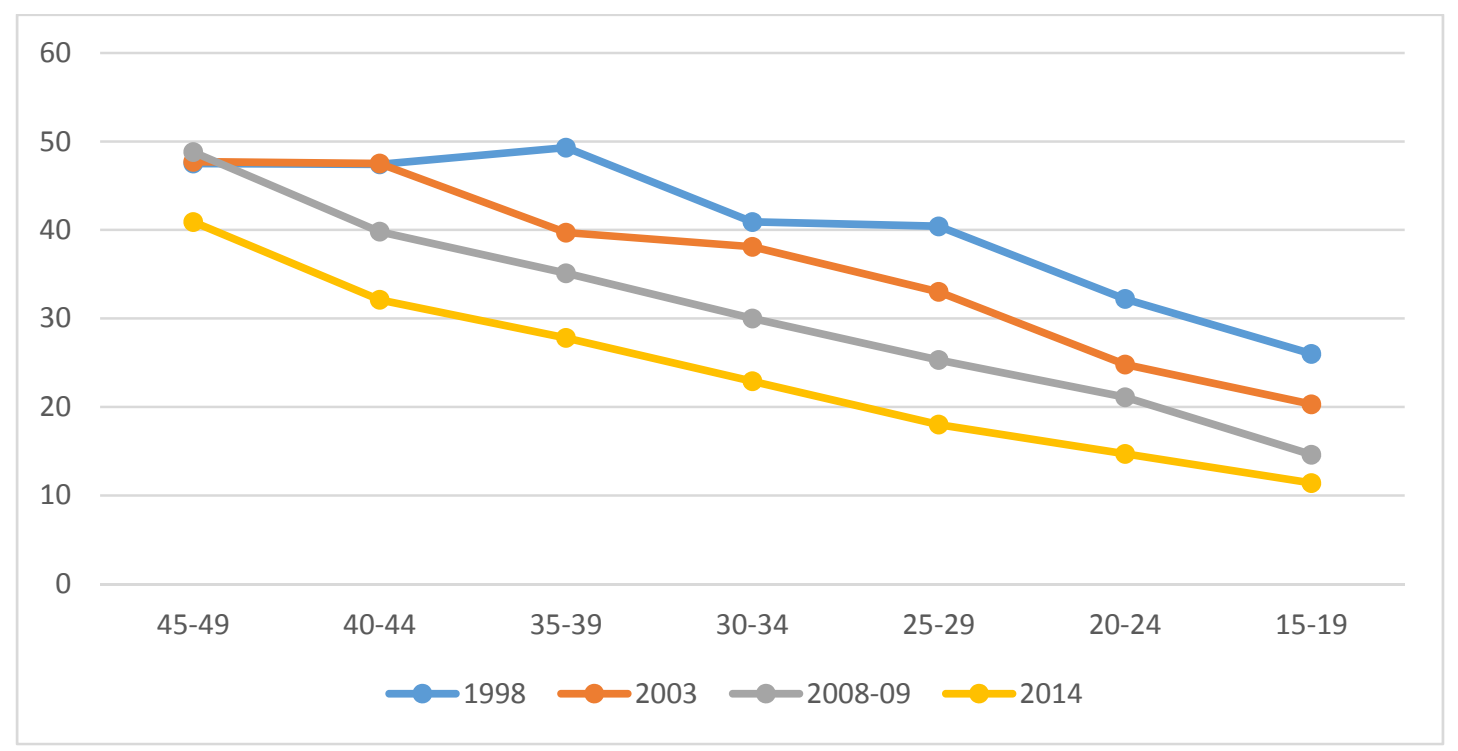

*The 1998 KDHS survey sample excluded the entire Northeastern Province and northern parts of Rift Valley and Eastern Provinces. 
Subdividing the data along the lines of ethnicity reveals variation in rates of decline across different cohorts of women (Figure 15). Rates of FGM/C remain very high among ethic Somali women. Rates of FGM/C are very high in older cohorts of Maasai and Kisii women, but appear to be declining in the youngest age cohorts. Other ethnic groups have shown significant long-term declines in FGM/C across age cohorts. In the youngest age cohort, the prevalence of $\mathrm{FGM} / \mathrm{C}$ has dropped to $5 \%$ or lower among four ethnic groups: Kalenjin, Kamba, Kikuyu, and Taita/Taveta.

Figure 15. Prevalence of FGM/C by Cohorts and Ethnicity, KDHS 2014

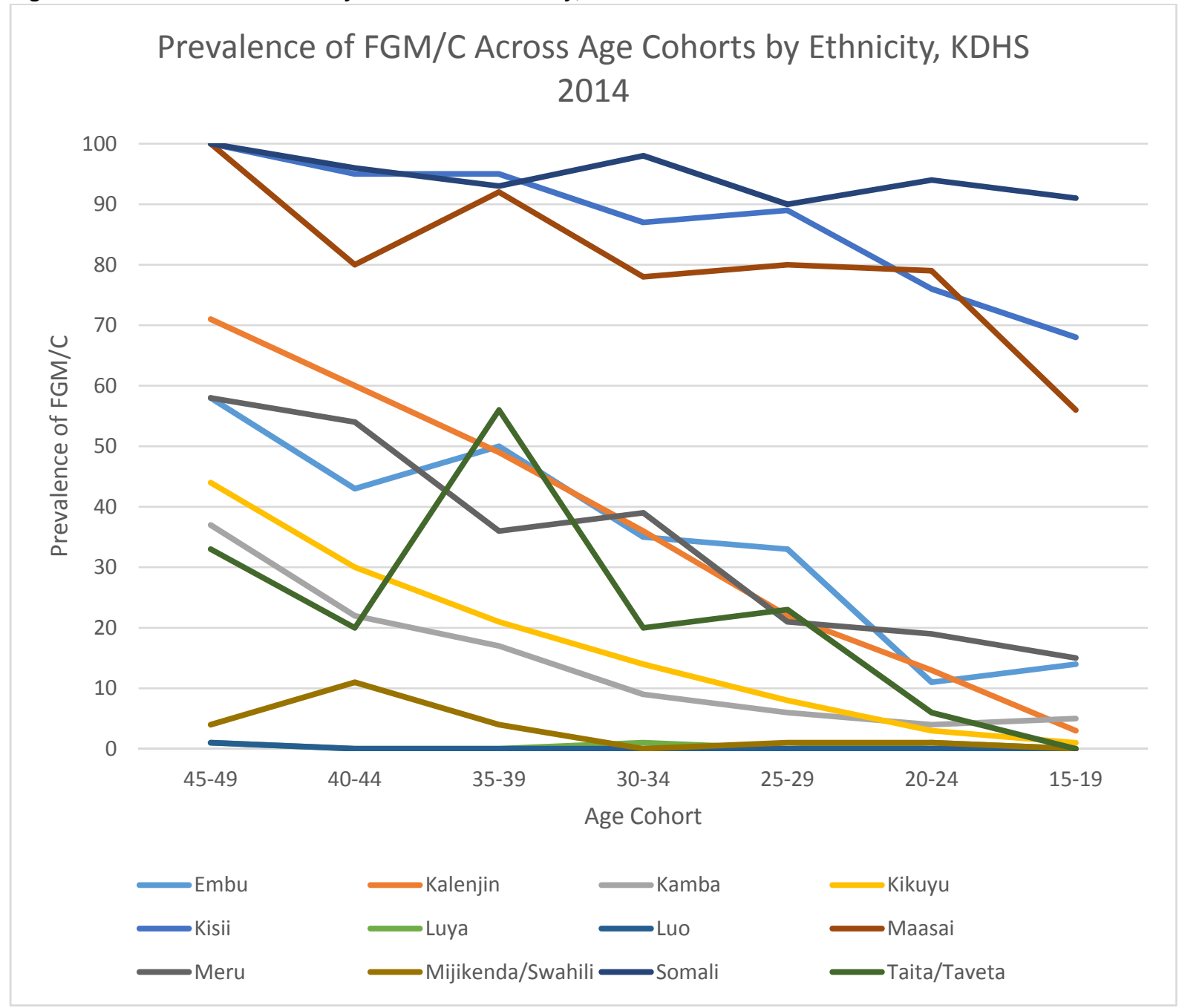


Text Box 2. Prevalence of and Support for FGM/C before and after Passage of a Law: Considerations Regarding Reliability of Survey Data

Legislative measures that prohibit the practice of FGM/C have been put in place in many countries, including some where survey data have been collected both before and after enacting criminal bans. How does criminalization of FGM/C influence reliability of survey data collection? Analysts have looked, in particular, at potential impacts on two outcome measures: stated support for the continuation of FGM/C and self-reported FGM/C status. Deterrence theory suggests that where there is widespread knowledge of a law and belief in its enforceability, fear of prosecution should reduce support for FGM/C and contribute to a decline in the practice. However, when legal norms run counter to social norms, moral values or religious beliefs, legislative reform may have a limited effect on change in attitudes and practices, and it may drive the practice underground and influence truthfulness in survey responses regarding FGM/C. This could lead to inaccurate reporting on both support for FGM/C and a woman or daughters' cutting status. The degree to which survey respondents are influenced to change in FGM/C practices and attitudes resulting from fear of prosecution or, alternatively, influenced to be unwilling to honestly disclose their FGM/C status or views due to fear of prosecution or courtesy bias is, however, unclear and requires further research.

With data broken down by age cohorts from successive surveys, it is possible to detect under-reporting that may be caused by fear of prosecution. 2001 Kenya adopted the Children's Act, which criminalized FGM/C on girls under the age of 18. In 2011 the ban was broadened with the passage of the Prohibition of Female Genital Mutilation Act, criminalizing FGM/C performed on anyone, regardless of age. It also made it illegal to aid someone in performing FGM and mandates reporting cases of FGM, whether performed in Kenya or abroad. The tightened law did not apply to past cases of FGM/C. From a data collection point of view, and important question is raised: Did passage of the2011 law influence willingness of women to accurately self-report their FGM/C status?

Insight may be gained by comparing prevalence rates among age cohorts before and after passage of the law. Given that the time interval between successive surveys is 5 years, prevalence rates should be expected to be steady in an age cohort 5 years older at the time of the second survey. That is, women age 15-19 in 2008-09 are age 20-24 by the time of the 2014 survey, and the prevalence estimates of FGM/C should remain the same. Reading the table below diagonally, we see that FGM/C may have been under-reported in the 2014 survey in women 25-29, 30-34 and 35-39.

Table 4. Prevalence of FGM/C by age cohorts in surveys implemented before and after criminalization of FGM/C among adult women

\begin{tabular}{|l|l|l|l|l|l|l|l|}
\hline $\begin{array}{l}\text { Survey } \\
\text { Year }\end{array}$ & \multicolumn{7}{|c|}{ Age Cohort } \\
\hline & $15-19$ & $20-24$ & $25-29$ & $30-34$ & $35-39$ & $40-44$ & $45-49$ \\
\hline $2008-09$ & 14.6 & 21.1 & 25.3 & 30.0 & 35.1 & 39.8 & \\
\hline 2014 & & 14.7 & 18.0 & 22.9 & 27.8 & 32.1 & 40.9 \\
\hline
\end{tabular}

Subdividing national prevalence data along the line of region and socioeconomic characteristics also provides telling insights about factors that may be important to explore in multivariate models as potential correlates or drivers of change in FGM/C. Figure 16 demonstrates that there has been a steady decline in FGM/C across both urban and rural residential locations. 
Figure 16. Trends in Prevalence across successive surveys in urban and rural locations

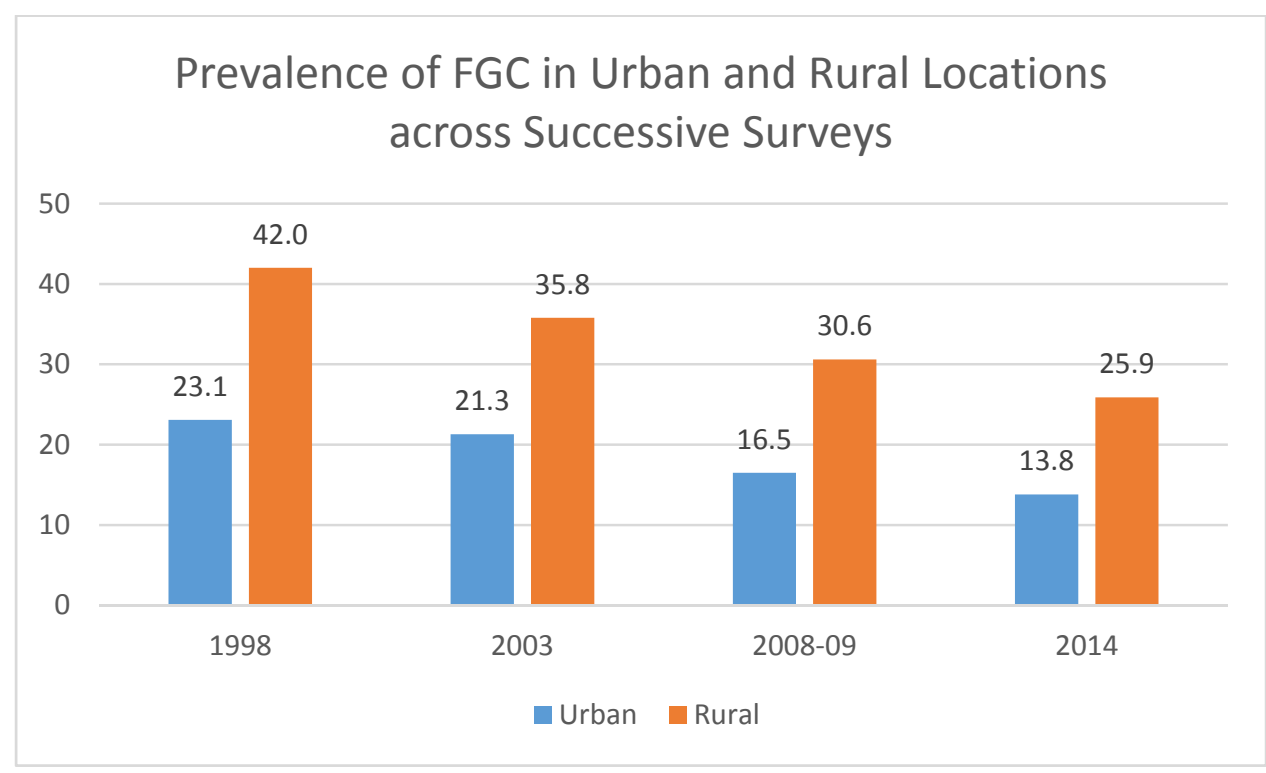

Similarly, data can be compared across successive surveys, subdivided by region or province (Figure 17). Note, that data were not obtained for certain regions in 1998, so this comparison does not include the 1998 survey. The data shown by region also reveal steady declines in prevalence, with the notable exception of Northeastern, where the prevalence of FGM/C remains near universal

Figure 17. Trends in prevalence across regions in successive surveys

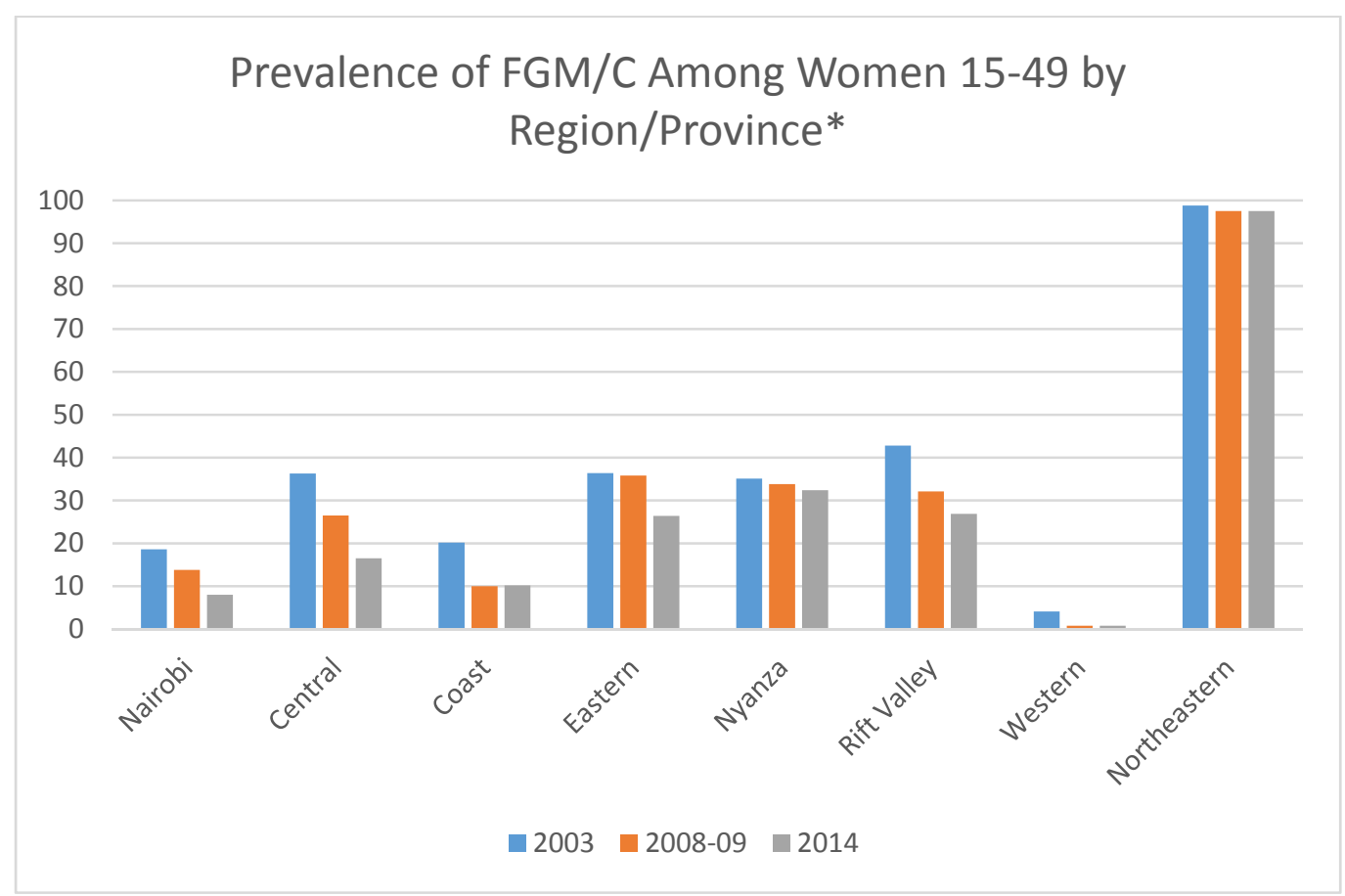

*Data from the 1998 survey are not included in this figure because the sampling frame differed from later surveys. The 1998 KDHS survey sample excluded the entire Northeastern Province and northern parts of Rift Valley and Eastern Provinces, areas that were included in all later surveys. 
Figure 18 contrasts national prevalence rates across successive surveys with data subdivided by ethnicity. This reveals that an overall downward trend in FGM/C was experienced in all groups, but with sharpest declines among Taita/Taveta and Kikuyu women.

Figure 18. Prevalence of FGM/C by Ethnicity across successive surveys

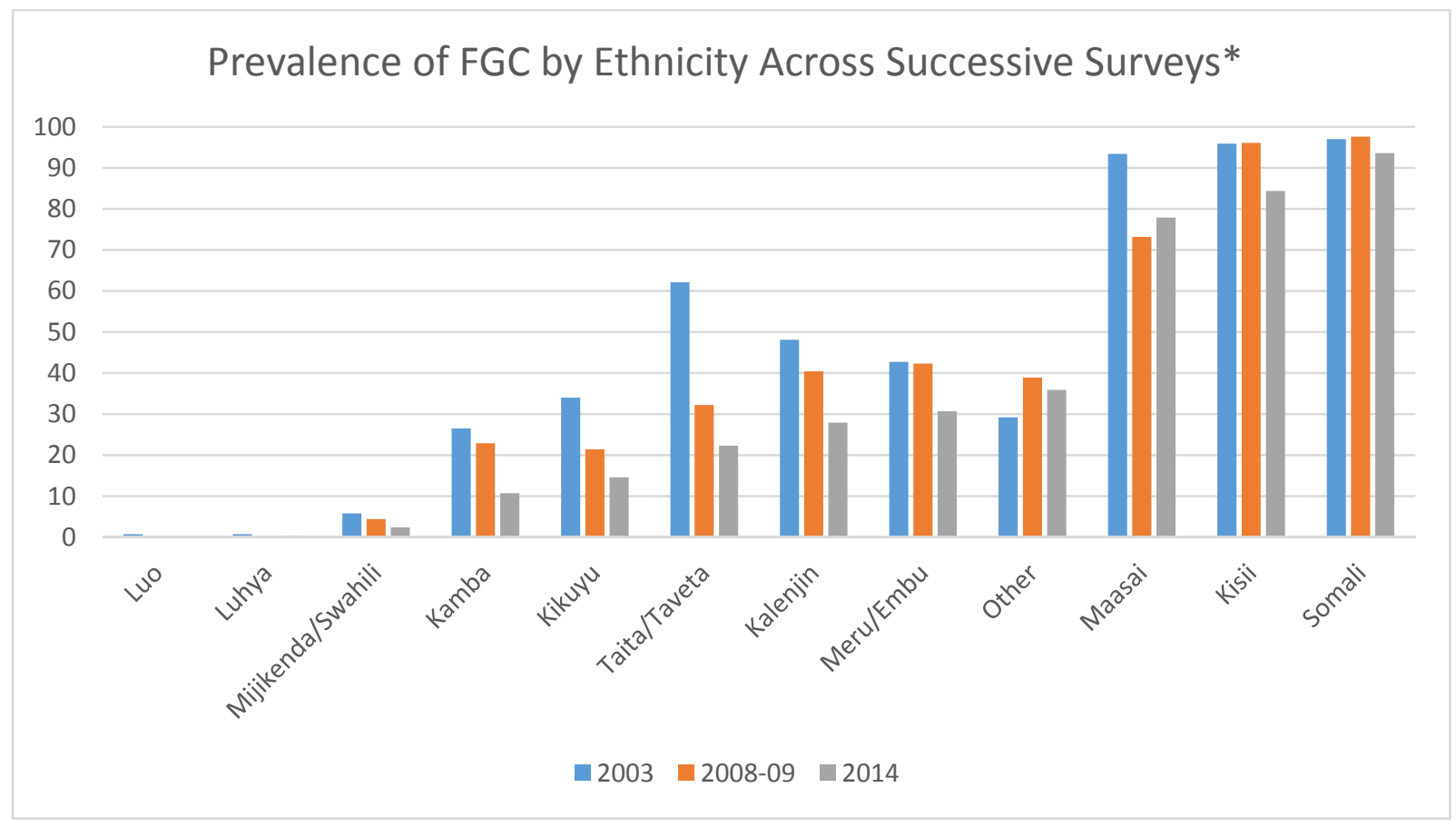

*Data from the 1998 survey are not included in this figure because the sampling frame differed from later surveys.

Figure 19 reveals that prevalence rates declined variably across different religious communities. While the prevalence remained steady across surveys between 2003 and 2014 for Muslim women, sharp declines were found among women in Catholic and Protestant and other Christian communities. The association between religion and prevalence of FGM/C alone does not provide information on the role of religious beliefs in the perpetuation of the practice. For this reason, questions on whether respondents view FGM/C as a religious obligation were added to the 2014 survey (see above). 
Figure 19. Prevalence of FGM/C among Women across Successive Surveys by Religion

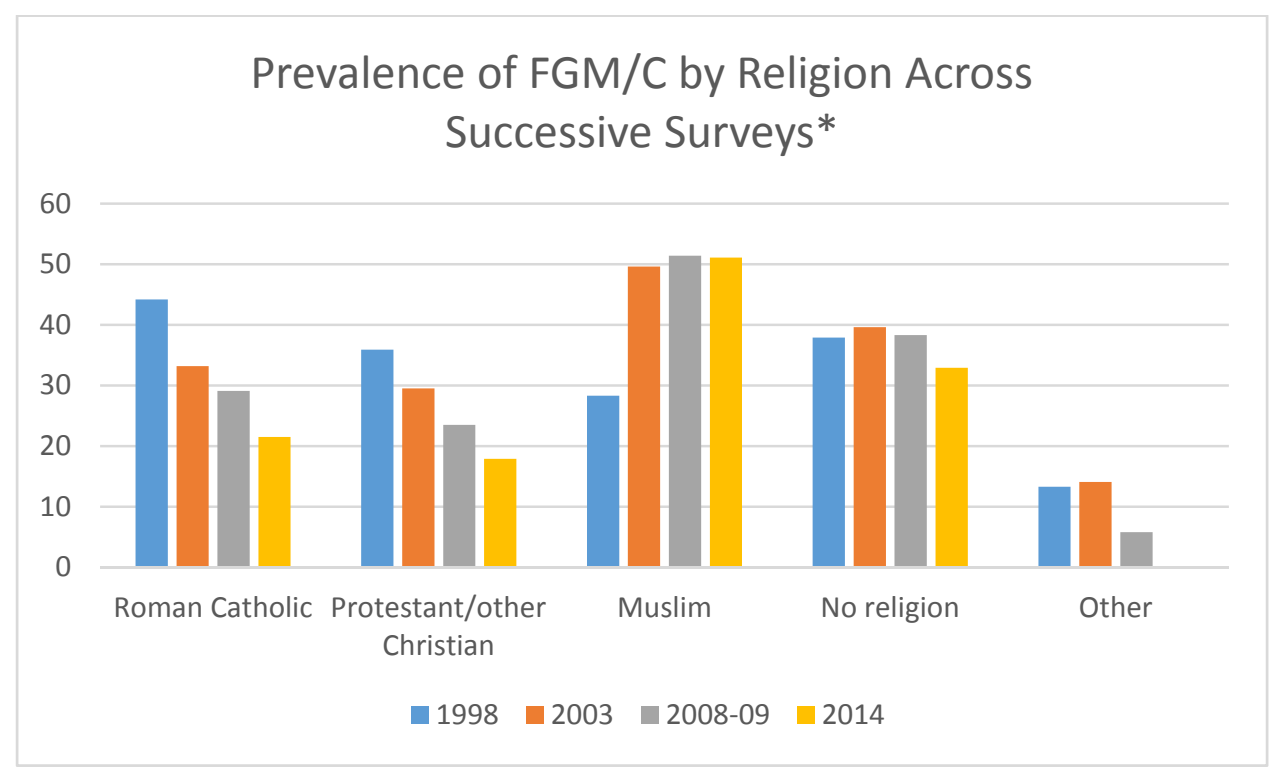

*The 1998 KDHS survey sample excluded the entire Northeastern Province and northern parts of Rift Valley and Eastern Provinces.

\section{Trends in when and how is $\mathrm{FGM} / \mathrm{C}$ performed}

\section{Trends in Age at which FGM/C is Performed}

Do the survey data support the impression that the age at which FGM/C is being performed is declining? The trends in age at cutting can be examined several ways. First, using repeat survey data from women aged 15-49, mean age at cutting can be compared. Second, cohort using single data survey, it is possible to examine the mean age at cutting across cohorts of adult women.

Consecutive survey data on self-reported age at cutting are available for women aged 15-49 in three surveys: 1998, 2008-09, and 2014. Comparisons shown in Figure 20 show that while there appears to be an overall decline in age at cutting, a substantial number of Kenyan women still report having undergone FGM/C at relatively late ages, including age 15 and over. 
Figure 20. Self-Reported Age at Cutting, Kenyan Woman

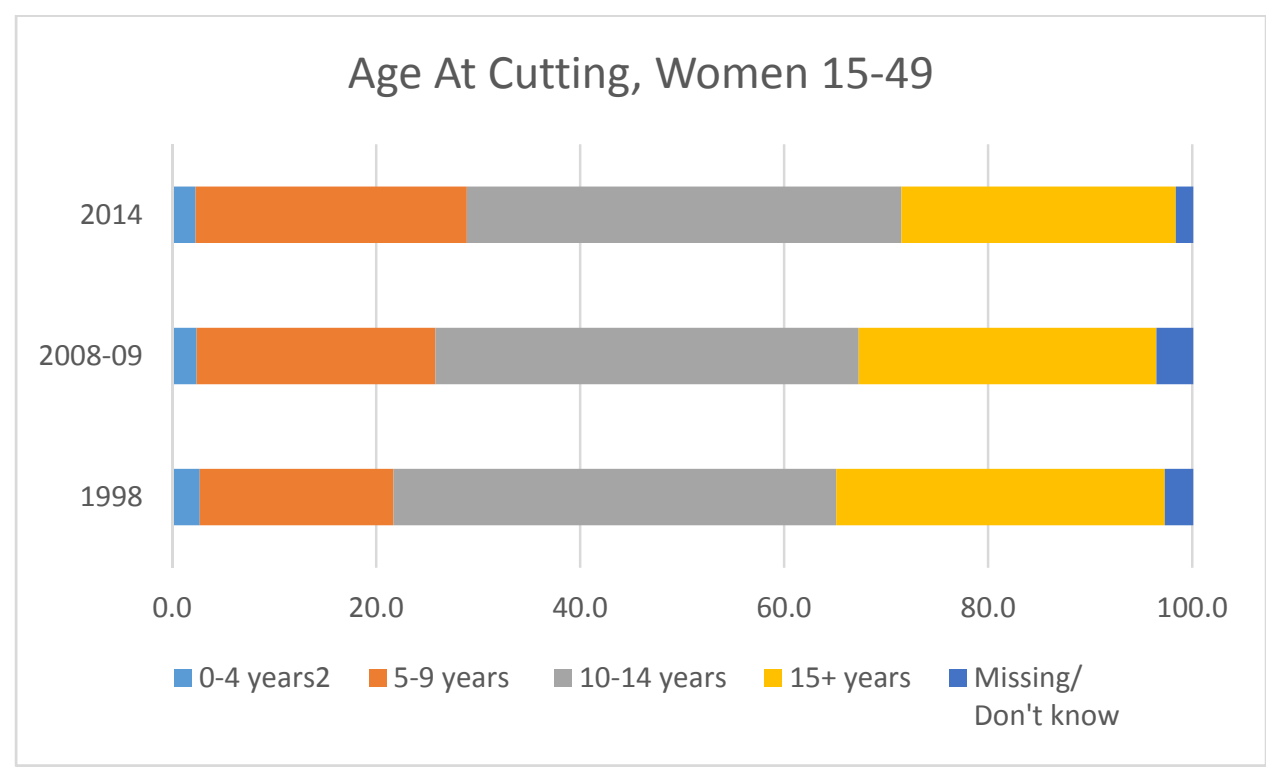

Trends in age at cutting can be more clearly seen when the data are subdivided for different age cohorts. This disaggregation of the data more clearly shows a trend in reduction of age of cutting. For most women, however, cutting still occurs relatively late, after age 9 . Only in the youngest age cohort (15-19 years of age) is cutting most commonly performed before age 10 (Figure 21). Additionally, this is the only age cohort with relatively little cutting at ages 15 and over.

Figure 21. Age at cutting by age cohort

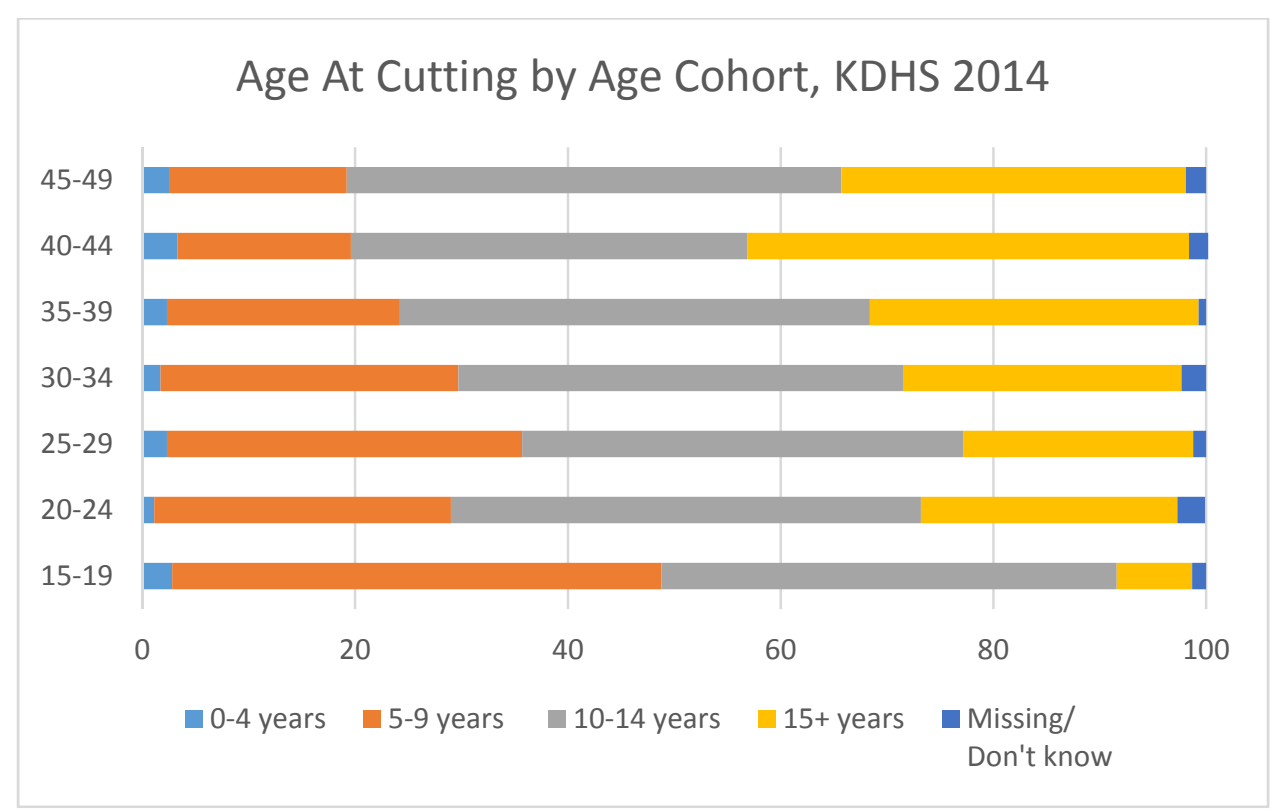


Age of cutting by ethnicity

Examining age at cutting by ethnicity highlights large variations with some communities practicing FGM/C when women are much older like the Kalenjin, while others like the Taita and Mijikenda cut at very young ages of 0-4 years (Figure 22).

Figure 22. Age of cutting by ethnicity

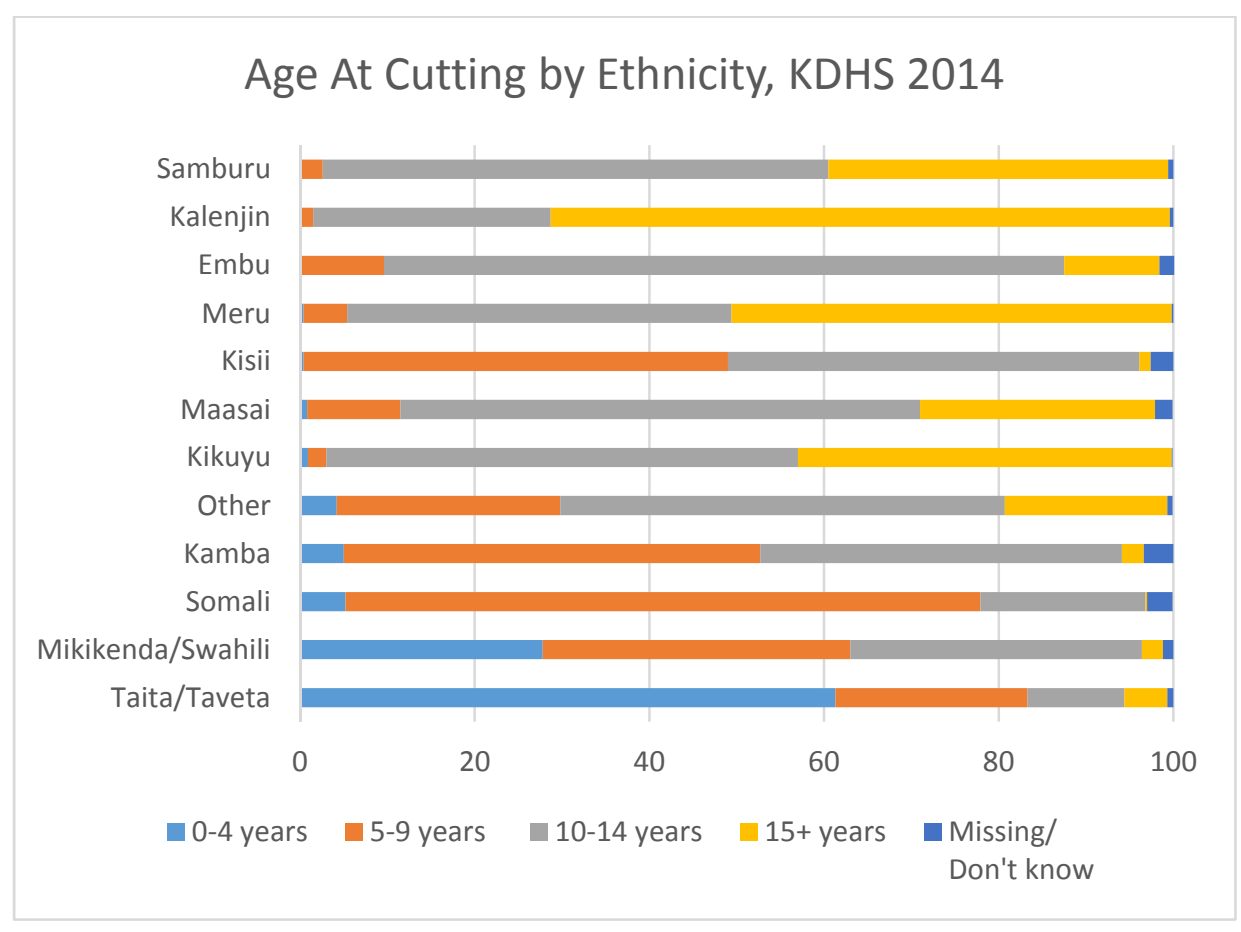

Age at Cutting by Region

A similar variation in the age of cutting is observed by region with the coast and North Eastern cutting before the age of 10 . This could be explained by the fact that these regions are mainly inhabited by the Somali, Mijikenda and the Taita (Figure 23). 
Figure 23. Age at cutting by region

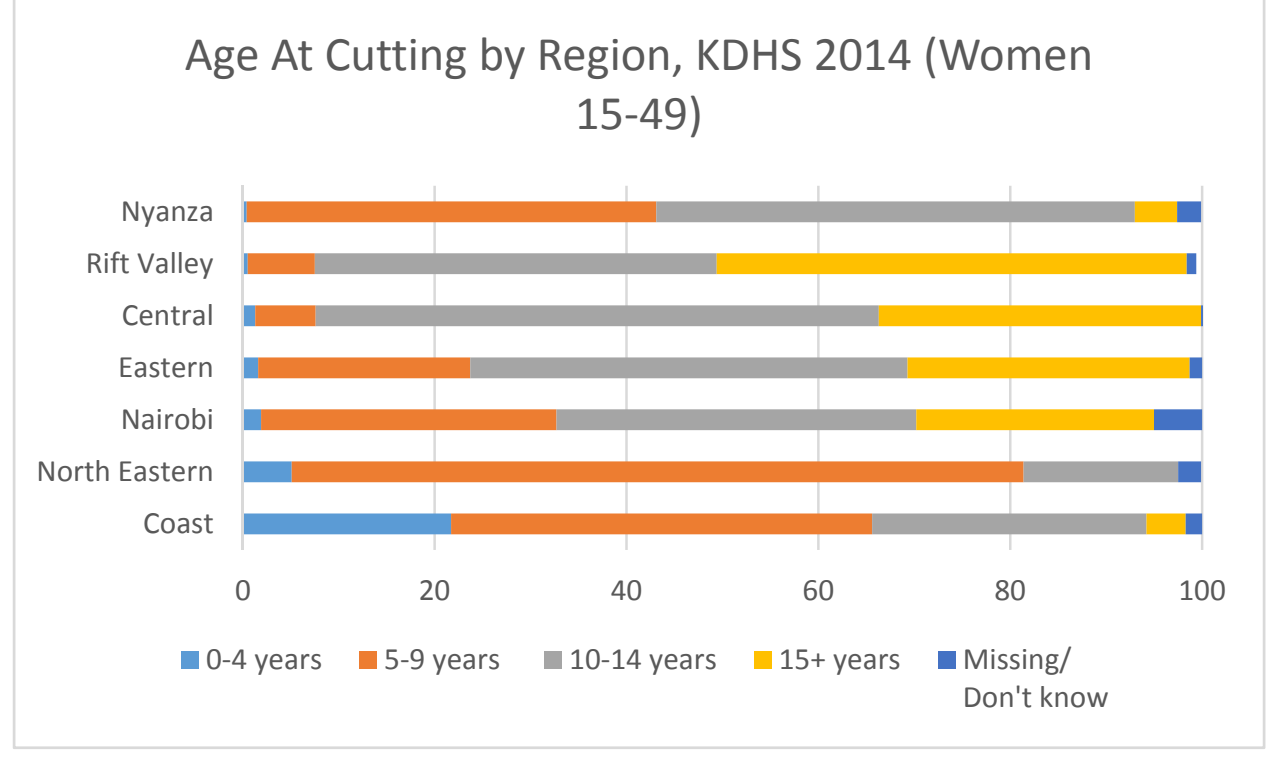

Type of Cutting

Questions on the type of cutting have changed over the years. Questions were asked in a similar manner in the last two successive surveys, thus allowing comparison. Self-reported survey data show a trend toward reduction in "sewn closed" from 13\% in 2008 to $9 \%$ in 2014 (Figure 24).

Figure 24. Type of FGM/C among women aged 15-49 years across successive surveys

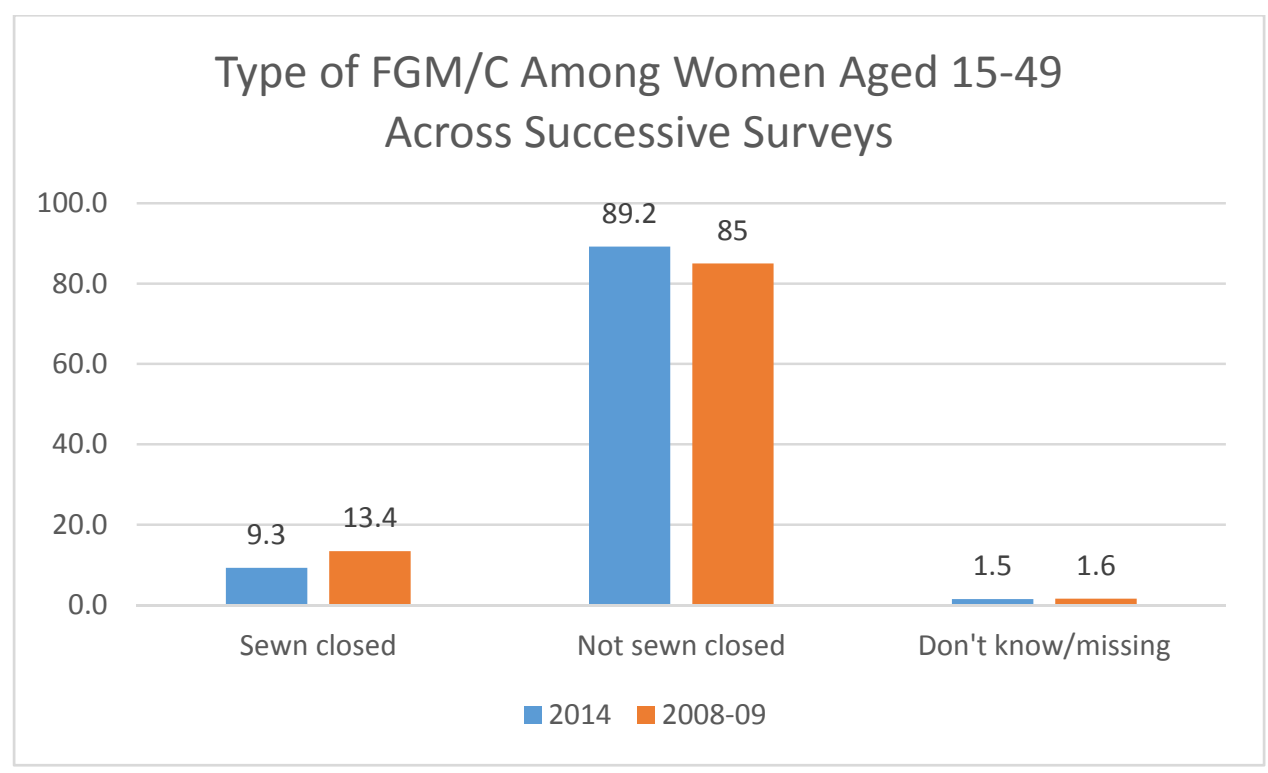




\section{Medicalization}

Comparing the 2008-09 and 2014 surveys, there was a decline in the proportion of women who reported to have been cut by health professional (doctor/nurse/midwife) from $19.7 \%$ to $14.7 \%$. This may have resulted from increased education campaigns on the legal implications on health professionals who engage in the practice (Figure 25).

Figure 25. Person who performed FGM/C among women aged 15-49 years

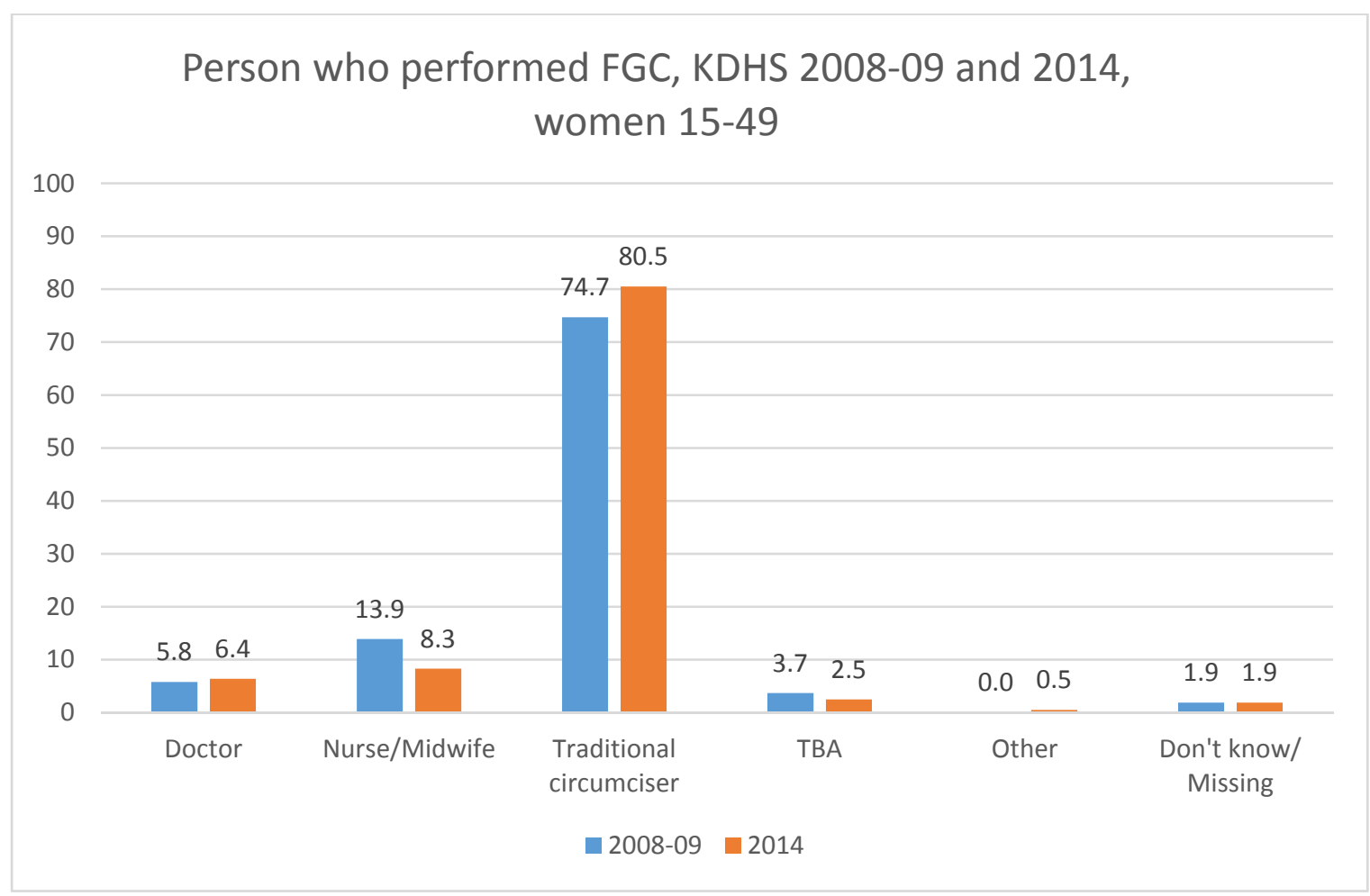

Trends in Attitudes toward FGM/C

Stated support for the continuation of FGM/C has gone down among women. In $199820 \%$ of women supported continuation of FGM/C, and by 2014 this number dropped to 6\% (Figure 26). 
Figure 26. Opinion about the continuation of FGM/C among women aged 15-49 years

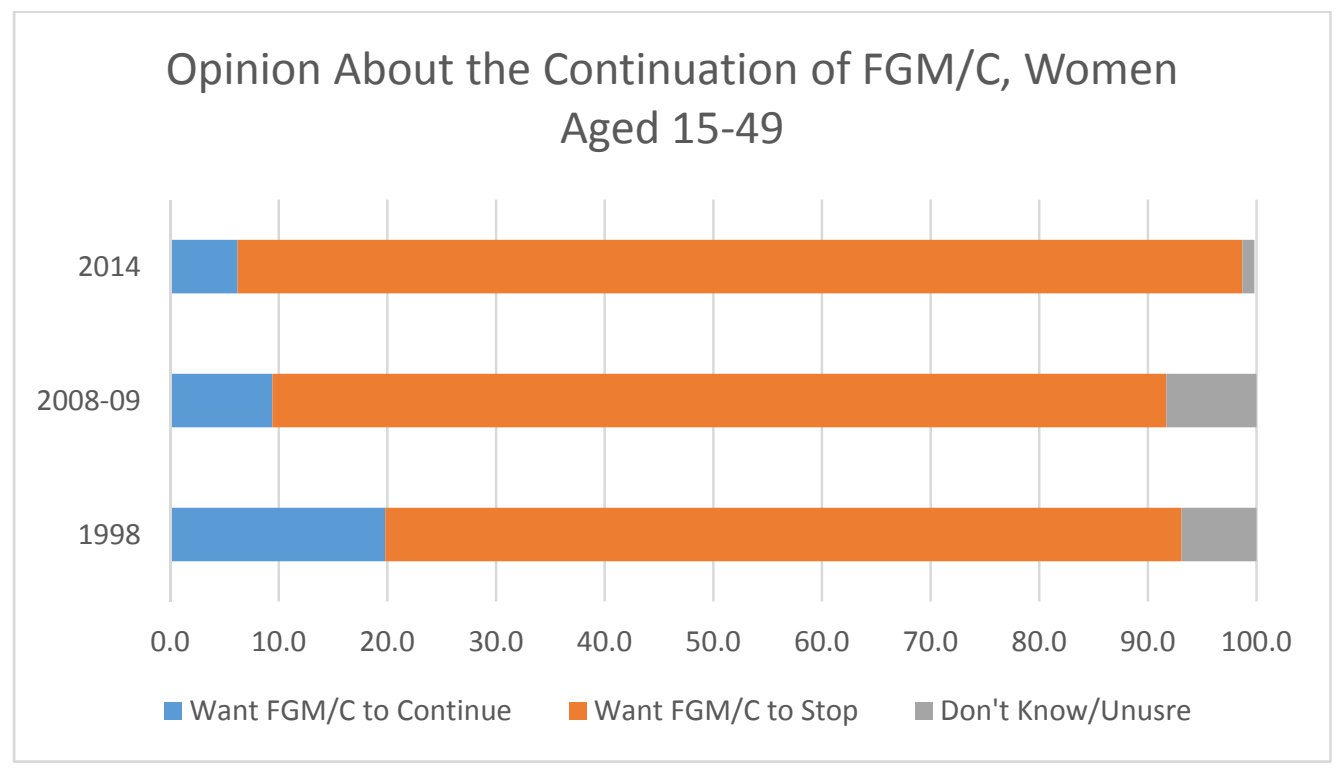

Across successive surveys, the level of support for FGM/C among women 15-49 has been consistently lower than prevalence of the practice. Figure 27 shows the percentage of women who want FGM/C to continue has decreased steadily since 1998 from $20 \%$ in 1998 to $6 \%$ in 2014, in parallel with a the declining pattern in women's FGM/C prevalence.

Figure 27. Trends in prevalence of and support for FGM/C

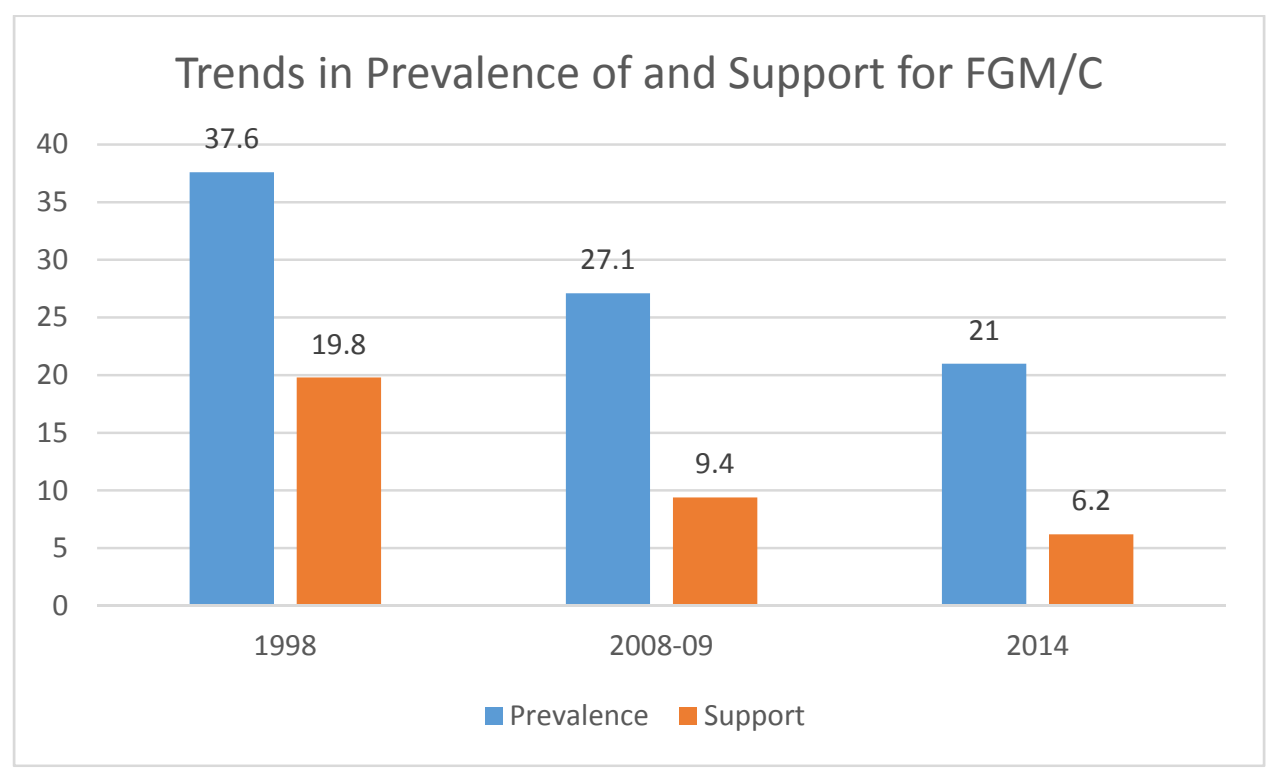

One factor that is thought to potentially drive continued support for FGM/C is the belief that the practice is required by religion. Therefore a question on this topic question was asked in the 2008-09 and 2014 surveys. The overall proportion of women who believe that FGM/C is required by religion has decreased from $7 \%$ to $4 \%$. This question was also included in the survey administered to men in $2014 ; 5.5 \%$ of men reported they believe FGM/C is required by religion (Figure 28). 
Figure 28. Percent of women who believe that $F G M / C$ is required by religion

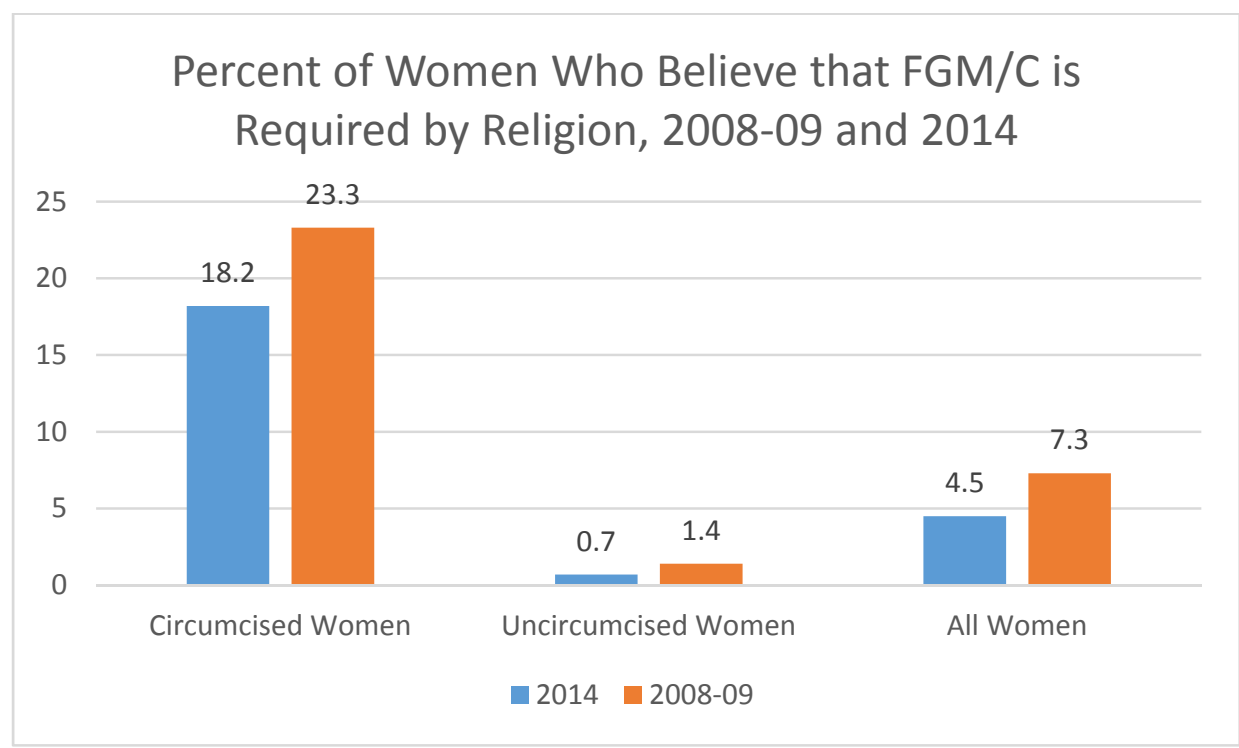

\section{FGM/C among Daughters}

\section{Different Ways that Data on Daughter's FGM/C has been Collected}

Information of the FGM/C status of daughters of women aged 15-49 surveyed has been collected in a variety of ways, some of which do not allow for the calculation of prevalence of FGM/C in the 0-14 year age groups. In surveys up to 1999, female respondents who had at least one living daughter were asked about their eldest daughter: whether she was cut, age at which FGM/C was performed, type of FGM/C and the person who performed FGM/C. When the eldest daughter was reportedly not cut, respondents were asked whether they intended to have their daughter cut.

Beginning in 1999, rather than asking about the eldest daughter, DHS surveys began asking respondents whether any of their daughters had undergone FGM/C. Those who answered negatively were asked whether they intended to cut any daughters. Those who answered positively were next asked how many of their daughters were cut. This was followed by questions on details about the FGM/C procedure (age, type of FGM/C and type of practitioner) for the daughter most recently cut.

Data on the cutting status of one daughter (either eldest or most recently cut) can be used to calculate the percent of women with at least one living daughter who is cut. It cannot, however, be used to estimate the prevalence of FGM/C among girls under the age of 15 because it does not provide the needed denominator. This is unfortunate since this age group is the one that has most recently been at risk of being cut, and where the impact of recent efforts to end FGM/C will be seen. To address this limitation, the Egypt DHS module on FGM/C began to collect information on FGM/C status on all respondent's living daughters. Since 2010 this has been standardized in the FGC modules used by DHS and MICS surveys.

Complete data on age at FGM/C amongst all daughters therefore has two benefits. First, it allows for the estimation of prevalence of FGM/C at the youngest ages where effects of recent changes will be detected. Second, it allows for the analysis of trends in age at FGM/C across generations. 


\section{Considerations for Analysis of Complete Daughter Data: Understanding the Difference between Current and Final FGM/C Status}

The analysis and interpretation of data on all daughters age 0-14 are not as straight forward as it might seem since not all girls have reached their final cutting status. Girls under the age of 15 include three groups:

1. Girls who are currently cut;

2. Girls who are currently uncut, but will be cut in the future; and

3. Girls who are currently uncut, and never will be cut.

Since not all daughters have attained their final cutting status it is difficult to distinguish whether prevalence is going down, or if a sizable fraction of girls are simply not yet old enough to be cut. Statistical analysis of these type of data require specialized approaches.

Cases in which a girl may still be at risk of being cut in the future are described as statistically "censored" observations. As age at cutting varies in different settings, the amount of censoring will vary. In countries where most cutting is done in infancy, the effects of censoring on daughter prevalence data is minimal. In Kenya, however, many girls are cut at older ages, and therefore censoring is an important concern. Failure to adjust for the effects of censoring results in underestimation of prevalence rates.

In an effort to minimize the level of censoring, the 1998 and 2003 KDHS surveys asked about the FGM/C status of the eldest daughter, and then calculated the prevalence using data using only data for eldest daughters who have reached at least 15 years of age. The 1998 Kenya DHS report provided the following explanation:

"Because a woman's eldest daughter may still be at an age which precedes traditional or eventual age at circumcision, circumcision rates for daughters are calculated only for cases where the respondent's eldest daughter has reached 15 years of age. Without this adjustment, rates among daughters would have been understated substantially. It is acknowledged that, even with this adjustment procedure, the rates could still be slightly underestimated. The current solution, i.e., using a threshold age of 15, was based on an examination of the distribution of the data on age at circumcision. Raising the age threshold even higher would have reduced the effective sample size below acceptable levels and possibly introduced a bias in the daughters' estimates related to selection of mothers who survived to older ages (i.e., only older mothers have older daughters)."

Based on these age restrictions in the denominator, the prevalence among eldest daughters age 15 or older was reported at $24.1 \%$ in 1998 and $21.0 \%$ in 2003 but $2.8 \%$ among all living girls $0-14$ years in 2014. (Figure 29). These numbers suggest that rates of FGM/C have dropped precipitously. However, it must be noted that different methods have been used to generate the estimates from different survey waves. 
Figure 29. Percentage of girls who have undergone FGM/C for successive surveys

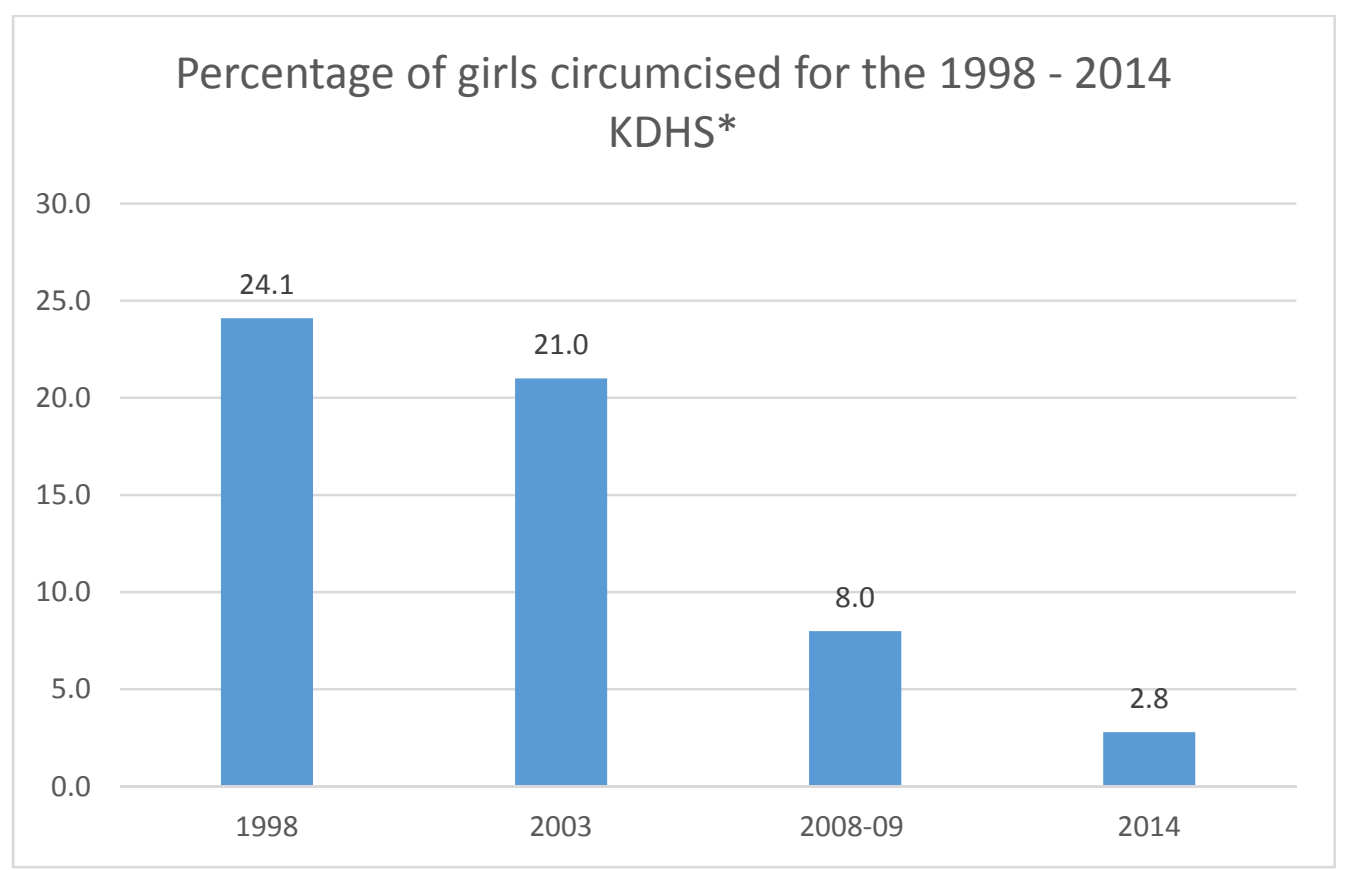

*The 1998 survey refers to the eldest daughter age 15 or older; the 2008-09 KDHS refers to the most recently circumcised daughters; the 2014 survey refers to all daughters aged 0-14 years

Data on daughter prevalence show variation based on region of residence. Prevalence of FGM/C is higher among daughters living in rural (3.2\%) than urban (2.0\%) locations. Even greater variation is seen when looking across Provinces. As show in Figure 30, rates of cutting are highest in Northeastern (40\%).

Figure 30. Prevalence of FGM/C among daughters aged 0-14, by Province

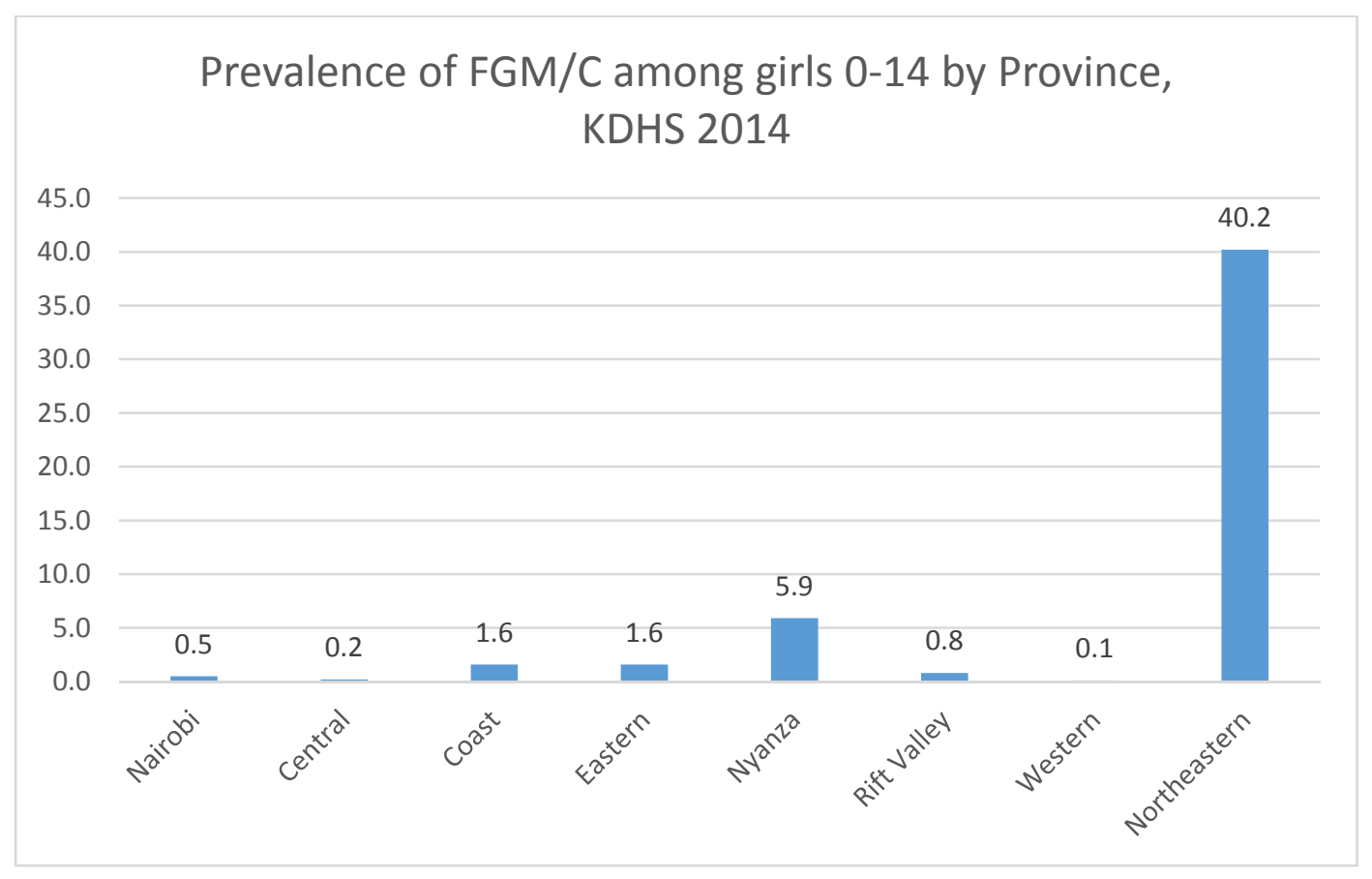


Because the population densities vary substantially between provinces, it is useful to examine the residential distribution of all girls under age 15 who have undergone FGM/C. Using population figures from the U.S. Census International Data Base, along with KDHS 2014 prevalence estimates of FGM/C of FGM/C in girls aged 0-14, we estimate that a total of 570,765 girls under age 15 have been cut. Of these, $65 \%$ live in Northeastern Province, and $20 \%$ live in Nyanza (Figure 31).

Figure 31. Distribution of Kenyan Girls under Age 15 who have Undergone FGM/C

\section{Residential Distribution of Kenyan Girls under Age 15 who} have undergone FGM/C

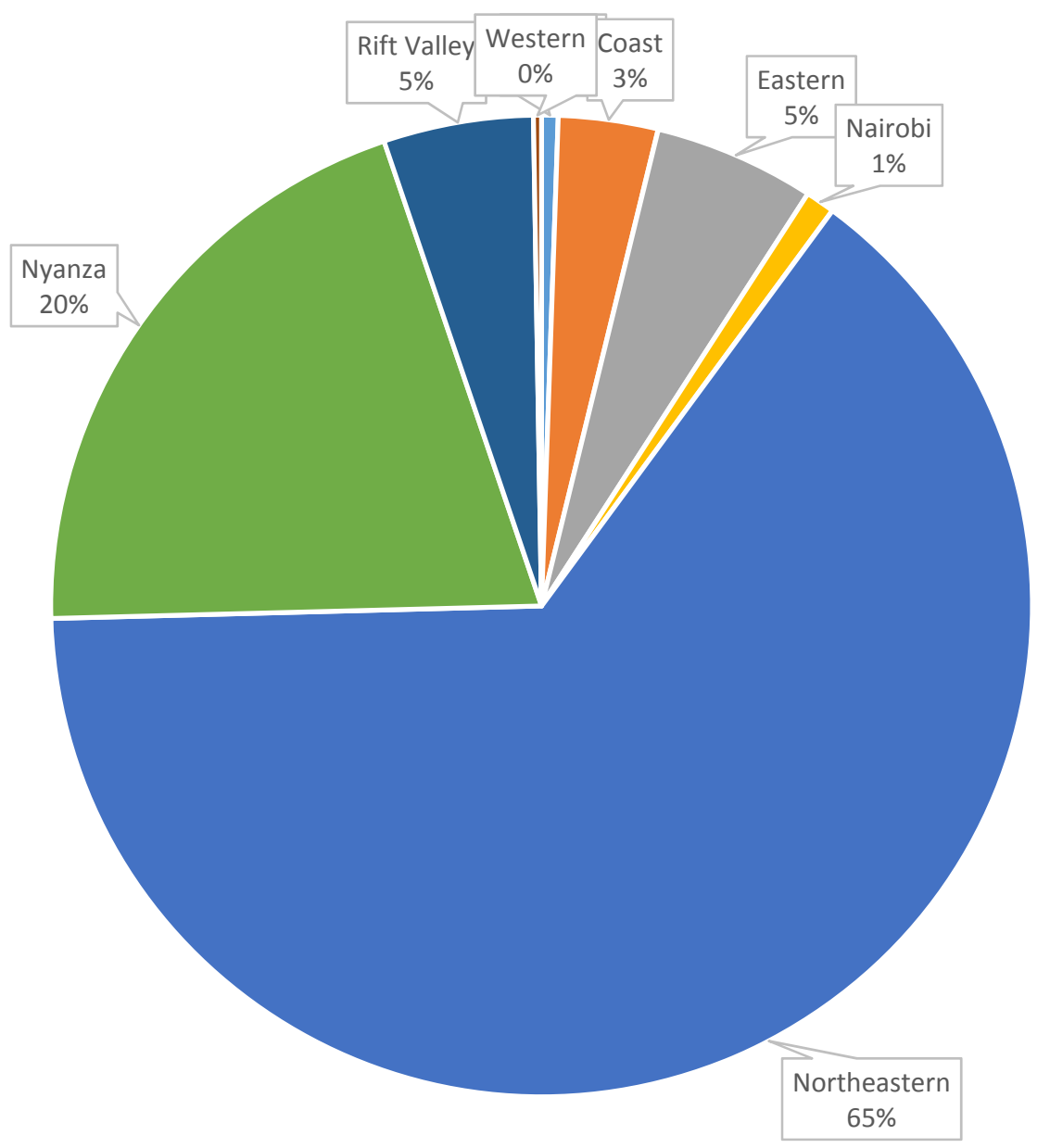




\section{Prevalence of FGM/C Among Daughters 0-14 Along Sociodemographic Lines}

\section{Religion}

Table 5 shows rates of $\mathrm{FGM} / \mathrm{C}$ among daughters aged $0-14$ by religion of their mother, revealing that cutting is most common among daughters of Muslims women.

Table 5. Prevalence of FGM/C among daughters aged 0-14 by religion, KDHS 2014

\begin{tabular}{|ll|}
\hline Religion & $\%$ \\
Roman Catholic & 2.1 \\
\hline Protestant/Other Christian & 1.3 \\
\hline Muslim & 19.8 \\
\hline No religion & 0.1 \\
\hline
\end{tabular}

\section{Household Wealth}

Household wealth may be an important determinant of FGM/C among daughters. As noted above, modernization theories predict that economic improvements, particularly for women, will have result in a reduced demand for FGM/C by altering traditional family structures and economic dependence of women. Household wealth is measured using an index that combines survey items on household assets, material living conditions (Rutstein et al., 2000; Rutstein, 1999), and is then divided into quintiles ranging from one (lowest) to five (richest). Consistent with predictions of modernization theory, the prevalence of $\mathrm{FGM} / \mathrm{C}$ among daughters aged 0-14 decreases steadily with increased household wealth (Figure 31).

Figure 31. Prevalence of FGM/C among daughters by household wealth

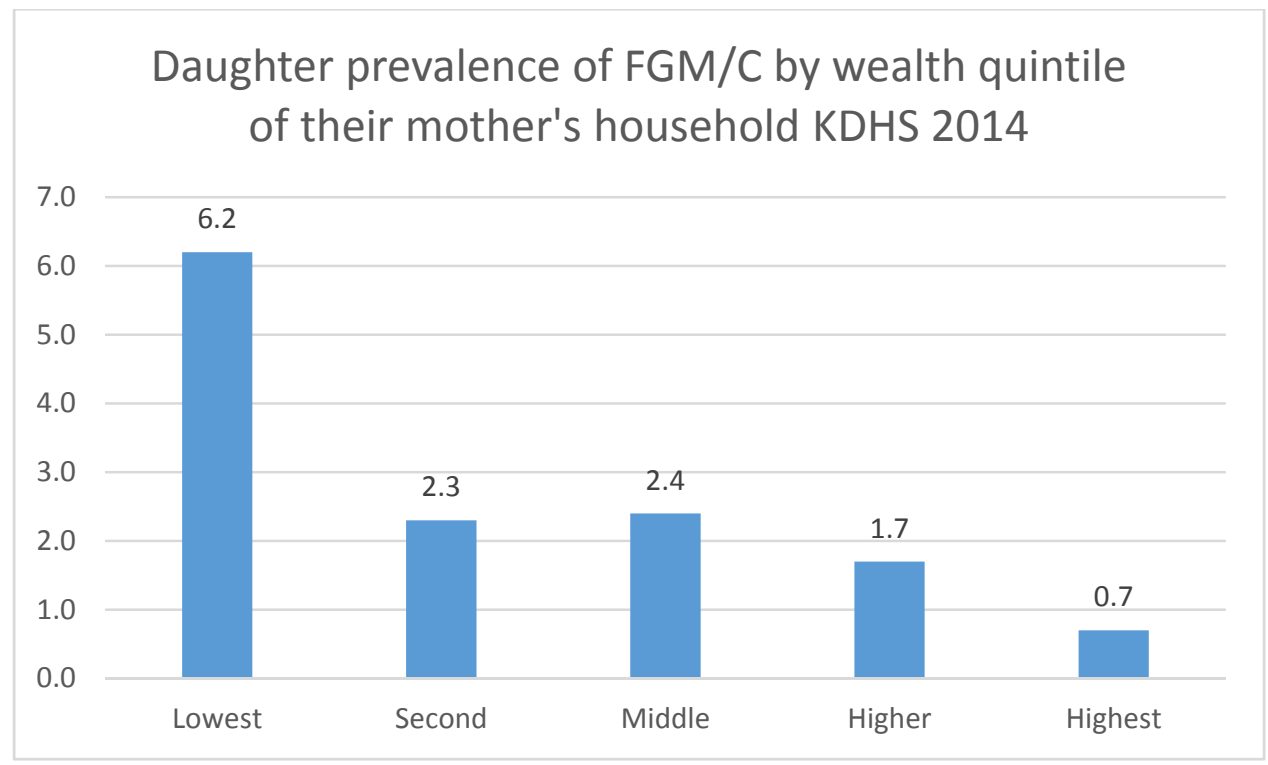




\section{Mother's Education}

In the demographic literature there is a robust positive association between women's level of education and measures of health and access to healthcare. For that reason, education is often thought to be associated with FGM/C status. The presumed link between FGM/C and education rests on the assumption that, in comparison to women with little or no education, educated women will be less likely to support the practice of FGM/C. Reasons for the decline in support are rarely specified. It may be the case that, while in school, girls develop social ties with peers and mentors who oppose the practice of FGM/C. This could provide a reference group where there are not normative sanctions for failing to comply with FGM/C. Additionally, educated girls may have higher exposure to intervention programs, media messages, and the international discourse that denounces the practice, potentially creating sanctions for continuing FGM/C.

The assumption that more highly educated women are less likely to have less likely to have their daughters undergo $\mathrm{FGM} / \mathrm{C}$ is examined by disaggregating prevalence of FGM/C among daughters (Figure 32). The data reveal a dramatic difference in rates of FGM/C among daughters of women with no education in comparison to women with any level of education.

Figure 32. Prevalence of FGM/C among daughters by mother's education

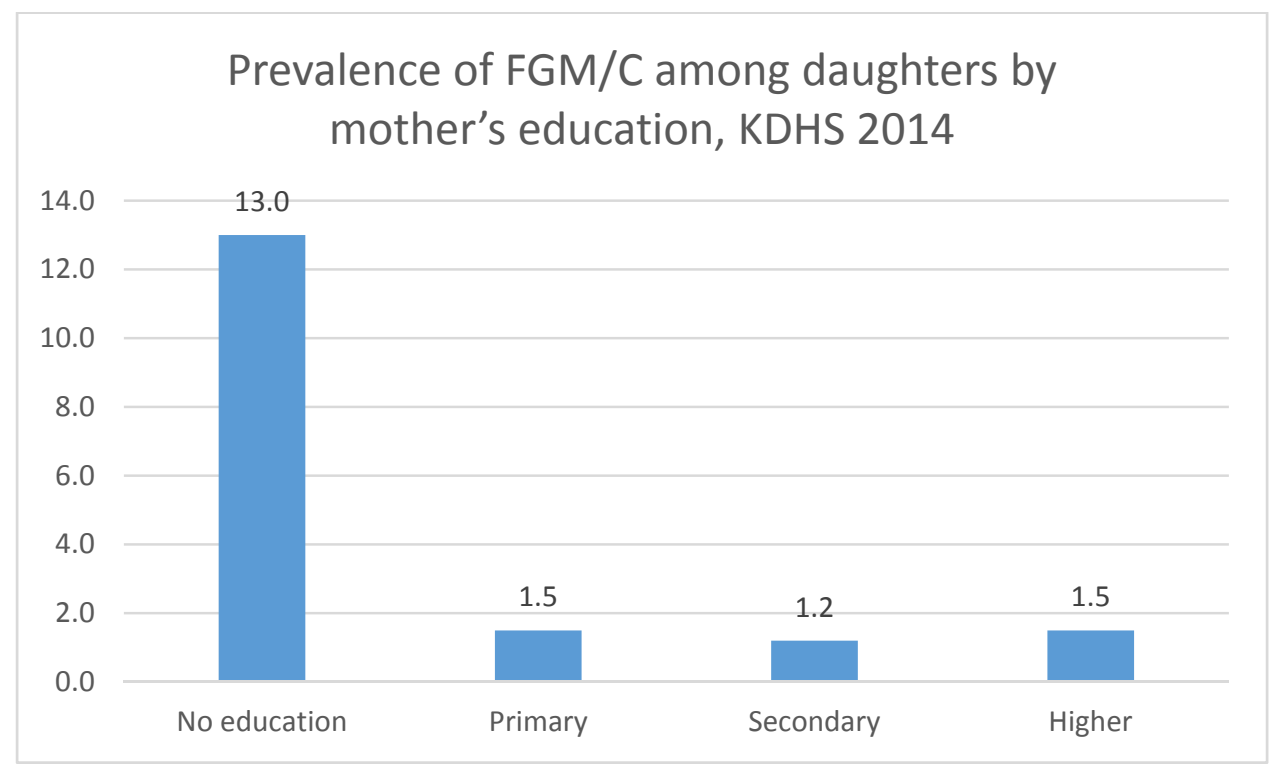

\section{Ethnicity}

The prevalence of FGM/C among daughters varies substantially along lines of ethnicity. The prevalence is less than $1 \%$ among Luo, Turkana, two groups known to not traditionally practice circumcision among either boys or girls. Notably, the prevalence of FGM/C also less than 1\% among daughters of Kikuyu women; this is an ethnic group that once commonly practiced FGM/C (See Figure 15, showing that among Kikuyu women aged 40-49, the prevalence of $\mathrm{FGM} / \mathrm{C}$ is 44\%). Reported rates of FGM/C among daughters are highest among daughters of ethnic Somalis (36\%) and Kisii (16\%). 
Figure 33. Prevalence of FGM/C among daughters by ethnicity of their mother

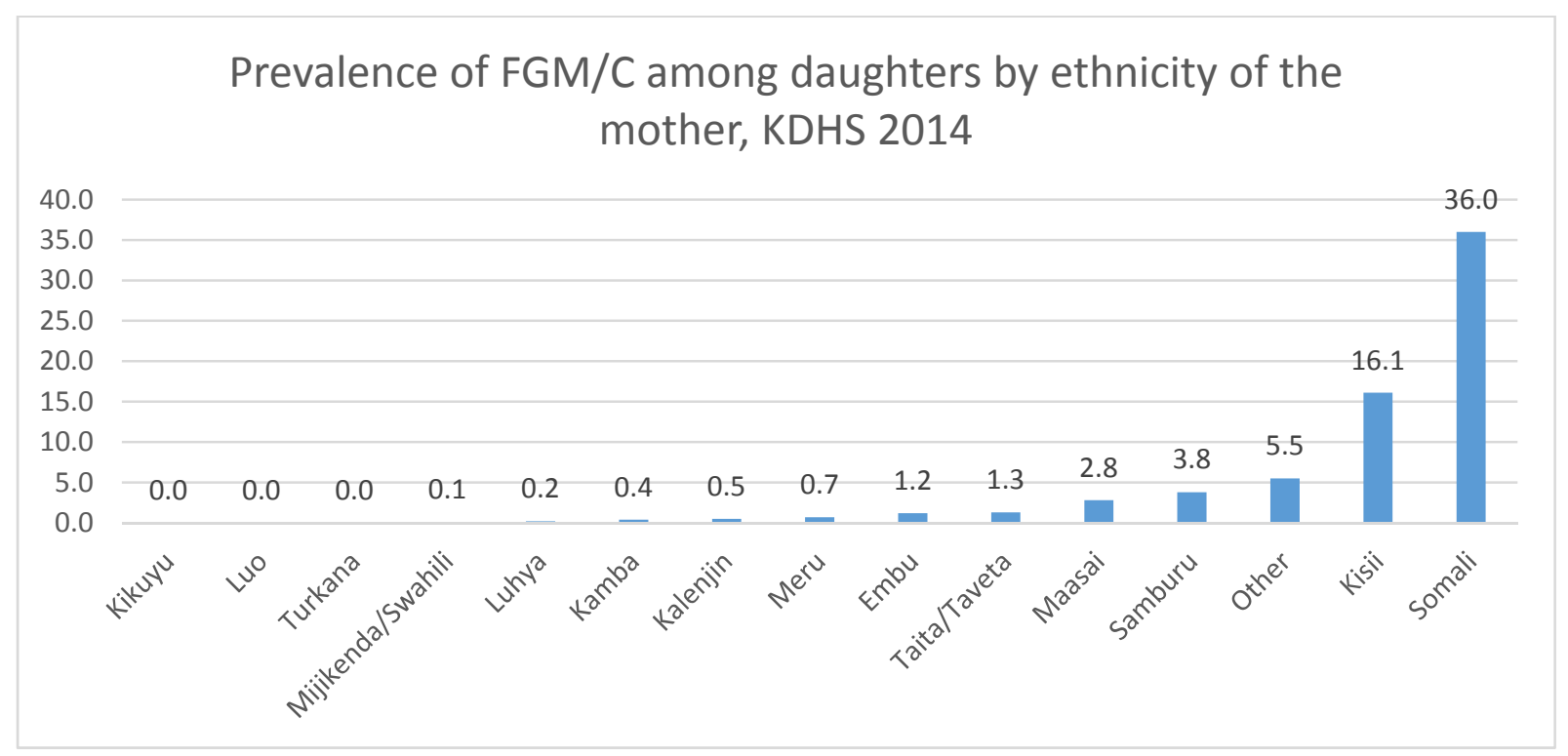

How and When is FGM/C Performed among Girls Aged 0-14?

Age at Cutting and Type of Cutting

The data show that nearly one in four girls aged 0-14 are cut between the ages of 5 and 9 years. Among girls who have been cut, the majority have $86 \%$ been cut without being sewn closed (possibly corresponding to FGM Types I, clitoridectomy, or Type II, excision). Eight percent of girls were reportedly "sewn closed."

Figure 34. Cumulative proportion of daughters aged 0-14 cut by age

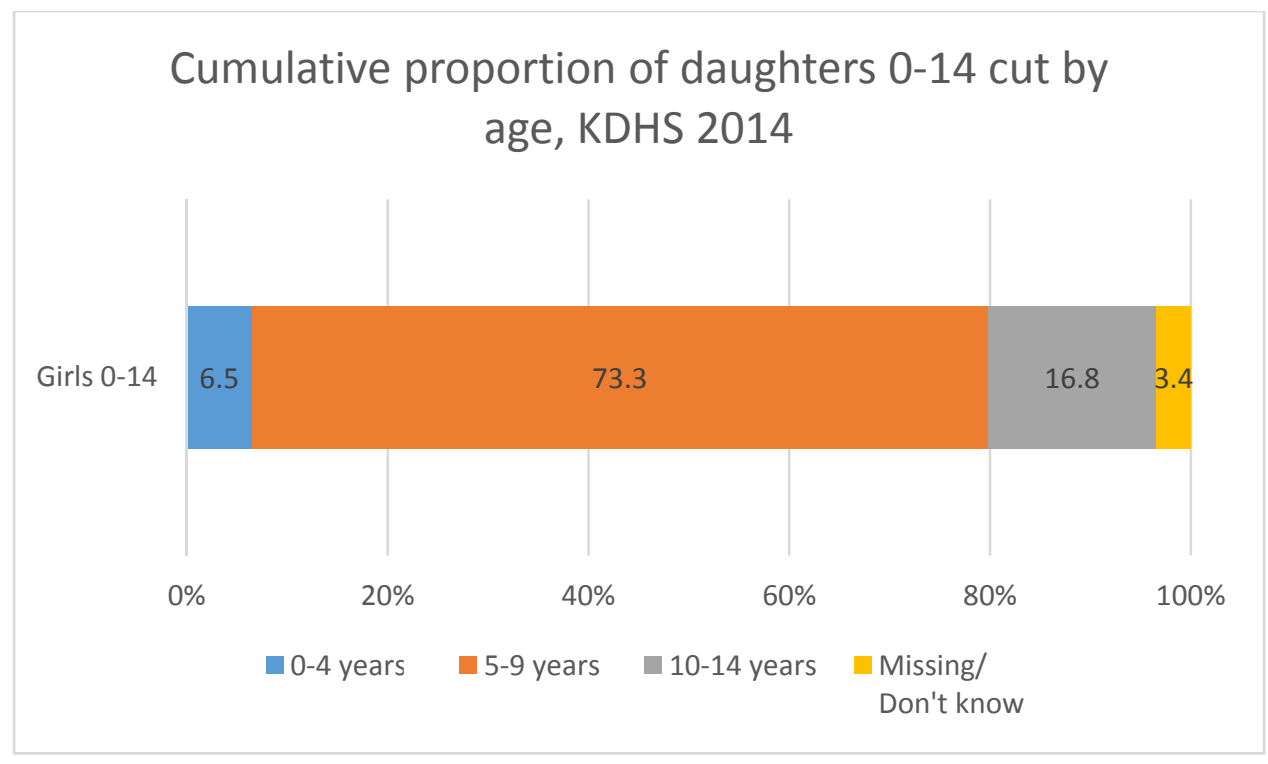




\section{Person who Performed FGM/C on Daughters}

Among girls aged 0-14 who have undergone $\mathrm{FGM} / \mathrm{C}$, the $75 \%$ have been cut by a traditional practitioner. The rate of medicalization (FGM/C performed by a doctor, nurse, or trained midwives) is $20 \%$. Medicalized cutting of girls 0 14 is not found in all regions of the country. Reported cases of medicalization among girls $0-14$ is found in just two provinces: Rift Valley and Nyanza.

Figure 35. Person who performed FGM/C on daughters aged 0-14

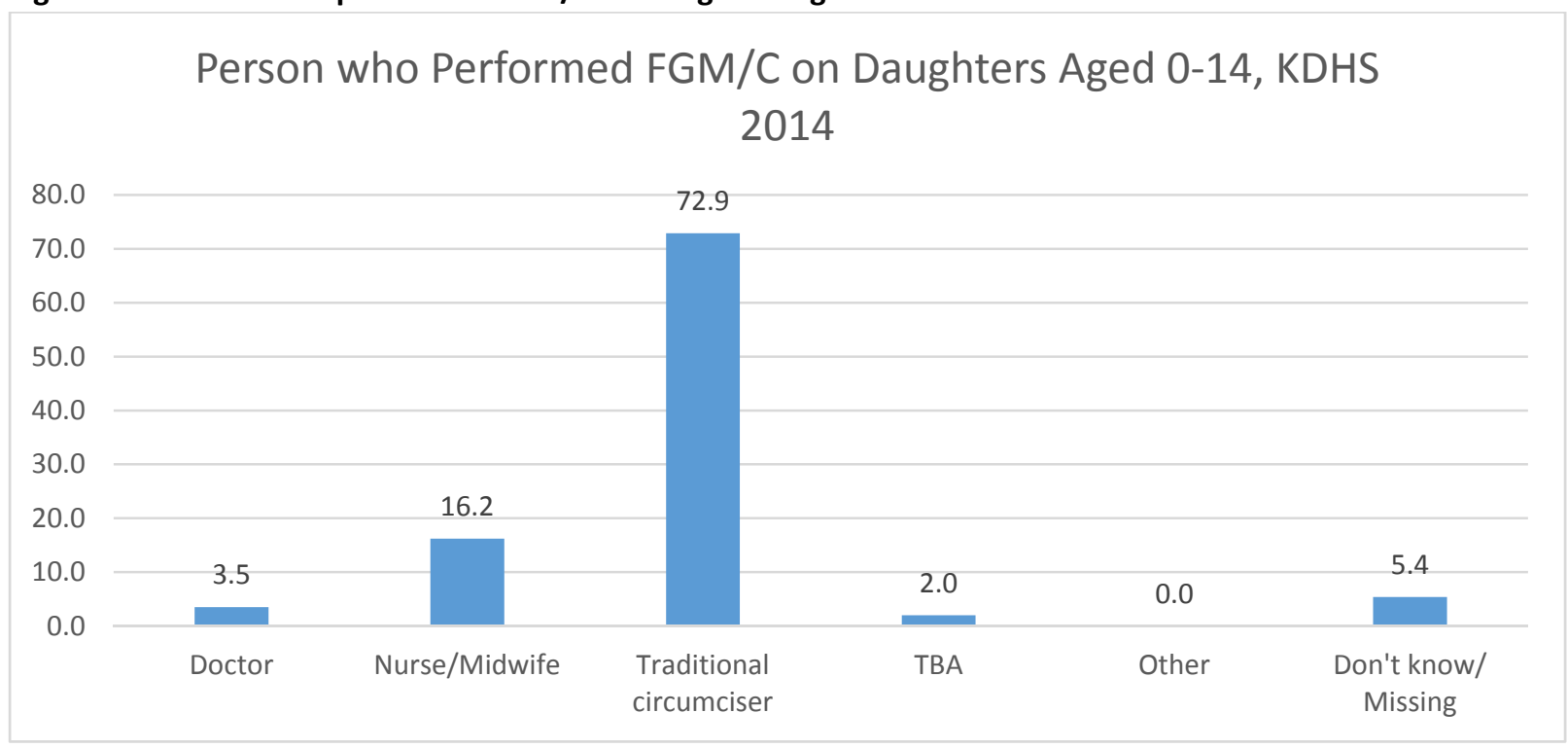

\section{Intergenerational Changes: Mother-Daughter Comparisons}

\section{Considerations for Making Mother-Daughter Comparisons}

Given that FGM/C is a traditional practice that is passed down in families, there is interest in making comparisons between generations. Is the practice being carried out is similar ways? Is it being altered or abandoned?

As noted above, some daughters who are currently uncut may be still cut in the future. Hence, it is inappropriate to directly compare prevalence of FGM/C among daughters ages 0-14 to that of women ages 15-49 without taking into account censoring. Doing so, however, is not a straight forward task. One simple method that has greater validity, though is still not perfect, is to compare the age-specific cutting rates of women and girls of different ages. In other words, one can compare the proportion of girls cut by their current age $\mathrm{X}$ to the proportion of women who reported having been cut by age X. Data from the 2014 Kenya DHS illustrate this (Figure 36). It is important to note a key difference between the data on girls and women: women age 15-49 are presumed to be at the final cutting status, while girls age 0-14 reflect current cutting status. A portion of these girls may still be cut in the future. This portion, however, decreases as age does up. Hence we have clues that rates of cutting appear to be declining in the younger generation of Kenyan women. 
Figure36: Age-specific rates of FGM/C among Kenyan women age 15-49 and girls age 0-14

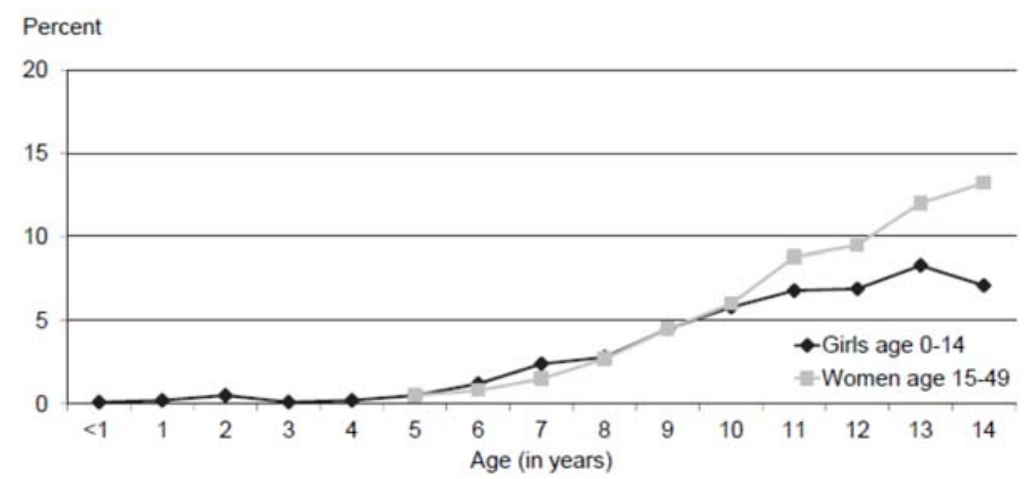

(Source: Kenya Demographic and Health Survey 2014 Report)

\section{Intergenerational Comparison of Age at Cutting}

Also of interest is a comparison of the way FGM/C is performed across generations, including a comparison of average age of cutting between mothers and daughters. A direct comparison of the mean age at FGM/C between mothers and daughters is inappropriate because a portion of the currently uncut girls will be cut in the future. Consequently, girls who are cut at later ages are systematically underrepresented, resulting in an underestimation of the mean age at FGM/C. These censored cases provide valuable information because we know that girls did not undergo FGM/C at least until the date of the interview. An analytical technique known as survival analysis can handle censored data, allowing for comparisons between mothers and daughters.

The survivor functions, show in Figure 37 reveal that the age at FGM/C is lower among daughters than among mothers, and the log rank test reveals that this is a statically significant difference $\left(\chi^{2}=377, p<0.001\right)$. This suggests that the trend toward decreased age at FGM/C detected across cohorts of adult women is continuing in the next generation.

Figure37. Age at cutting for eldest daughter and woman, KDHS 2014

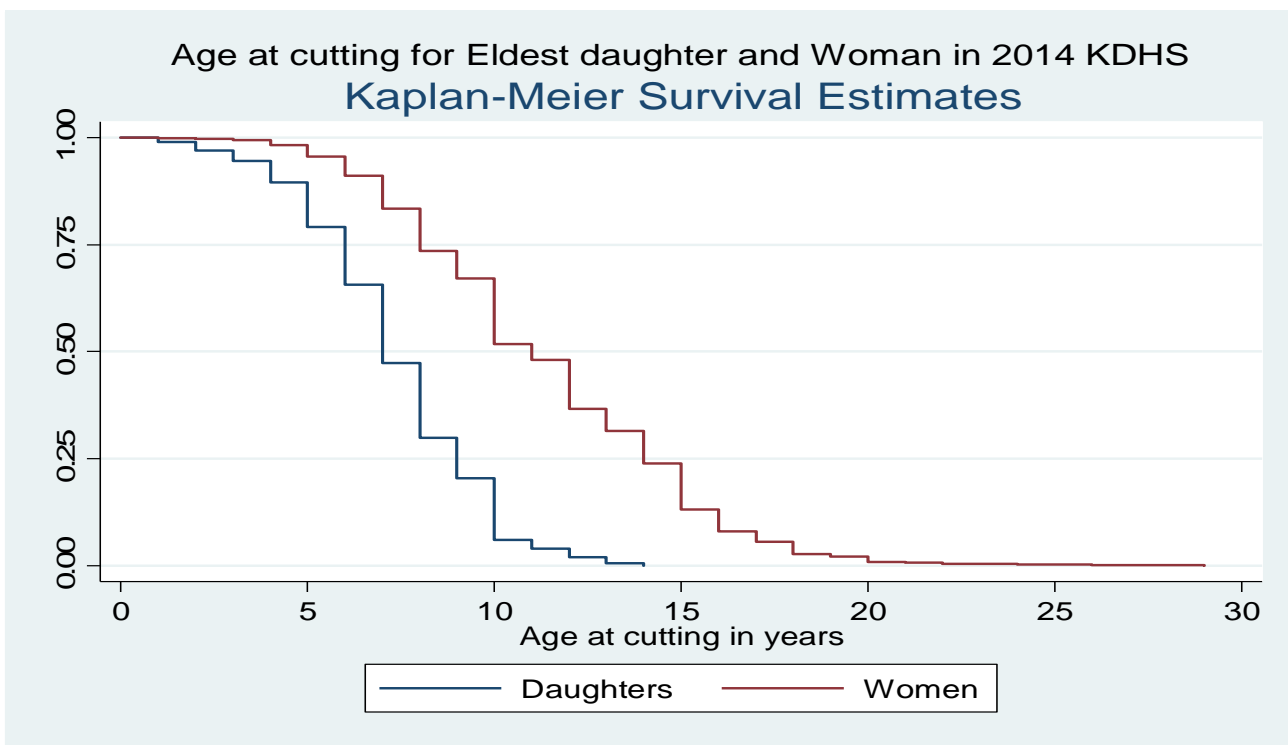




\section{Intergenerational Comparison of Medicalization}

In 2001 the Ministry of Health issued a policy directive in 2001 making it illegal to perform FGM/C in healthcare facilities (Njue and Askew, 2004). Additionally, the Children's Act, passed in 2001, criminalizes the performance of $\mathrm{FGM} / \mathrm{C}$ on girls under the age of 18 . Hence, there is interest in knowing if medical personnel have been deterred from providing FGM/C. The reported rate of medicalization (FGM/C performed by a doctor, nurse or trained midwife) among women aged $15-49$ is $15 \%$. The reported rate of medicalization on daughters under age 15 is $20 \%$ (Figure 38).

Figure 38: Comparison of person who performed FGM/C on mothers (15-49) and daughters (0-14)

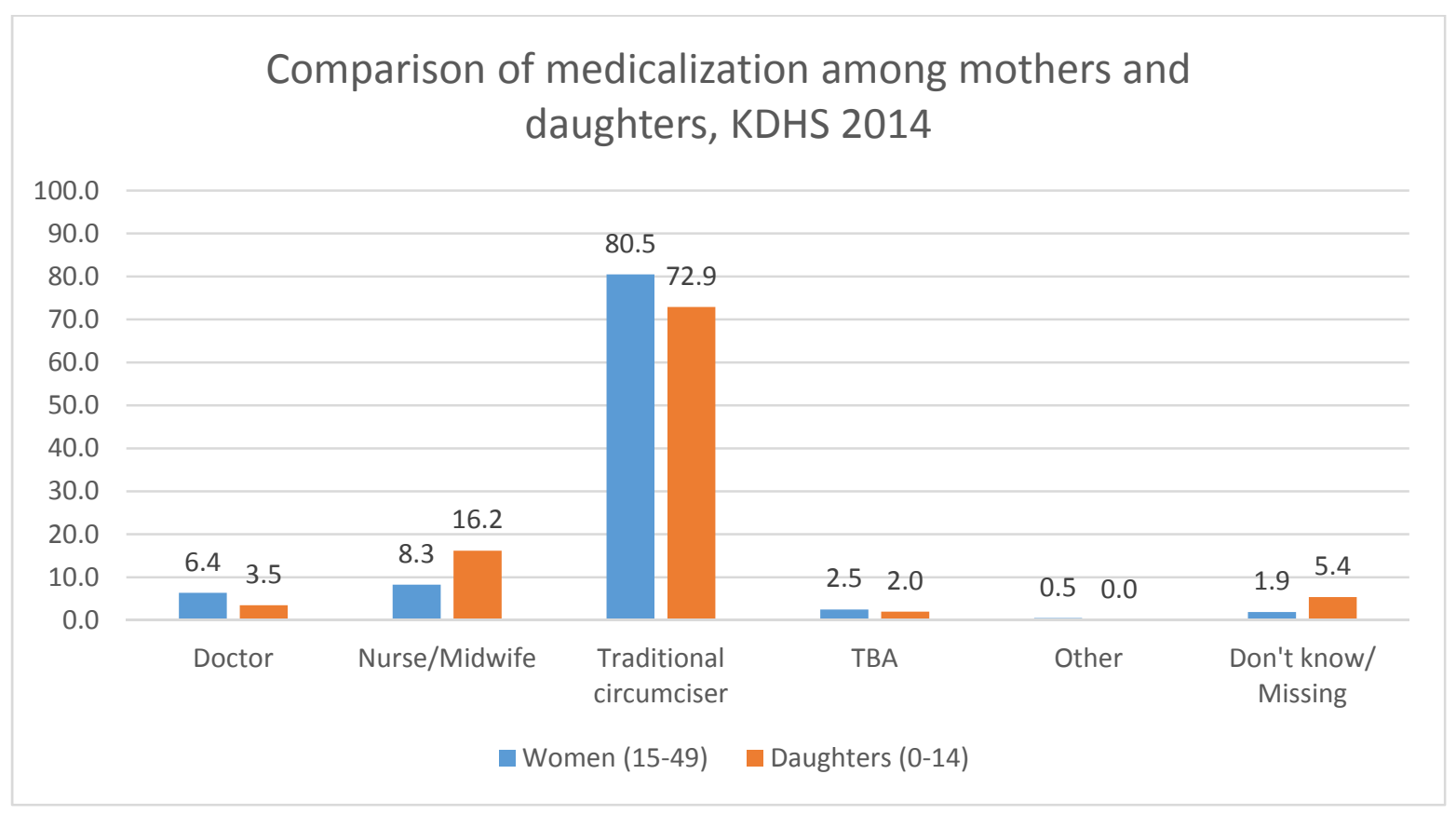

\section{Type of Cutting}

Survey question on the type of FGM/C performed on women and their daughters make it possible to examine whether there are changes in the type of cutting across generations. Two separate forces may be at play influencing the extent of cutting. Social convention theory predicts that under the originating conditions of extreme resource inequality, competition for the wealthiest husbands made the practice prone to exaggeration (Mackie, 2000). It is possible that in current contexts of disparity, though far removed from the originating conditions, there is continued exaggeration of the severity of cutting. Alternatively, it might be expected that the prevalence of more severe forms of FGM/C is decreasing. Parallel to the situation with medicalization, decades of educational campaigns centered on the health risks may have motivated individuals to seek less severe forms of cutting for their daughters.

The 2014 survey data indicate there is a great deal of intergenerational stability in the form of cutting among Kenyan women and daughters (Figure 39). 
Figure 39: Type of FGM/C among women aged 15-49 and daughters under age 15

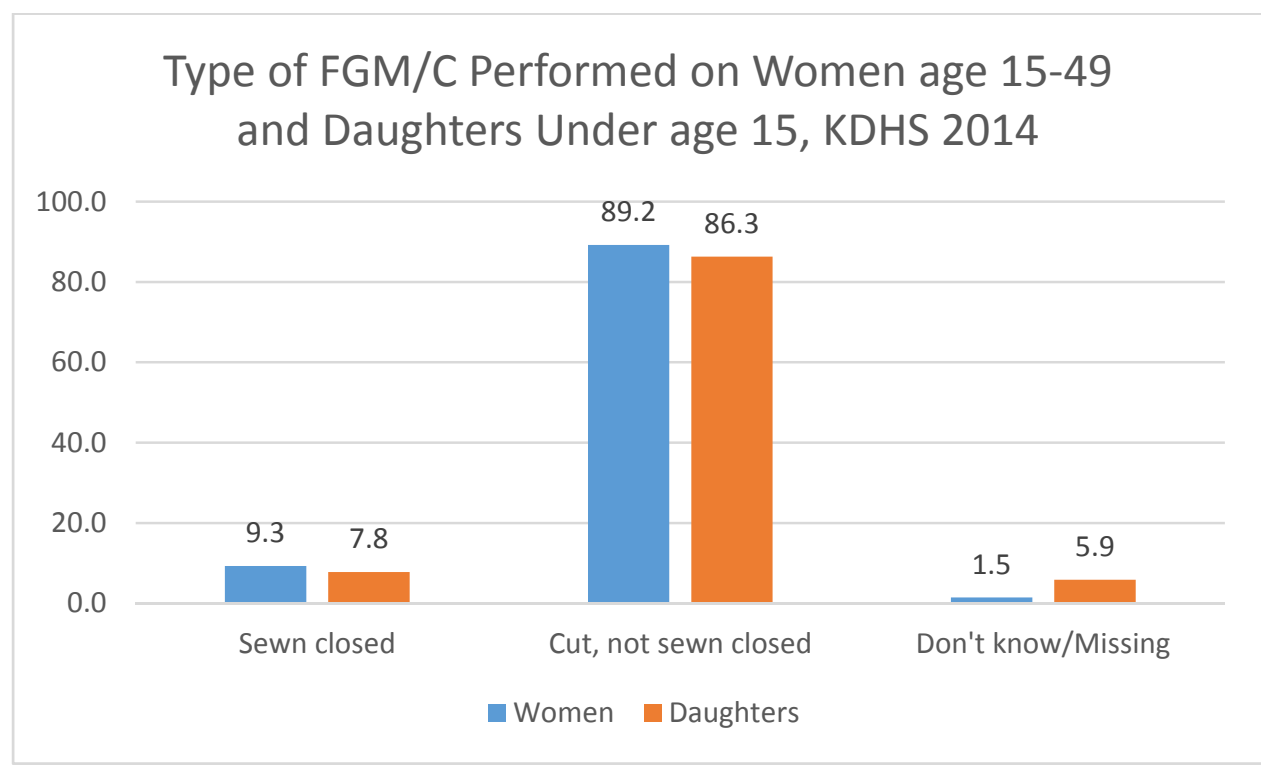

\section{Conclusions}

Nationally representative survey data on FGM/C in Kenya are available from four waves of Demographic and Health Surveys, implemented in 1998, 2003, 2008-09, and 2014. These survey data provide a rich and detailed picture of when, where and how FGM/C has been carried out, and trends in changes in the practice.

Key findings from the 2014 survey include the following: The estimated prevalence of FGM/C among women aged $15-49$ is $21 \%$. The prevalence varies substantially by Province, with the highest prevalence in Northeastern Province $(98 \%)$ and lowest prevalence in Western Province (1\%). As population densities vary in different regions of the country, it is also of interest to know where most women 15-49 living with $\mathrm{FGM} / \mathrm{C}$ reside. The data show that $72 \%$ of Kenyan women living with FGM/C reside in three provinces: Northeastern, Rift Valley and Nyanza. Prevalence of FGM/C also varies along sociodemographic lines, most strikingly in relation to ethnicity. Less than $1 \%$ of Luhya and Luo women report being cut, while $94 \%$ of ethnic Somali women report being cut. The circumstances surrounding FGM/C also vary. Nationwide, among all women who report having undergone FGM/C report having had flesh removed, but not being sewn closed. $9 \%$ of women report having been sewn closed. The vast majority of women report having been cut by a traditional practitioner $(83 \%)$, while $15 \%$ report that the person who performed their $\mathrm{FGM} / \mathrm{C}$ was a health care professional. Regarding age at cutting, $70 \%$ of women report having been cut between age 5 and 14 years. In most countries it is rare for women to undergo FGM/C after the age of 15 . In this regard, Kenya is an exception; $27 \%$ of women report having been cut age 15 or older. Data from the 2014 KDHS show that the majority of both women (93\%) and men (89\%) are opposed to the continuation of FGM/C. Two questions in the 2014 survey are designed to measure social or religious norms. The data show that $5 \%$ of women and $6 \%$ of men report that they believe $\mathrm{FGM} / \mathrm{C}$ is required by religion. Additionally $8 \%$ of women and $11 \%$ of men report that they believe that $\mathrm{FGM} / \mathrm{C}$ is required by their community.

Examination of successive waves of survey data allow us to examine trends in FGM/C in Kenya, with the key question being: Is the practice of $\mathrm{FGM} / \mathrm{C}$ declining? National prevalence data from successive waves of surveys show a steady decrease in the prevalence of FGM/C among women aged 15-49, declining from $38 \%$ in 1998 to $21 \%$ in 2014 . By 
looking at the prevalence across 5 year age cohorts, we see that there has been a steady, long-term decline in rates of FGM/C that began in the early 1980's. The declines have not occurred evenly among women from all ethnic groups. Rates of FGM/C remain very high among ethnic Somali women. Rates of FGM/C are high in older cohorts of Maasai and Kisii women, but appear to be declining among younger cohorts of women. Other ethnic groups have had long-term steady declines in FGM/C. The prevalence of FGM/C has dropped to $5 \%$ or lower in the youngest cohort of women (aged 15-19) in four ethnic groups: Kalenjin, Kamba, Kikuyu and Taita/Taveta. Other changes over time include a trend toward younger age at cutting, increased medicalization (cutting performed by a health care professional, as opposed to a traditional practitioner).

The most recent changes in $\mathrm{FGM} / \mathrm{C}$ are found by looking at data reported by mothers regarding their daughters. The 2014 KDHS survey provides information on the prevalence of FGM/C among girls aged $0-14$. Overall $2.8 \%$ of girls under age 15 have been cut. Interpretation of this number requires understanding that not all girls have reached their final cutting status; some girls who are not cut may still be cut in the future. Specialized statistical methods are, therefore, needed to conduct multivariate analyses on these data. Rates of cutting among girls 0-14 vary in several ways: rates of cutting are higher among girls from poor household, those whose mothers have no education, and those whose mothers are ethnic Somali or Kisii. Girls age 0-14 who have been cut live in either Northeastern Province (65\%) or Nyanza (20\%). In comparison to their mothers, girls with FGM/C are being cut at earlier ages, and are more likely to be cut by a medical practitioner than were their mothers. Medicalized cutting of daughters is located exclusively in Nyanza and Rift Valley Provinces.

\section{Next steps}

While the data we report is descriptive, it provides useful insights on the progress of FGM/C abandonment at national and sub-national levels. The observed changes observed overtime provide an important opportunity for understanding how, where and in what sub-groups change is happening. These findings are useful for policy makers in steering discussions on policies, but also for guiding where to target interventions especially due to the large ethnic and religious diversity. It also highlights where there are large numbers of women living with FGM/C who may be in need of specialized health services.

However, to better understand trends overtime and the determinants of FGM/C we propose further multivariate analysis that take into account censoring but also time and space. For instance, the DHS surveys collect information on current FGM/C status of daughters, however, this is different from final FGM/C status: a girl who is not cut may still be cut in the future. This type of challenges could be addressed statistically, through censoring an approach we have attempted by using survival analysis methods but can be improved upon. Additionally, there is a proposition that FGM/C is a social norm, as such, communities that close to one another are likely to harbor similar practices compared to those further away. Because DHS data has coordinates of the clusters sampled during each survey, spatio-temporal models can be used to account for space and time and therefore provide more precise estimates adjusted for space, time and other determinants. These analyses are now ongoing and will compliment this report. 


\section{References Cited}

Adinma, J. (1997). Current status of female circumcision among Nigerian Igbos. West African Journal of Medicine, 16, 227-231.

Askew, I. (2005). Methological issues in measuring the impact of interventions against female genital cutting. Culture, Health and Sexuality, 7(5), 463-477.

Boyle, E. H. (2002). Female Genital Cutting: Cultural Conflict in the Global Community. Baltimore: Johns Hopkins University Press.

Boyle, E. H., \& Preves, S. E. (2000). National politics as international process: The case of anti-female-genital-cutting laws. Law and Society Review, 34, 703-737.

Chege, J. N., Askew, I., \& Liku, J. (2001). An Assessment of the Alternative Rites Approach for Encouraging Abandonment of Female Genital Cutting in Kenya. Retrieved from New York, NY: Population Council:

Christoffersen-Deb, A. (2005). Taming tradition: medicalized femal genital practices in western Kenya. Medical Anthropology Quarterly, 19, 402-418.

Eliah, E. (1996, March, 1996). REACHing for a healthier future. Populi, 12-16.

Elmusharaf, S., Elhadi, N., \& Almroth, L. (2006). Reliability of self-reported form of female genital mutilation and WHO classification: cross sectional study. BMJ, 333(7559), 124-128.

Gele, A. A., Bo, B. P., \& Sundby, J. (2013). Attitudes toward female circumcision among men and women in two districts in Somalia: Is it time to rethink our eradication strategy in Somalia? Obstetrics and Gynecology International. doi:10.1155/2013/312734

Gruenbaum, E. (2001). The Female Circumcision Controversy: An Anthropological Perspective. Philadelphia: University of Pennsylvania Press.

Hayes, R. O. (1975). Female genital mutilation, fertility control, women's roles, and the patrilineage in modern Sudan: A functional analysis. American Ethnologist, 2(4), 617-633.

Hayford, S. (2005). Conformity and change: Community effects on female genital cutting in Kenya. Journal of Health and Social Behavior, 46(2), 121-140.

Hernlund, Y. (2000). Cutting without ritual and ritual without cutting: Female "circumcision" and the re-ritualization of initiation in the Gambia. In B. Shell-Duncan \& Y. Hernlund (Eds.), Female "Circumcision" in Africa: Culture, Controversy, and Change (pp. 235-252). Boulder, CO: Lynne Rienner Publishers.

Hernlund, Y., \& Shell-Duncan, B. (2007). Contingency, context and change: Negotiating female genital cutting in The Gambia and Senegal. Africa Today, 54(4), 43-57.

Hosken, F. (1993). The Hosken Report: Genital and Sexual Mutilation of Females (5 ed.). Lexington, Massachusetts: Women's International Network News.

Jackson, E. F., Akweongo, P., Sakeah, A., Hodgson, R., Asuru, R., \& Phillips, J. E. (2003). Inconsistent reporting of female genital cutting status in Northern Ghana: Explanatory factors and analytical consequences. Studies in Family Planning, 34(3), 200-210.

Kennedy, J. G. (1970). Circumcision and excision in Egyptian Nubia. Man, 5, 175-191.

Kenyatta, J. (1978 [1938]). Facing Mount Kenya: The Tribal Life of the Gikuyu. New York: Vintage.

Klouman, E., Manongi, R., \& Klepp, K. I. (2005). Self-reported and observed female genital cutting in rural Tanzania: Associated demographic factors, HIV and sexually transmitted infections. Tropical Medicine and International Health, 10(1), 105-115.

Mackie, G. (2000). Female genital cutting: The beginning of the end. In B. Shell-Duncan \& Y. Hernlund (Eds.), Female "Circumcision" in Africa: Culture, Controversy, and Change (pp. 253-283). Boulder, CO: Lynne Rienner Publishers.

Morison, L., Dirir, A., Elmi, S., Warsame, J., \& Dirir, S. (2004). How experiences and attitudes relating to female circumcision vary according to age on arrival in Britain: A study among young Somalis in London. Ethnicity and Health, 9(1), 75-100.

Msuya, S. E., Mbizvo, E., Hussain, A., Sundby, J., Sam, N. E., \& Stray-Pedersen, B. (2002). Female genital cutting in Kilimanjaro, Tanzania: Changing attitudes? Tropical Medicine and International Health, 7(2), 159-165.

Murray, J. (1976). The Church Missionary Society and the "female circumcision" issue in Kenya, 1929-1932. Journal of Religion in Africa, 8(2), 92-104.

Njue, C., \& Askew, I. (2004). Medicalization of female genital cutting among the Abagusii in Nyanza Province, Kenya. Retrieved from Nairobi, Kenya: Frontiers in Reproductive Health Program, Population Council: 
Obiora, L. A. (1997). Bridges and barricades: rethinking polemics and intransigence in the campaign against female circumcision. Case Western Law Review, 47(2), 275-378.

Pederson, S. (1991). National bodies, unspeakable acts: The sexual politics of colonial policy-making. Journal of Modern History, 63, 647-680.

Rutstein, S. (1999). Wealth versus expenditure: Comparison between the DHS wealth index and household expenditures in four departments of Guatemala. Calverson, Maryland: ORC Macro.

Rutstein, S., Johnson, K., \& Gwatkin, D. (2000). Poverty, health inequality, and its health and demographic effects. Paper presented at the Annual Meeting of the Population Association of America, Los Angeles, CA.

Shell-Duncan, B. (2001). The medicalization of female "circumcision": Harm reduction or promotion of a dangerous practice? Social Science and Medicine, 52, 1013-1028.

Shell-Duncan, B. (2008). From health to human rights: Female genital cutting and the politics of intervention. American Anthropologist, 110(2), 225-236.

Shell-Duncan, B., Hernlund, Y., Wander, K., \& Moreau, A. (2010). Contingency and Change in the Practice of Female Genital Cutting: Dynamics of Decision Making in Senegambia. Summary Report. http://csde.washington.edu/bsd. Retrieved from

Shell-Duncan, B., Naik, R., \& Feldman-Jacobs, C. (2016). A State-of-the-Art Synthesis on Female Genital Mutilation/Cutting: What Do We Know Now? October 2016. New York: Population Council http://www.popcouncil.org/EvidencetoEndFGM-C.

Shell-Duncan, B., \& Njue, C. (2017). The medicalization of female genital mutilation/cutting: What do the data reveal?

Shell-Duncan, B., \& Olungah, O. (2009). Between Crime, Faith and Culture: Contesting Female Genital Cutting and the "Best Interest of the Child". Paper Presented at the Annual Conference of the American Association of Anthropology.

Shell-Duncan, B., Wander, K., Hernlund, Y., \& Moreau, A. (2011). Dynamics of change in the practice of female genital cutting in Senegambia: Testing predictions of social convention theory. Social Science and Medicine, 73, 12751283.

Snow, R. C., Slanger, T. E., Okonofu, F. E., Oronsaye, F., \& Wacker, J. (2002). Female genital cutting in southern urban and peri-urban Nigeria: Self-reported validity, social determinants and secular decline. Tropical Medicine and International Health, 7(1), 91-100.

Thomas, L. (2000). "Ngaitana (I will circumcise myself)": Lessons from colonial campaigns to ban excision in Meru, Kenya. In B. Shell-Duncan \& Y. Hernlund (Eds.), Female "Circumcision" in Africa: Culture, Controversy, and Change (pp. 129-150). Boulder, CO: Lynne Rienner Publishers.

Thomas, L. (2003). Politics of the Womb: Women, Reproduction, and the State in Kenya. Berkeley: University of California Press.

UNICEF. (2005). Changing a Harmful Social Convention: Female Genital Mutilation/Cutting. Florence, Italy: United Nations Children's Fund (UNICEF).

UNICEF. (2013). Female Genital Mutilation/Cutting: A Statistical Overview and Exploration of the Dynamics of Change. NEW York: UNICEF.

UNICEF. (2016). Female Genital Mutilation/Cutting: A Global Concern. New York: UNICEF.

Van der Kwaak, A. (1992). Female circumcision and gender identity: A questionable alliance? Social Science and Medicine, 35(6), 777-787.

WHO. (2008). Eliminating female genital mutilation: An Interagency statement. (WHO, UNFPA, UNICEF, UNIFEM, UNHCHR, UNHCR, UNECA, UNESCO, UNDP, UNAIDS). Retrieved from Geneva:

WHO. (2010). Global Strategy to Stop Health-Care Providers from Performing Female Genital Mutilation. Retrieved from Geneva:

WHO. (2015). Fact Sheet - Female Genital Mutilation.

Yoder, P. S., Abderrahim, N., \& Zhuzhani, A. (2004). Female Genital Cutting in the Demographic and Health Surveys: A Critical Comparative Analysis. Calverton, Maryland: Macro International.

Yoder, P. S., \& Mahy, M. (2001). Female Genital Cutting in Guinea: Qualitative and Quantitative Research Strategies. Retrieved from Calverton, MD:

Yount, K. (2002). Like mother, like daughter? Female genital cutting in Minia, Egypt. Journal of Health and Social Behavior, 43, 336-358. 